
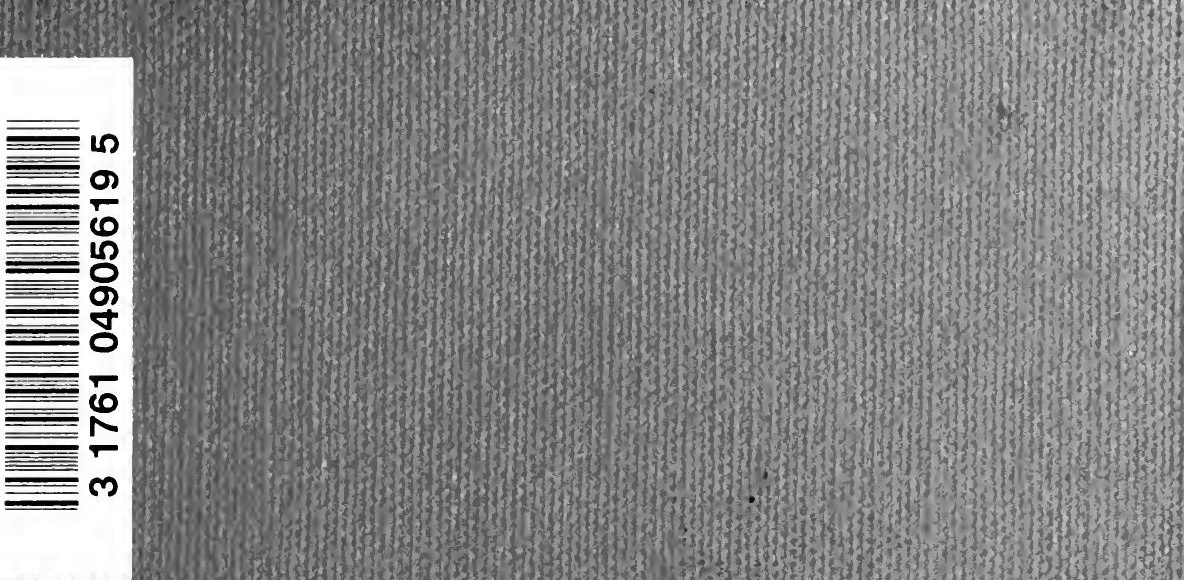


Digitized by the Internet Archive in 2008 with funding from Microsoft Corporation 


IMMUNI'TY IN HEALTH 
PUBLISHED BY THE JOINT COMMITTEE OF HENRY FROWDE AND HODDER \& STOUGHTON AT 17, WARWICK SQUARE, NEWGATE STREET, LONDON, E.C.4. 


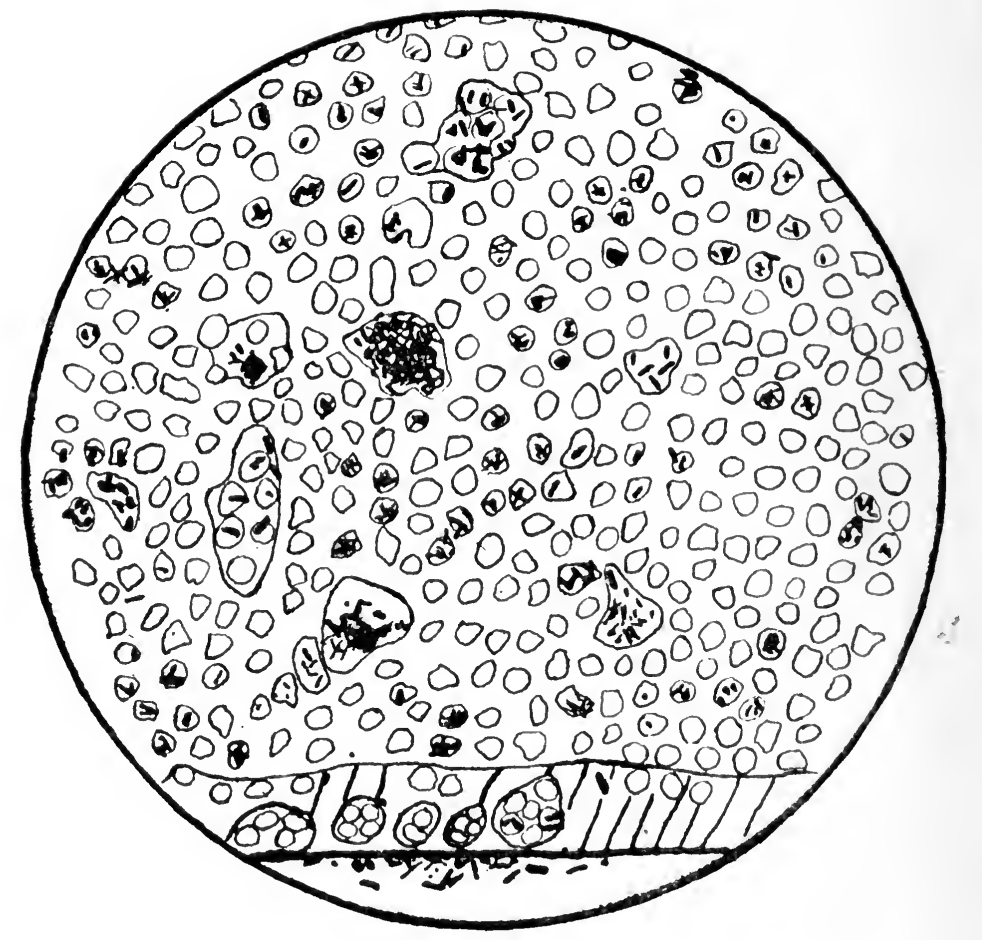

Fig. 1.

Section of part of the wall of a healthy rabbit's appendix, stained with cosin and then by Gram's method. (From a camera lucida drawing; 1/12 in. objective.)

'This section shows the enormous number of ingested bacteria in the lymph node, and also the migration of the glandular lymphocytes through the overlying epithelium.

A small part of the lumen of the appendix is visible below. 


\title{
IMMUNITY IN HEALTH
}

THE FUNCTION OF THE TONSILS AND OTHER SUBEPITHELIAL LYMPHATIC GLANDS IN THE BODILY ECONOMY

\author{
BY \\ KENELM H. DIGBY, \\ M.B., B.S. ; F.R.C.S,
}

Ho Tung Professor of Clinical Surgery and Professor of Anatomy at the University of Hong Kong; Honorary Visiting Surgeon to the
Government Civil Hospital, Hong Kong.

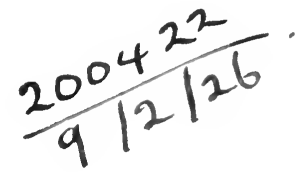

\section{LONDON}

HENRY FROWDE HODDER \& STOUGHTON Oxford University Press 2o, Warwick Seuare, E.C.4. I 919 


\section{QR \\ 181. D54}

PRINTED IN GREAT BRITAIN BY KING AND JARRETT, LIMITED. HOLLAND STREET, BLACKFRIARS, LONDON, S.E. 1. 


\section{CONTENTS.}

Chapter I.-Introduction

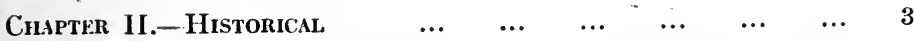

Chapter III.-Previous Theories as to the Function of tile

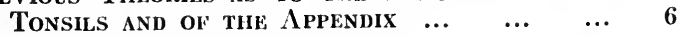

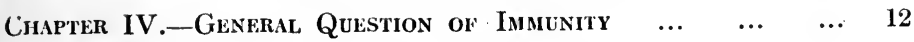

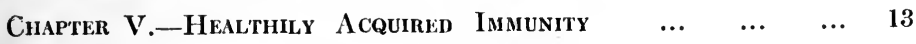

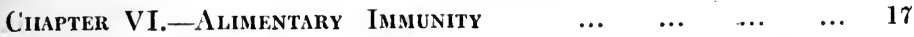

(inafter VII.-Distribution of the Subepithelial Lymphatic

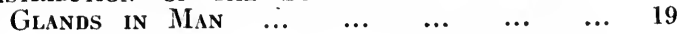

C.hapter VIII.-Comparative Anatomy of the Subepithelial Lymphatic Glands $\quad \ldots \quad \ldots \ldots \quad \ldots \quad \ldots$

Chapter IX.-Structure of the Subeprthelal Lympiatic

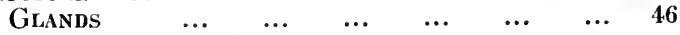

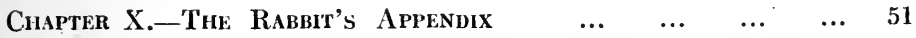

Chapter XI.-Life History of the Subepithlial Lymphatic Glands $\quad \ldots \quad \ldots \quad \ldots \quad \ldots \quad \ldots \quad \ldots$

Chapter XII.-Presince of Bacteria in the Subepithelial Lympintic Glands $\quad \ldots \quad \ldots \quad \ldots \quad \ldots$

Chapter XiII.-Mode of Ingestion of Bácteria by the Subepithllial Lrmpiatic Giands $\ldots$...

Chapter XIV.-Patiology of the Subepithelial Lymphatic $\begin{array}{lllllll}\text { Glands } & \ldots & \ldots & \ldots & \ldots & \ldots & \ldots\end{array}$

Chapter XV.-Acute Inflammations of the Subepitielial Lymphatic Glands $\quad \ldots \quad \ldots \quad \ldots \quad \ldots$

Ciiapter XVI.-Simple Enlargenent or Hyperplasia of. the SubepithelinL Lymphatic Glands ... ...

Chapter XVII.-Other Diseases of tile Subepithelial,

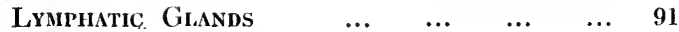

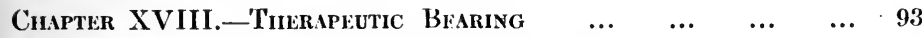

Chapter XIX.-Sone. General Considerations $\ldots$..

Chapter XX.--R'esumé of the Hypothesis and Summary of the EVIDENCE FOR AND AGAINST $\ldots$...

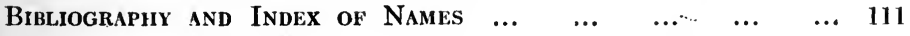

$\begin{array}{llllllllll}\text { Subject Index } & \ldots & \ldots & \ldots & \ldots & \ldots & \ldots & \ldots & \ldots & 117\end{array}$ vii, 


\section{LIST OF ILLUSTRATIONS.}

FIG.

PAGE

1. Bacteria in wall of healthy rabbit's appendix ... frontispiece

2. Micro-section of vermiform appendix with obliterated lumen 8

3. Diagram showing the circumpharyngeal ring of lymphoid $\begin{array}{llllllllll}\text { tissue } & \ldots & \ldots & \ldots & \ldots & \ldots & \ldots & \ldots & \ldots & 21\end{array}$

4. Diagram of the lymphoid tissue near the ileo-cæcal junction 23

5 . Diagram of the human alimentary canal showing the distribution of the subepithelial lymphatic nodules $\quad \ldots \quad \ldots 2^{2}$

6. The protuberant and tubular types of the faucial and cæcal $\begin{array}{lllllllllll}\text { tonsils } \quad \ldots & \ldots & \ldots & \ldots & \ldots & \ldots & \ldots & \ldots & 29\end{array}$

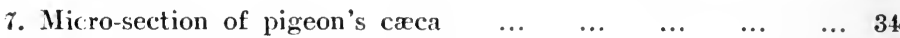

8. The appendix of lagomys pusillus $\ldots \begin{array}{lllllll}\ldots & \ldots & \ldots & \ldots & \ldots & 37\end{array}$

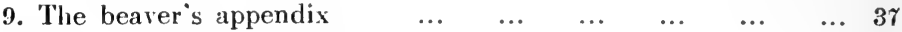

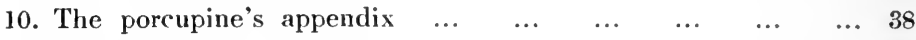

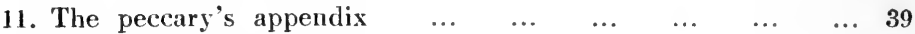

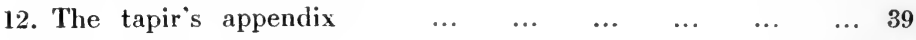

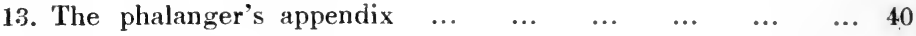

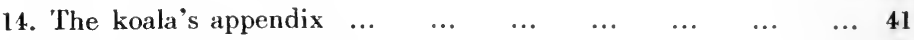

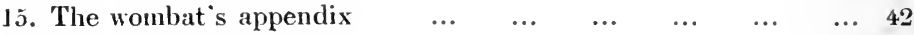

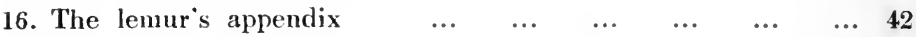

17. The slow lemur's appendix $\ldots \begin{array}{llllllll} & \ldots & \ldots & \ldots & \ldots & \ldots & 43\end{array}$

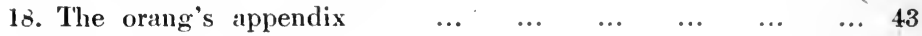

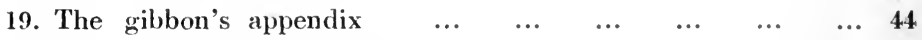

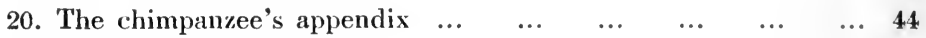

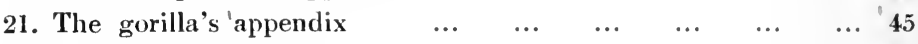

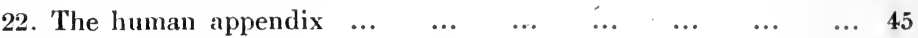

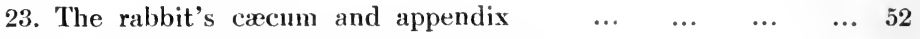

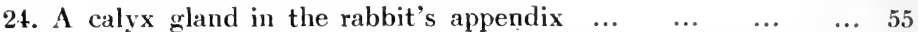

25. The wall of the rabbit's appendix at birth, at 14 days and

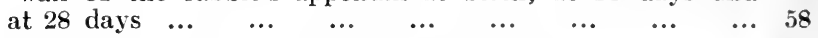

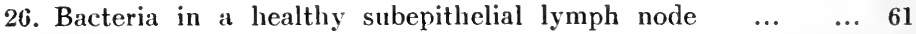

$2 \pi$. Micrococci in the lymphoid tissue of a healthy rabbit's tonsil 62

28. Bacilli in the lymphoid tissue of a healthy rabbit's Peyer's $\begin{array}{llllllllll}\text { patch } & \ldots & \ldots & \ldots & \ldots & \ldots & \ldots & \ldots & \ldots & 63\end{array}$

29. Bacilli in the lymphoid tissue of a healthy rabbit's appendix 64

3n. Bacilli in the lymphoid tissue of a healthy rabbit's appendix 65

31. Micro-section of a Peyer's patch from a rabbit which had soot administered with its food for three weeks ... 


\section{CHAPTER I.}

\section{INTRODUCTION.}

AFTER the doctrine of evolution was formulated the values of the various organs in the body were critically examined, and it came to be suggested that structures sometimes persisted in a race of animals long after they had ceased to perform any useful function or indeed any function at all. The question raised is a wide one and has been hotly discussed; it is usually conceded as a possibility that a structure, especially if it does not become directly injurious, may persist (in a more or less undeveloped form) even when it has ceased to function for generations. Many organs in the body have at one time been claimed to belong to this group of vestigial structures, but with increasing physiological knowledge the list steadily shrinks.

Tonsils, Adenoids, and the Vermiform Appendix are still commonly regarded as useless, even dangerous, relics of a past usefulness (Schäfer, 1912). But the investigations recorded in the following pages point in quite another direction, and appear to support the view that these structures (together with the Noduli Lymphatici Solitaii et Aggregati) should be grouped together 
into one class of "Subepithelial Lymphatic Glands"*; that they constitute important antibacterial weapons and share a great and valuable function in the preservation of health (Digby, 1911). Evidence will be adduced to show that these subepithelial lymphatic glands are not so much local defences to strengthen weak spots as organs for the development of general systemic immunity.

These considerations do not involve an attack upon surgery for the removal of some of the organs of the subepithelial lymphatic system. The recognition of their utility does not, of course, imply their inviolability when they unhappily become the base or focus of disease. The eye is useful, yet at times it may be necessary to sacrifice even a partially functioning eye for the general health of its owner.

* Noubts may arise as to the propriety of using the word " glands" in this commection. 'Ihe word "organs" might indeed be substituted. But " glands" has long been employed for other lymphoid collections and is retained in the B.N.A. terninology. It, therefore, seems well to write "Lymphatic Glands" and to describe these as falling into two classes:-

1. Interstitial, e.g. :-

Axillary,

Bronchial,

Cervical,

Aortic, etc.

2. Subepitlielial, e.g. :-

Solitary nodules,

Aggregated nodules,

Vermiform process,

Faucial tonsil, etc. 


\section{CHAPTER II.}

\section{HistoricaL.}

THE history of the Subepithelial Lymphatic Glands is a history of neglect.

The very existence of some of these structures was unknown to early anatomy. The tonsils must have been seen by the first physician who inspected a patient's throat: but of the vermiform appendix the earliest record seems to have been in 1524, by Berenger Carpi (Kelynack), while it was not till 16 z7 that Peyer described the agminated follicles in the intestines, and it was as late as $\mathbf{1 7 2 4}$, when Santorini was the first to describe the pharyngeal tonsil.

The part played by the subepithelial lymphatic glands in disease was a comparatively late discovery in Medicine, though it is probable that inflammation of the tonsils was recognised early. According to Kelynack, a case of perforation of the appendix was described in 1759 by Mestivier, but the frequency with which the appendix is the starting point of abdominal suppuration has only been realised within the last thirty years. "That ent'eric fever was an entity marked by intestinal lesion was realised in the early part of the Nineteenth Century"' (Dreschfield, 1896). The harmful effects of enlargement of the pharyngeal tonsil were pointed out by Meyer, of Copenhagen, in 1868 .

It was still later before analogies began to be drawn between the various members of the Subepithelial Lymphatic Group. In 1876 Watney described the 
lymphatic structure of the vermiform appendix and drew a comparison with the tonsil. Analogies between the tonsils and the vermiform appendix have since been noted by other observers. Ransohoff in $\mathbf{1 8 9 0}$ pointed out that both were liable to recurrent inflammatory attacks; Bland-Sutton added in 1891 that in each of the structures the inflammatory attacks were particularly common in early life. Kelynack in 1893 observed " that the calculi frequently met' with in the tonsils are, as far as their inorganic constituents are concerned, practically identical with concretions of the vermiform appendix." Murchison in 1866 described ulceration of the appendix as accompanying ulceration of Peyer's patches in one case of typhoid fever, and many similar cases have been related since.

In 1890 Dr. Armand Ruffer showed the presence of micro-organisms undergoing phagocytic destruction in tonsils, Peyer's patches, and vermiform appendix in various animals. (The penetration of Peyer's patches by micro-organisms had been shown five years previously by Ribbert and Bizozzero.)

As to their function, it has hardly ever been conceded that the subepithelial glands are of net utility. Darwin in 1874 wrote that the appendix was "useless." Treves in 1885 spoke of "it's very slight physiological importance," and in 1890 had hardened himself to write it down as "useless and functionless.". Macewen in 1904 was almost the first to suggest that there might well be a function. Keetley was sufficiently imbued with the idea of a value for the appendix to propose his operation of transplanting the appendix into the abdominal wall instead of appendicectomy in certain cases, and Edred Corner (1912) and Keith (1912) have each written favourably of the activities of the appendix, whilst Mackenzie (1912) has taken up the defence of the tonsils. 
Various theories as to the use of the tonsils have been propounded and will be dealt with immediately. But, except for the extravagant idea that they were associated with sexual function (as taught by Chassaignac, according to Mackenzie) the functions proposed have been subsidiary and trivial for the most part.

That appendix and tonsils in some way protected the body against alimentary poisons must have occurred to a number of thinkers. Adami concedes the likelihood of this. A similar idea has been elaborated by the present writer in several papers in 1911, 1912 and 1913. McCulloch (1913) claims to have anticipated some of these views in 1907. 


\section{CHAP'TER III.}

\section{Previous Theories as to the Function of the Tonsils and of the Appendix.}

IT is worth while to put aside for a moment the views to be advanced in this book and to consider the previous hypotheses. These hypotheses may be tabulated thus :-

(1) That the tonsils and appendix are ontogenetic or phylogenetic remnants. Darwin (1874) strongly urged that the vermiform appendix was a vestigial:? organ, a dangerous and useless relic, which unfortunately had not yet been eliminated by the process of natural selection. The idea has always received a large measure of support and demands careful examination.

A structure is said to be vestigial when it ceases to perform any service useful to the individual. It represents some structure the homologue of which has been of value at some period in ancestral history and which itself may be useful to the individual at some stage of development. Two instances may usefully be given. The actions of the small intrinsic and extrinsic muscles of the pinna of the ear are practically negligible. In some remote progenitor of man they were probably as helpful in picking up and locating noises as they are in the horse to-day. Meckel's diverticulum-of inconstant occurrence in the adult-is another vestige, representing perhaps a primitive intestinal arrange- 
ment and one which has a direct nutritive function during a part of embryonic life. True vestigial structures are not numerous. An organ of no value becomes a direct encumbrance and will tend to hinder its owner in the struggle to perpetuate its kind. Still the museles of the auricle and Meckel's diverticulum must be admitted as examples. Is the vermiform appendix such another? In favour of so regarding it, several observations are made. It varies greatly in size, in position and in the mode of its junction with the cæcum. These points however are of little weight : the spleen is more variable in size, all other mesenterial organs vary as much or more in position: whilst in connection with the third point it must be remembered that slight arrests of development are liable to occur even in the most important parts of the body. It is said that the blood supply is poor and hence the occasional gangrene of acute appendicitis. But the intense congestion seen in catarrhal appendicitis completely negatives such a view. In fact the gangrene which may occur is the result of the virulence of the infecting crganisms and the absence of collateral circulation rather than of the meagreness of blood súpply. It is said that retrogression is evidenced by. its being smaller than other part's of the cxcum. Actually, though its lumen is smaller its walls are much thicker and more complex in structure.

But the two most important witnesses to be interrogated are Comparative Anatomy and Embryology and their evidence will be taken later (Chapters VIII. and XI.). Suffice it here to say that the tonsil is homologous with a mass of lymphoid tissue in the internal eleft recess of some of the earliest vertebrates, and that the appendix is homologous with the lymphoid mass at the apex of the primitive form of excum, and that in man they show a more highly developed structure than in most 
mammals and one that only attains its full form late in development.

The vermiform appendix and the tonsils therefore neither represent a persistent fœtal structure as does Meckel's diverticulum, nor do they exhibit the atrophied condition of the muscle of the external ear. Moreover, unlike these relics, they are so often the point of serious disease that they could hardly be expected to

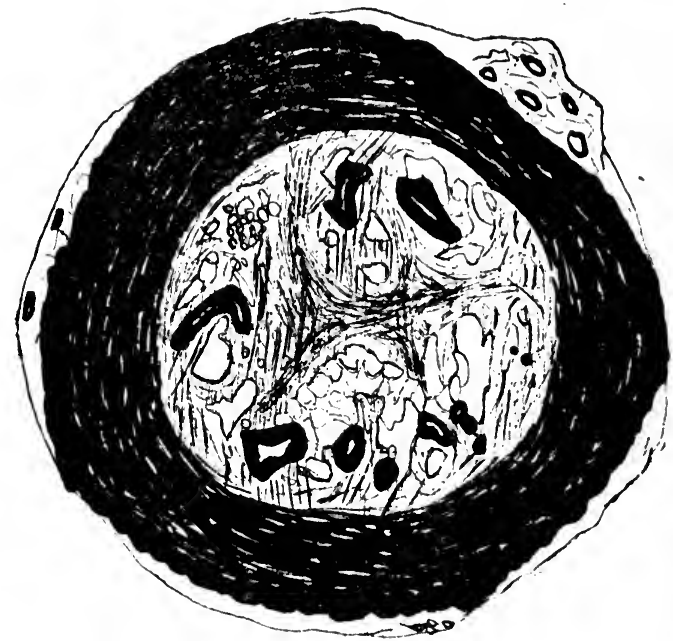

lis. 2.

Microscopical section of a human vermiform appendix with complete obliteration of the lumen, showing large thick-walled blood vesseis, fat-spaces and fibrous tissue in place of the mucous membrane and lumen. The tumica serosa and the two muscle coats are not specially abnormal in alpearance. (From a camera lucida drawing.)

survive if their presence had no counterbalancing advantages. Treves, in his slassic Hunterian Lectures of 1885, stated that he never found congenital absence of the human appendix, * but in three out of one

* The Morphological Museum of Columbia University contains two apparently renuine specimens of congenital absence of the human vermiform appendix (see Huntington). But the condition is extremely rare. 
hundred cases examined, he noted that the lumen was obliterated. There is excellent reason to-day for saying that occlusion of the appendix is the result of old inflammation. This is seen in the microscopical section of an obliterated appendix. (Fig. 2.) Treves then wrote, "Such specimens may be of interest in connection with the question as to whether the appendix has a function or is functionless," seeming to suggest that these cases argued against the possession of any useful function. As a matter of fact, they point the other way. In a large workshop you may find three per cent. of the men with stiffened or amputated fingers, but it would be the reverse of the truth to infer that fingers were therefore useless.

(2) That the tonsils and appendix secrete a lubricating mucus which facilitates deglutition in the one case and the passage of faces in the other. This is hardly worthy of serious consideration, for a knowledge of their histology shows that the appendix in man could produce relatively little mucus, and the human tonsil practically none.

(3) That the tonsils and appendix form some of the colourless corpuscles in the blood. This is undoubtedly true, though probably only an incomplete expression of their activities.

(4) That the tonsils and appendix produce internal secretions. What these internal secretions might be has never been clearly defined, though Savini in 1914 brought forward evidence of an appendicular hormone having an excito-motor influence on the large intestine and some evidence of glycolytic action by the tonsils has been adduced (Farmachidis \& Vatterone, 1913). Perhaps we are to regard the lymphocytes in some sense as an internal secretion. But a suggestion in this connection is made subsequently (end of Chapter V.). 
(5) That the lymphoid tissues of the tonsils and appendix represent barriers protecting weak spots. against bacterial invasion. These regions are often exposed to bacterial assault; moreover, chronic bacterial attacks in any part of the body lead to the accumulation of lymphocytes and even the production of lymphoid tissue. But the epithelium which is usually a sufficient protection elsewhere also lines these regions. Nor do sore throat's seem more common after complete enucleation of the tonsils. Doubtless the full development of these subepithelial lymphatic glands in the individual is stimulated by bacteria, but the perpetuation of the lymph nodes in the race is probably the result of other functions of greater utility.

(6) That the tonsils and appendix are purely mischicvous, acting as "portals of entry" and chronic focuses of disease. In pathological circumstances they do so act (Gouget, 1912), as indeed do other parts of the body in diseased states. But this does not disprove any useful function under physiological conditions.

(7) That the tonsils and appendix produce lymphocytes, which pass into the lumen of the alimentary tract and there keep down the numbers and restrain the activities of the bacteria. Lymphocytes containing ingested bacteria may be found in the mucus on the surface of the tonsils, in the saliva and in the lumen of the appendix. It is most likely also that the body in some way, and to a certain extent, can control bacterial activity in the alimentary canal. Yet when one considers the very small number of lymphocytes and the myriads of bacteria, the conception is no longer plausible.

(8) That distension of the appendix initiates peristalsis in the large intestine. To quote Adami and McCrae (1914), "The fluid contents of the ileum pour into the cxcum, and there and in the ascending 


\section{PREVIOUS THEORIES}

colon undergo inspissation prior to their discharge per anum. In other words the cæcum and ascending colon have physiologically to undergo great variation in the volume of their contents. It' would be to the detriment of their functions were they to be acutely susceptible to pressure changes, were they to undergo peristalsis and void their contents immediately they hecame filled from the ileum. We must regard them thus, as in the normal state distinctly irresponsive to pressure effects. It is the appendix we hold that is the hydrostatic agent initialling peristalsis in the large gut. In it we have a narrow tube, with no such pronounced variations in calibre, so situated that the weight of the column of forming fæces is communicated to it, and we presume that when this weight reaches a certain point, the distending force acting upon its walls, originates muscular contractions which spread directly int'o the cæcum and so initiat'e the forward movement of their contents. Such a view explains the tendency to constipation in the bed-ridden, in whom the gravitational effect of the contents of the ascending colon can have little effect'; it explains the normal tendency to empty the bowels, either shortly after rising and assuming the erect position or after the first meal when stimulating peristalsis of the small bowel has driven extra contents into the crecum and so.increased the load, it explains the constipation that follows some interval removals of the appendix."

This view takes no account' of the lymphoid tissue in the wall of the appendix, of the presence of the appendix in many four-footed animals, nor of the importance of the ileo-cæcal sphincter in initiating peristalsis of the large bowel. Moreover the usual experience is that appendicectiomy tends to relieve rather than to cause constipation. 


\section{CHAPTER IV.}

Generil Question of Immunity.

WARFARE is a necessary condition of existence. The struggle is not only between different animals of like size but also between the largest of animals and the smallest of microscopic bacteria. The weapons of defence in the two instances are, however, different: teeth, horns and claws for the one foe ; antiseptic secretions and phagocytic cells for the other.

The anti-bacterial weapons are produced for the most part in certain restricted areas of the body and distributed throughout the blood stream. The chief anti-bacterial factories are the spleen* (Luckhardt and Beckt, 1911), the marrow and the lymphatic glands. These three are normally concerned in the destruction of waste products (poisons arising within the body), the first two concerned with purifying the blood, the third with purifying the lymph.

When bacteria and their toxins (poisons introduced from outside the body) appear on the scene it is natural that their removal should fall to these same organs, which react by a great' excess production of anti-toxins, bacteriolysins and specially equipped leucocytes which pour into the blood stream to the general protection of the body.

* And other hamo-Iymph glands. 


\section{CHAPTER V.}

\section{Healthily Acquired Immunity.}

IT is an arresting fact in medicine that some degree of immunity may be acquired by mere contact with cases of an infectious disease without an obvious attack. This may be called healthily acquired immunity.* Thus, the protection of those who have never contracted the disease and yet seem immune in spite of exposure to infection is high where the disease has been rampant previously. Conversely, in "virgin soil," i.e., a community not previously exposed to infection, the ravages have been widespread and excessive, and very few persons have escaped. Quite recently there was an instance of this on the island of St. Kilda, in the Outer Hebrides (Hall, 1913). On the arrival of the fortnightly boat from the mainland an epidemic of influenza broke out and all the inhabitants with the exception of six elderly persons were struck down within a few days. There are many similar experiences in epidemiological records (see articles in Encycloprdia Britannica) the rapid and terrible spread of "Russian" influenza in 1890 ; the introduction of measles into the Faroe Islands in 1846 (three-quarters of the population being attacked within six months); and the similar epidemic in Fiji in

* Immunity may be inherent; or it may be acquired, either by artificial or by natural means. Immunity may be acquired naturally either in a healthy physiological way (where the patient does not exhibit the disease), or in a pathological way (where the patient suffers from the complaint). 
1875 (when 27 per cent. of the inhabitants succumbed in the space of three months) ;* and the spread of phthisis amongst the South African Kaffirs. Indeed, it is a general rule that the first epidemic of any disease in a community is the most virulent, each successive outbreak conferring certain immunity even on those not apparently attacked by the disease. $\dagger$

It has also been recorded by Arctic explorers that after a prolonged healthy sojourn in isolation, the return to civilisation was marked by exceptionally severe colds. It may be recalled, in this connection, that immunity against coryza is of short duration. When there is an outbreak of scarlatina in a family or school, some members will escape the illness though freely exposed to infection. Such children may have experienced a slightly increased redness of the tonsils, but nothing which can fairly be called scarlatina. This subject has been investigated of late years by bacteriological methods, and it has been found that many of these "contact" cases, who have never suffered from an attack of the infectious disease, carry the virulent organisms in their throat's and alimentary canals with apparent impunity. These persons form one class of the so-called "healthy carriers" of infectious diseases which constitute such a difficult problem for the Medical Officer of Health to solve. These immune carriers often outnumber the cases of disease; in epi-

\footnotetext{
* Butler gives an account of the epidemics of measles in Fiji and the Faroe Islands, and refers to similar outbreaks in "virgin soil" on the banks of the Amazon, among the natives of $A$ storia, among the North American Indians, among the Hottentots, and among the natives of 'Iasmania.

$\dagger$ It is only fair to point out that some of the extra virulence of an epidemic in a "virgin" community may be due to the early picking ont of those individuals below the general average of resistance. Later when the most susceptible individuals have suffered from the disease the epidemic becomes less violent. It is, however, unlikely that this factor alone is responsible for the dying down of epidemics.
} 
demic cerebro-spinal meningitis they may be ten times as numerous (Ledingham, 1912). So that of every eleven persons whose throats are reached by the meningococcus ten are enabled to resist any general invasion of their bodies. In what way have they become immune? At first one might imagine that they had all suffered from very mild infections of the blood stream. But when their blood has, at times, been examined, no agglutinins have been found such as are present in the blood stream of convalescents. One is tempted, then, to look elsewhere, and reasons will be given for saying that immunity has been acquired through the agency of the subepithelial lymphatic glands, often, perhaps, without any invasion of the blood stream at all.

It is perhaps the general view of bacteriologists that the immunity acquired against an infectious disease by contacts who have not obviously suffered from the illness is due, nevertheless, to an invasion of the blood stream by the causal organism. There is evidence that this is sometimes the case. But whether the infecting organisms reach the blood or not, there is, in the light of evidence adduced in subsequent sections, good reason for supposing that the infecting organisms are first drawn into the subepithelial lymphatic glands. Antibacterial substances and specially provided lymphocytes are formed in the subepithelial lymphatic glands and pass into the blood stream. It is true that the lymphocytes do not provide the chief reaction to all acute infections. Nor is 'it usually considered likely that the lymphocytes are transformed later into polymorphonuclear leucocytes.* Yet the ingestion of bacteria in enormous numbers by the subepithelial

* Some observers, however, have considered that the natural fate of lymphocytes is conversion into polynuclear leucocytes (see Gruner, $1913)$. 
lymphatic glands must surely confer some measure of protection. And, perhaps, some of the ingested and consequently attenuated organisms pass via the subepithelial and interstitial lymphatic glands into the blood stream and so t'o those other manufactories of anti-bacterial weapons, namely-the red marrow and the spleen. 


\section{CHAPTER VI.}

\section{Alimfntary Immunity.}

AND it is proposed to argue that not only have these glands a prophylactic tendency against infectious disease such as scarlatina, measles, variola, diphtheria, whooping cough, influenza, acute anterior poliomyelitis, epidemic cerebro-spinal meningitis, rheumatic fever and typhoid fever; but also that to these glands man owes his protection against most of the bacteria in his alimentary canal. The high degree of tolerance that man displays towards the teeming denizens of his intestines has often been noted as a remarkable fact. Streptococci, pneumococci and diphtheroid bacilli are almost constantly present in the throat; coli bacilli swarm in the intestines; one half of the weight of the fæces is contributed by the bodies of micro-organisms (Starling, 1912). All these, it will be here alleged are rendered impotent for evil at least partly because the body is forewarned and forearmed by its outpost forts of lymphoid tissue. Of course, the living epithelium of the alimentary tract' is in itself a formidable barrier. But when that is passed the body is still capable of disposing of considerable numbers of intestinal bacteria, unless it is hindered by mechanical or chemical irritation. Many a surgeon has marvelled at the bactericidal powers of the peritoneum in cases of wounded 
intestines if only the gross pieces of fæcal material have been removed. And many a physician must have wondered at the comparative harmlessness of coli bacillæmia as evidenced by even extreme degrees of coli bacilluria.

- It may be noted, too, that the alimentary tract alone is exposed to the bovine type of tubercle bacilli, and that the incidence of bovine infection diminishes with increasing age. 


\section{CHAP'TER VII.}

Distribution of the Subepithelial Lymphatic Glands IN MAN.

IT will be in order to commence an account of the subepithelial lymphatic glands by describing their anatomy. They are nearly all distributed along the course of the alimentary canal,* situated directly beneath the epithelium, but often in some "backwater" or diverticulum and lying especially in those sections, namely, throat, ileum, and cæcum where bacteria "most do congregate." The following is a list of the subepithelial lymphatic glands in the human body, given in the order in which they are met with in passing along the alimentary tract from mouth to anus.

Faucial tonsils. Each faucial tonsil projects medially into the isthmus faucium between the anterior pillar (arcus glossopalatinus) in front and the posterior pillar (arcus pharyngopalatinus) behind. The embedded portion includes the great bulk of the gland and is en-

* Lymph nodes occur along the larger air passages in the normal mammalian lung especially at the points of division of the bronchial tubes. But for the most part they lie outside the nuscular layer and often ontside the cartilages (Miller, 1911). A nodule may. however, at one point reach directly to the ciliated columnar cpithelium as is shown in the figure of a besutiful preparation by Klein, 1873. Lymph nodules also oceur sparingly in the larynx. (ilands, analogous to' lymphoid follicles, and called by Henle "trachoma", glands are foumd in the conjunctiva, and, according to Strohmeyer, are chiefly situated near the medial palpehral commissure. 'T'hey were first described by Brush in his description of Peyer's patclies of the small intestine as identical structures existing in the under eyelid of the ox (Gray, 1916). These trachoma glands would be better known as "conjunctival", subepithelial lymphatic nodules. 
closed in a connective tissue capsule. Laterally it rests upon the superior constrictor of the pharynx. The greater portion of the free surface tends to bulge inwards, but at the upper part is a small depression thinly surrounded by lymphoid tissue (Hett). This used, wrongly, to be known as the supratonsillar fossa but should be called the tonsillar recess.* From the free surface some ten to twenty crypts or lacunae pass into the tonsil and reach almost to the capsule (Foster, 1912). During deglutition the two faucial tonsils are squeezed towards the middle line thus coming into intimate contact with the saliva, the mucus or the bolus of food. $\dagger$

The lingual tonsil includes the small masses of lymphoid tissue at the posterior part of the dorsal surface of the tongue. This part also is pressed into close contact with any swallowed material. The crypts are said to be lined with columnar epithelium, partly ciliated and partly goblet cells (Browne), but the sections I have seen showed stratified epithelium only. (See also Sohotta.)

The nasopharyngeal tonsil hangs in thick folds from the roof and posterior wall of the nasopharynx. A specially deep cleft separates the right and left halves of the organ. The epithelium covering it is ciliated columnar or stratified in type. Mucus from the nasal

* It is possible that we should homologise the tonsillar sinus in man running forwards deep to the plica triangularis and not the supratonsillar fossa with the tubular part of the tonsil in such animals as the rabbit. (See Chapter VIII.)

† Dr. Griffith thus expresses it:- "Bacteriology teaches that germs of pneumonia, influenza, diptheria, tuberculosis and mild and virulent pus are constant inhabitants in our mouths, and are found thickest on, in and about the tonsils. Due to the fact that in every swallowing action the toncils are extruded between the flattened pillars of the pharynx, these organs act their function by screening over the crypts the organisms swept by in the food mass and strain the salivary sticam of hosts of microbes as cobbles clean a brook." 
fossæ which trickles or is sniffed backwards comes in contact with its surface, or is brushed on to it from the superior aspect of the soft palate when that is raised.

The posterior wall of the oropharynx presents dis-

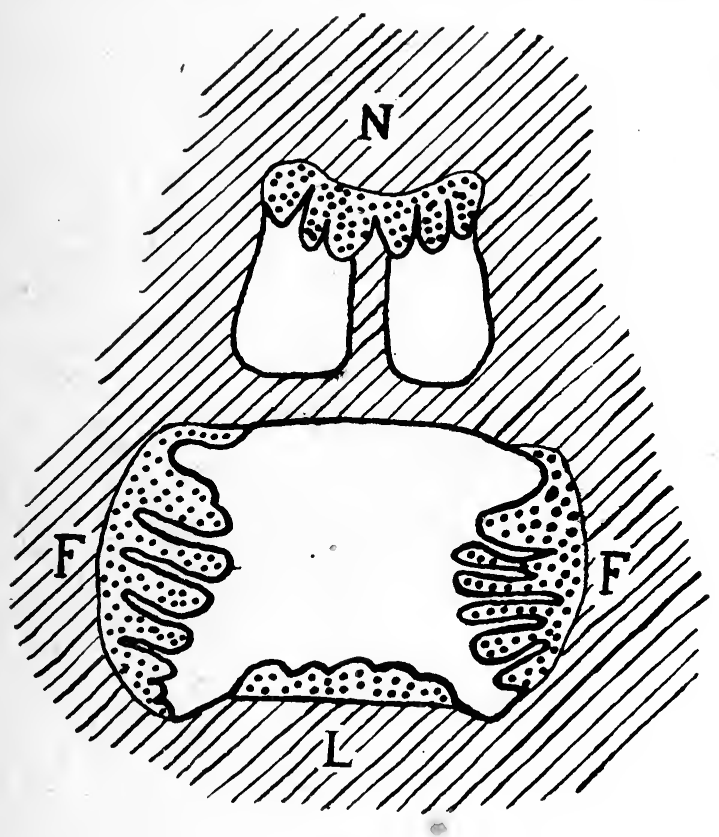

FIG. 3.

Diagram showing the (ircumpharyngeal Ring of Lymploid Tissue (Waldeyer's Ring).

N. Naso-Pharyngeal 'Tonsil.

F.F. Faucial 'T'onsils.

L. Lingual Tonsil.

crete lymphoid patches, which may however be regarded as outlying portions of the nasopnaryngeat tonsil. Some lymphoid tissue is said to occur about the lower end of the tuba auditiva. Lymphoid tissue only occurs very sparsely in the œsophagus (Sobotta). 
The pyloric division of the stomach presents a number of solitary lymphatic nodules which become more numerous as the pyloric sphincter is approached and which continue into the proximal part of the duodenum. A special patch it is said often exists near the entrance to the common bile duct.

The noduli lymphatici aggregati (Peyer's patches) et solitarii of the small intestine occur in the jejunum but are more frequent in the ileum especially towards its lower end. The lymphatic nodules when single are termed solitary and are irregularly dispersed, but when collected together they form oval patches ( $\left(\frac{1}{2}\right.$ to $1 \frac{1}{2}$ inches long) with their long axes in the axis of the bowel and invariably situated on the side of the intestine remote from its mesentery. It is said that from twenty to forty-five of these patches may be found (Quain, 1912). The last one is situated a short distance from the ileocreal valve. They are not always easy to see with the unaided eye. When inflamed or active they may be more obvious from the peritoneal than from the mucous aspect.

The vermiform process (vermiform appendix) is a blind tube one to six inches in length. Grauer has recorded one over twelve inches long (Lockwood, in Allbutt's System of Medicine). It's walls are thick, and as much as half the thickness may be due to the lymphoid tissue beneath the mucous membrane. The lumen is small and contains a little material which is similar to the contents of the cæcum. The appendix opens into the left side of the cæcum about one centimetre below the ileocæcal valve, but that it represents the original apex of the cæcum is shown by the continuance to it of the tæniæ coli. A moment's consideration will show that the lymphoid tissue in the appendix is situated on the side of the large bowel remote from 
its original mesentery and therefore strictly homologous with the Peyer's patches (Fig. 4).

The vermiform appendix is able either to fill itself from, or empty itself into, the cæcum.

The noduli lymphatici solitarii of the large intestine are scattered throughout from the cæcum to the rectum. A large patch is said to occur at the junction of the rectum and anal canal.

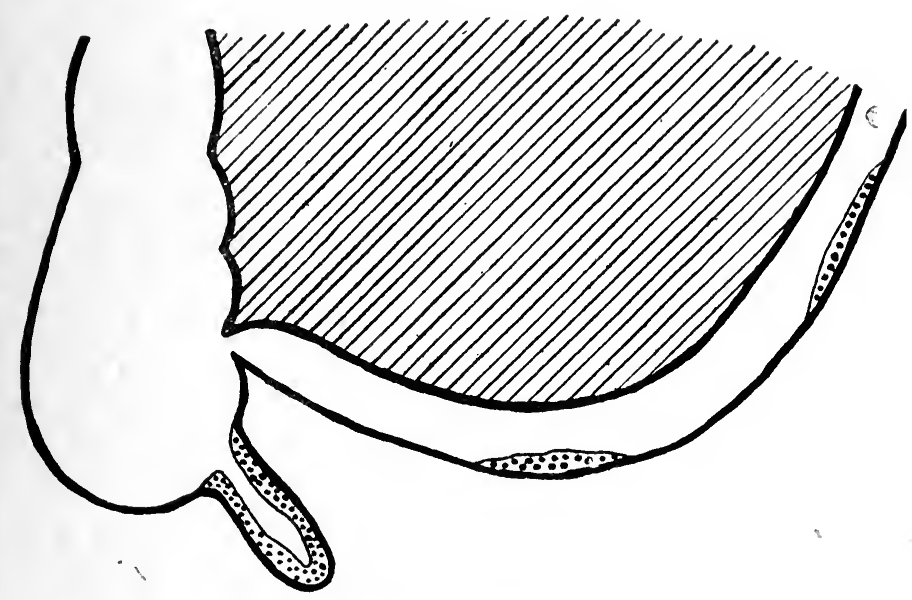

FIG. 4.

Diagram of Lymphoid Tissue near the Ileo-Cacal Junction, illustrating the serial homology of the lymphoid tisue in the vermiform process (appendix) with that of the noduli lymphatici agrregati (')eyer's patches).

The most significant fact in connection with the distribution of these subepithelial lymphatic glands is that they are found wherever bacterial activities are greatest. There are certain frontiers of the body which are weak spots from the point of view of bacterial invasion. The dry skin with its dense layers is usually a sufficient 


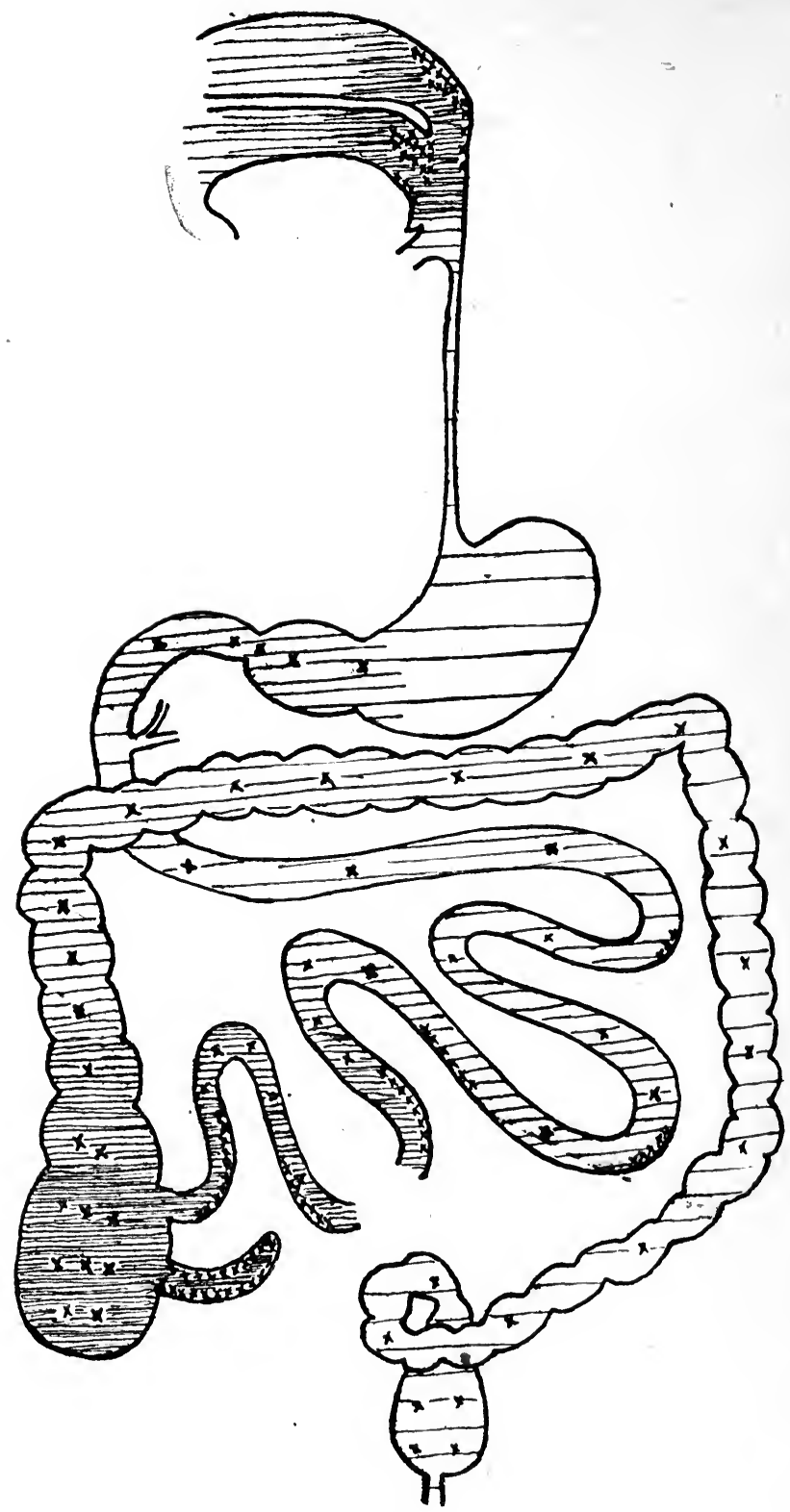

FIG. 5 ,

Diagram of the IItuman Alimentary Canal. The shading marks those parts where bacteria flourish most abundantly. The crosses indicate roughly the positions of the subepithelial lymphatic nodules. 
barrier for the external surface of the mammal; the nasal filtering of the inspired air and the ciliary action in the air passages sterilise the inspired air and protect the lungs : but the alimentary tract is only lined by a mucous membrane which is thin, delicate, moist, absorbing and in continuous contact at many points with hordes of hostile bacteria. The alimentary lining is clearly the anxious frontier, at some points being weaker than at others. At the fauces come first the fresh organisms in food and drink and also from the dusty or spray-laden atmosphere, and here they colonise and multiply. The œsophagus is safer, as material does not remain in contact with its walls. In the stomach the acid secretions of the cardiac portion numbs or destroys the bacteria, though the activity is less pronounced towards the pylorus. The alkaline contents of the small intestine are readily decomposable and swarm with micro-organisms. In the lower half of the duodenum and upper part of the jejunum the bacteria are still not very active but towards the lower end of the ileum the longer incubation causes increase in their numbers and activity. Here the frontier is greatly threatened. The cæcum with it's very infective fluid contents is in like case, but the walls of the colon and rectum are less menaced, for the inspissation of the fæces does not favour bacterial activity.

It is in these dangerous localities-the fauces, the ileum and the cæcum-that the subepithelial lymphoid tissue is developed (Fig. 5). Though widely scattered, this tissue is not insignificant in amount. If the human faucial, naso-pharyngeal and lingual tonsils, the solitary and the aggregated lymphatic nodules, and the vermiform appendix were massed together, they would form an organ of some bulk.

It should be noted, however, that the subepithelial lymphoid tissue does not form a complete covering for 
the weak places. Such a disposition would, indeed, interfere with the absorption of food. The frontier is defended, not by a wall, but by a chain of forts which draw the attack.

There are two apparent exceptions to the rule that the subepithelial lymphoid tissue occurs wherever bacteria are most abundant. The fore parts of the nasal fossæ strain off most of the inspired bacteria, yet there is no tonsil in the front of the nose. In health, however, the bacteria do not multiply in the nasal mucus. Moreover lymphoid tissue being so prone to enlarge would frequently block the air way, as indeed adenoid tissue often does even in the much wider nasopharynx. The point is referred to in a subsequent Chapter (XVI.).

Similarly, the mouth, which always contains pathogenic organisms and is extremely liable to septic infections (for example, decayed teeth) is devoid of lymphoid tissue. But it must be remembered that the buccal cavity is lined by thick stratified epithelium and not by a delicate columnar layer. And, of course, the faucial tonsils are immediately adjacent.

It may be noted before closing this section that the thymus appears originally as subepithelial lymphatic tissue about the third internal cleft recesses and is thus serially homologous with the faucial tonsils. It soon, however, migrates, losing its connection with the pharynx, though epithelial remnants in it persist as "Hassal's concentric corpuscles." 


\section{CHAPTER VIII.}

Comparative Anatomy of the Subepithelial Lymphatic Glands.

IT is not easy to obtain accurate data on this branch of the subject. Solitary and aggregated lymphatic nodules vary much in size and visibility according to their activity and the age of the individual. It is often impossible to distinguish human Peyer's patches with the unaided eye. Microscopical assistance is necessary : yet very little histological investigation has been undertaken.

The following imperfect account of the comparative anatomy of these glands has been drawn largely from the facts recorded by Berry (1895 and 1901), Huntington (1903), Stapley (1911) and Seccombe Hett and Butterfield (1910 and 1913), which have in some instances been confirmed by the present author.

The three main groups-namely the faucial, the ileal and the cæcal-are represented in most if not all the higher animals. Each group must be considered in turn.

The Faucial Group is arranged round the fore part of what represents the primitive pharynx. In the walls of the fish's pharynx, which is highly developed subserving gill respiration, wandering amœebocyt'es can be seen, and "thymus glands" have been described in the dorsal diverticula of all the gill slits. 
However I have not found any clear evidence that definite lymphatic glands-whether interstitial or subepithelial-ever nccur except in birds and mammals.* Anyhow it is in the internal cleft recesses and the corresponding parts of the roof and floor of the embryonic pharynx that the faucial group of lymphoid collections develops, at least in mammals.

The faucial tonsils usually retain more or less evidence of their origin from the second internal cleft' recess. Mammalian tonsils $\dagger$ may be roughly divided into two classes : the first, where the principal feature is a protuberant mass of lymphoid tissue partly projecting into the throat; the second where the principal feature is a blind tube or recess lined by lymphoid tissue and running backwards to open into the throat. (Fig. 6.) But the distinction is one of degree rather than of kind ; for in the projecting tonsils some depression is usually found in the upper part, whilst in the tubular tonsils the lower lip of the orifice is thickened with lymphoid tissue and pouting. Projecting tonsils occur in the following animals :-

Man (IIomo Sapiens),

Gorilla (Gorilla Savagei),

Gibbon (IIylobates),

Hippopotamus (IIippopotamus Amphibius),

Dog (Canis Familiaris),

Hairy armadillo (Dasypus Villosus),

Mouflon (Ovis Musman).

Tubular tonsils occur in the following animals :-

Grivet Monkey (Cercopithecus Griseo-viridis),

* "Specimens of the intestinal canal of both the Skate and the Common Frog have been examined, but did not show any evidences of lymphoid tissue." (Berry, 1901.)

$\uparrow$ Mr. Hett found that no tonsil was to be found in a few mammals - the liat, the Beaver, the Porcupine and the Bat, but he showed that the great majority of mammals possessed tonsils. 

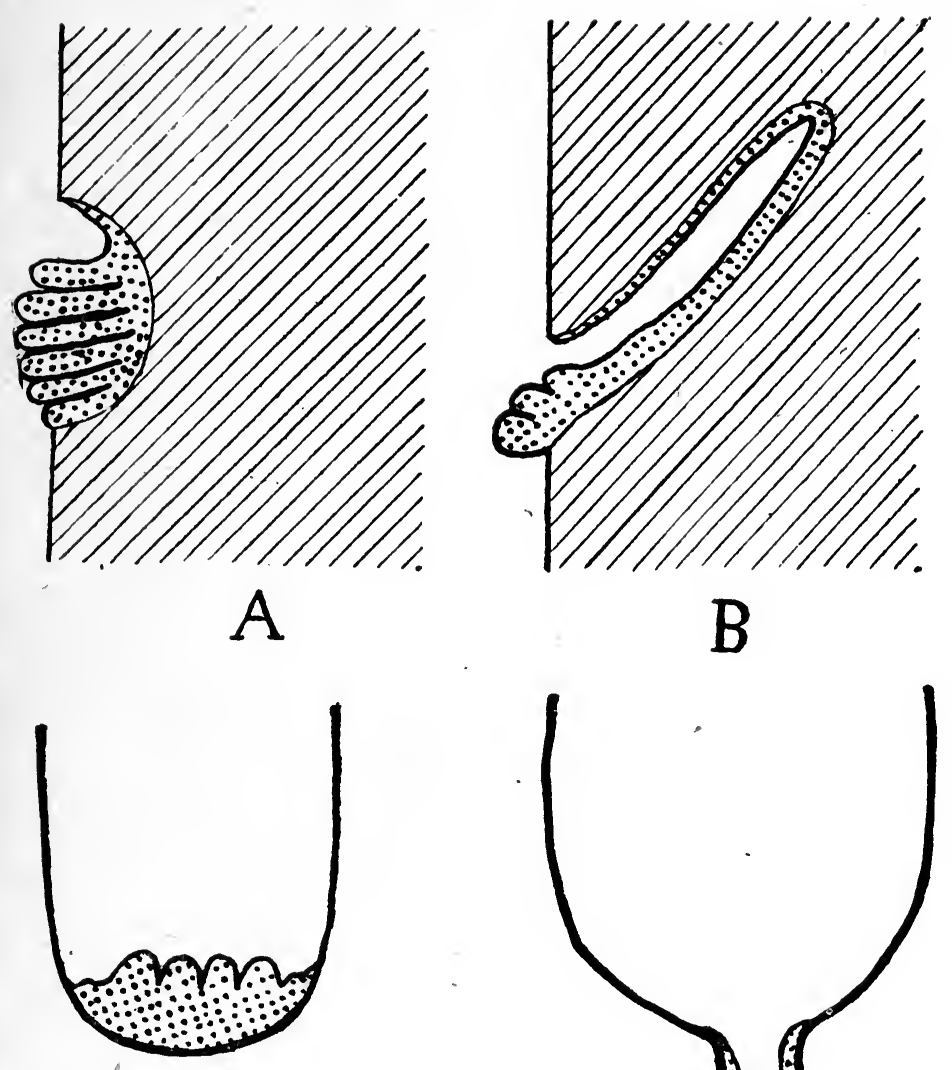

Fig. 6.

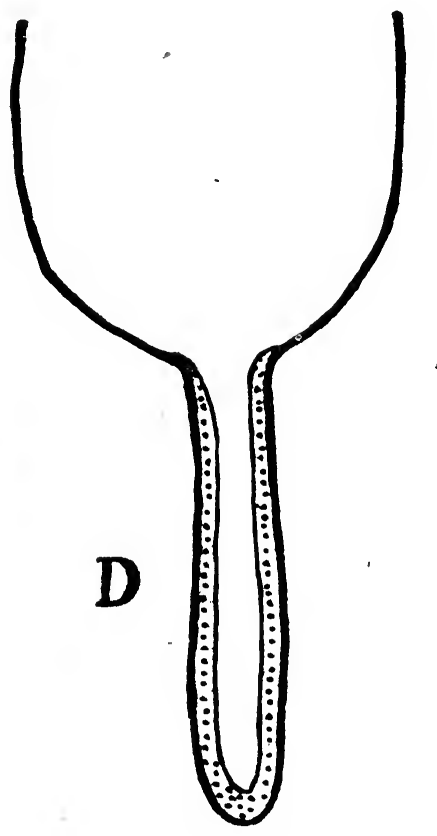

Diagram showing $A$, the Protuberant, and $B$, the Tubular types of Faucial Tonsil; and $C$, the Protuberant, and $D$, the Tubular types of Crecal Tonsil. 
Cat (Felis Domestica),

Leopard (Felis Pardus),

Cow (Bos Taurus),

Rabbit (Lepus Cuniculus),

Civet (Viverra Civetta),

Tasmanian Devil (Dasyurus Sp.),

Opossum (Didelphys Carnivora).

Many intermediate forms are to be found in other animals.

The nasopharyngeal tonsil has been traced in mammals, birds, and even reptiles, according to St. Clair Thompson, quoting Alagna (1902). In man the lymphoid tissue principally hangs from the roof and posterior wall as already described. This is not the case in all animals. In the sheep family the surface of the hinder part of the septum nasi is ridged and nodulated by the presence of masses of lymphoid tissue constituting the septal nasopharyngeal tonsil.

Excellent specimens, presented by H. Seccombe Hett, Esq., illustrating some of the above points, may be seen in the museum of the Royal College of Surgeons, London.

The Ileal Group of lymphatic tissues is probably of widespread occurrence. Huntington (1903), however, states that both aggregated and solitary follicles only occur together in mammals, and that solitary follicles alone only occur in birds. The aggregated patches, as in man, occupy the side of the bowel remote from the line of attachment of the mesentery. Stapley (1911) states that in pigs a continuous elongated patch six feet' in length is to be found. In the rabbit a specially large collection of lymphoid tissue is found stretching for an inch or so immediately above the ileo-cæcal valve. It sometimes nearly encircles the bowel at the extreme end of the ileum. Immediately beyond the ileo-cæcal sphincter is another pat'ch of about the same 
area with its long axis disposed at right angles to the ileal patch. (Fig. 23.) A terminal branch of the ileocæcal artery marks the ileo-cæcal junction on the exterior and sends twigs to both patches.

The lymphoid tissue massed in the cxcum however usually occurs at its apex and is present in very many different species. And the form in which it presents itself seems to be associated with the animal's diet rather than with the position of the species in the zoological scale.

The cæcum is the proximal part of the large intestine. Its walls secrete no.digestive juices and one of its chief functions seems to be that it provides a receptacle in which digestion by bacterial action can be carried on. The normal alimentary juice of higher animals can break up all food substances with one exception-namely cellulose. The body can deal satisfactorily with protein, carbohydrate and fat without bacterial assistance so long as these foodstuffs are not' enclosed in cellulose envelopes.

In cows and other herbivora, known as ruminants, bacterial decomposition of the cellulose takes place while the food is incubated in the pouch or first stomach. Then the food is chewed once more and swallowed, finally, a second time. In rodents such as the rabbit the bacterial decomposition of the cellulose takes place in a truly enormous cæcum provided with a number of spiral folds increasing the area for absorption.

In carnivorous animals the proximal part of the large intestine is of small size.

Thus in the same class of animals one may find varying degrees of cæcal development correlated to some extent with the diet of the particular species. Furthermore, it may be added, analogous modifications 
appear in genera so widely separated that quite independent though similar origins must be assumed.

The different types of junction of the small and large intestines.

Type A.-The junction of the large and small intestines may be hardly apparent', or may be indicated only by a change of calibre, an external constriction or an internal valve.

Most fishes,

Most amphibians,

Most reptiles,

A few birds, e.g., the Parrot,

Some carnivorous marsupials, e.g., the Tasmanian

Devil (Dasyurus Viverinus or Sarcophilus Satanicus),

Some edentata, e.g., the Three-toed Sloth (Bradypus Tridactylus),

The Laughing Jackass of Australia (Dacelo),

Most Whales,

Bears,

Bats,

Weasels.

Type B.--In addition to demarcation of the junction, the proximal part of the large intestine is dilated, chiefly by a bulging of the antimesenterial border, to form a single pouch or crcum.

This single cæcum is of small size in :-

A few fishes, e.g., the Dogfish (Scyllium Canicula), Some reptiles, e.g., the Indian Python,

A very few birds, e.g., the Heron,

Some monotremes, e.g., the Platypus (Orinthorhynchus),

Many carnivorous mammals, e.g., Cat (Felis DomesMan. tica), and Dog (Canis Familiaris),

The single cæcum tends to be larger in :- 
Most herbivorous mammals, e.g., Sheep, Horse, Elephant,

Some primates, e.g., the White-handed Gibbon (Hylobates Lar), and the Orang-outang (Simia Satyrus).

The single cæcum is relatively largest of all in the rodents, e.g., the Rabbit (Lepus Cuniculus).

Type C.-In addition to demarcation of the junction, the proximal part of the large intestine presents bilateral cxca.*

These are present in a few mammals :-

Some Armadillos, e.g., Dasypus Sexcintus and Clamydophorus.

The Little Anteater (Cyclothurus Didactylus).

The Manatee (Manatus Americanus) presents a bifid cæcum.

The bilateral type of cæcum is almost constant in birds. The Heron is an exception. They are however very small indeed in the Wedge-tailed Eagle (Aquila Audax) and the Lyre Bird (Menura Victorix). Generally speaking the cæca are short in carnivorous birds, for example, the Crow (Corvus Corone), and much longer in herbivorous ones. Long cæca occur in :-

The Ostrich (Struthio),

The Pheasant (Phasianus).

The Duck (Anas),

The Goose (Anser),

The Swan (Cygnus),

The Peafowl (Pavo),

The Bustard (Otis), and others.

The proximal part' of the large intestine nearly always contains subepithelial lymphoid tissue at any rate in birds and mammals. Thus it is found $\dagger$ in the bilateral

* A curious animal, the Hyrax, shows both a juxta-ileocrecal cæcum and also a pair of more distant crea. But this is quite exceptional.

† I have sectioned the rectal gland of the Dogfish and the pyloric caca of other fishes. These, however, do not exhibit lymphoid tissue. 
cæca of birds (Fig. 7) and in the single cæcum of such animals as possess one.*

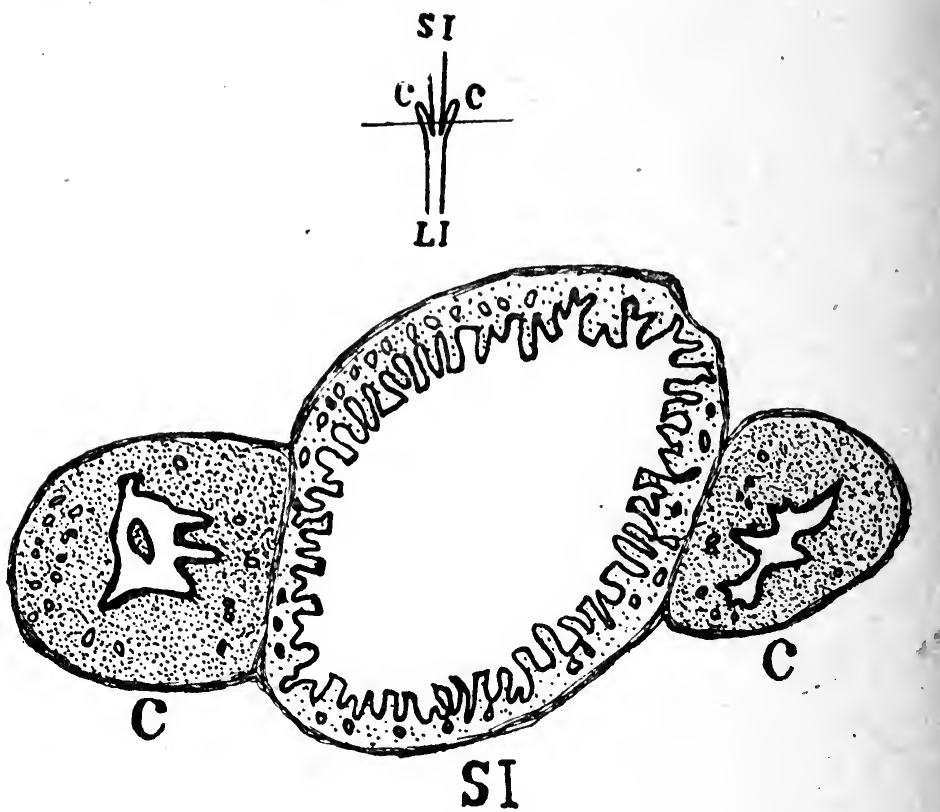

FIG: $i$.

Microscopical section of the small intestine and the two cæca of a pigeon, showing masses of lymphoid tissue in the cæca. The smaller tigure shows the line of section.

C.C. Coca.

S.1. Small intestine.

L.I. Large intestine.

The lymploid character of the pigeon's cxca is also depicted in plates illustrating Dr. Berry's paper (1901).

Considering the case of lymphoid tissue in the single cæcum one finds, here also, that the different types presented are associated rather with dietetic habits than with phylogenetic position.

Class A.- The simplest type consists of a mass of lymphoid tissue at the apex of the crcum slightly

* Berry sectioned the creal apex in 32 animals and found lymphoid tissue at or near the creal apex in all warm blooded animals with only one or two exceptions. 
bulging internally into the lumen. This may be called the cæcal tonsil and is characteristically present in the slightly developed cæca of carnivora.

It is seen in :-

The Dog (Canis Familiaris),

The Cat (Felis Domestica),

The Lion (Felis Leo), and others.

Class B.--The development of the lymphoid appendix is a further elaboration. The apical portion of the cæcum tapers gradually or, in its highest modifications, is of uniformly small bore being sharply demarcated from the rest of the cæcum. .

It' is interesting to observe that the lymphoid tissues in the fauces and in the cæcum each present themselves, at one time as a bulging mass, at. another time, as a blind tube. (Fig. 6.)

The vermiform appendix is of far more widespread occurrence than is generally recognised.* It attains its maximum size and complexity in the rodents, which also exhibit the highest development of the cæcum.

A well-developed vermiform appendix (or to avoid disputes as to terminology, a cæcal apex with reduced lumen but with lymphoid tissue in its walls) is to be found in the following species:--

Most rodents, e.g., Rabbit (Lepus Cuniculus), Fig. 23 ; Hare; Lagomys Pusillus, $\dagger$ Fig. 8 ; Beaver (Castor Fiber), Fig. 9; Canadian Porcupine (Erythrizon Dorsatus), Fig. 10.

* At the Royal Society of Medicine in 1916 the following mis-statement: "No mammals other than man have a cæral appendix except apes" occurred in a paper read before the Pathological Section.

+ This animal possesses two adenoid vermiform appendages, one close to the ileum and the other at the apex of the crcum. Some rodents present two lymphoid areas in the caccum, one immediately beyond the ileo-crcal sphineter, the other at the apex of the cacum. Anparently in this animal both areas have become converted into blind tubes. 
A few ungulates, e.g., Peccary (Dicotyles), Fig. 11; Tapir (Tapirus Americanus), Fig. 12.

Some marsupials, e.g., Vulpine Phalanger (Trichosurus Vulpinus), Fig. 13 ; Koala* (Phascolarctus Cinereus), Fig. 14; Wombat (Phascolymis Wombat), Fig. 15.

Most lemurs, e.g., Lemur Macaco (Figs. 16 and 17). All the anthropoid apes, Orang (Fig. 18); Gibbon (Fig. 19); Chimpanzee (Fig. 20); Gorilla (Fíg. 21). Man (Fig. 22).

A less well developed appendix also occurs in many other animals, such as the Puma, the Civet, and the Ichneumon.

* It must be admitted that the presence of lymphoid tissue has not been demonstrated in every instance in this list so far as I am aware. That the apex of the creum contains lymphoid tissue in its walls in almost all mammals has however been shown by Berry. Stapley, on the contrary, declares that the koala's crcum (in which term he includes the appendix) contains no lymploid tissue. He also failed to find lymphoid tissue in two out of three wombats' appendices which were sectioned. He does not, however, mention whether the wombats were old or young, and in this connection the atrophy of lymphoid tissue after puberty and its fibrosis following inflummation must be borne in mind It should perhaps be added that Stapley's general conclusions as to the form and nature of the appendix are quite opposed to those supported here. 


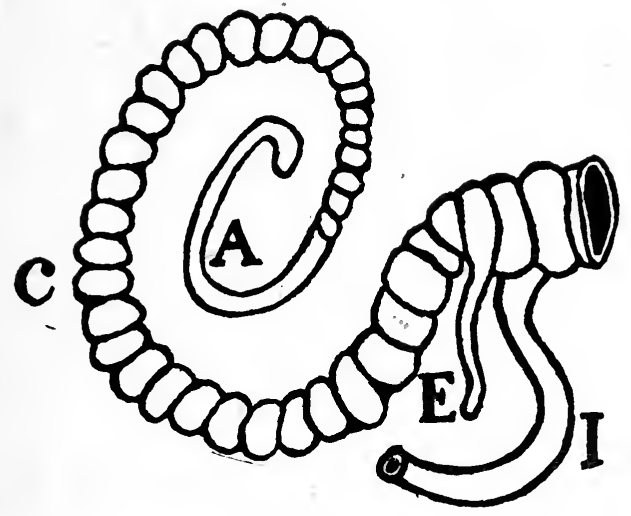

Fig. 8.

Cacal Apex with Sala Lumen.

Lagomys Pusillus, a rodent (after Pallos, reproduced by

I. Ileum. Huntington.)

C. Cæcum.

A. Appendix.

E. Extra appendix.

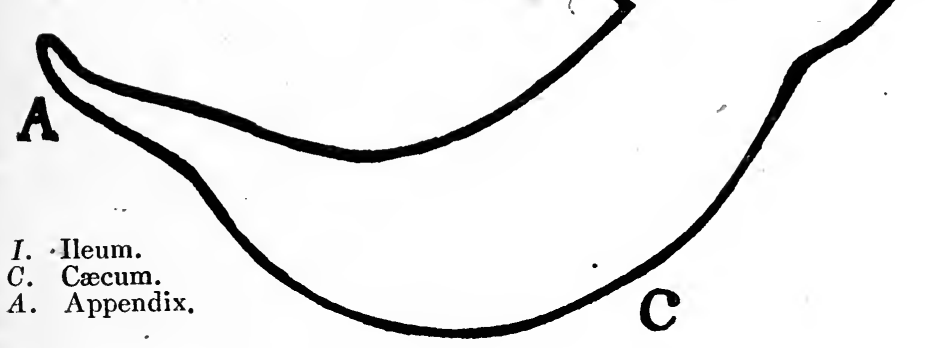

FIG. 9.

Cacal Apex with Small Lumen.

Castor Fiber, the Beaver (after Huntington). 


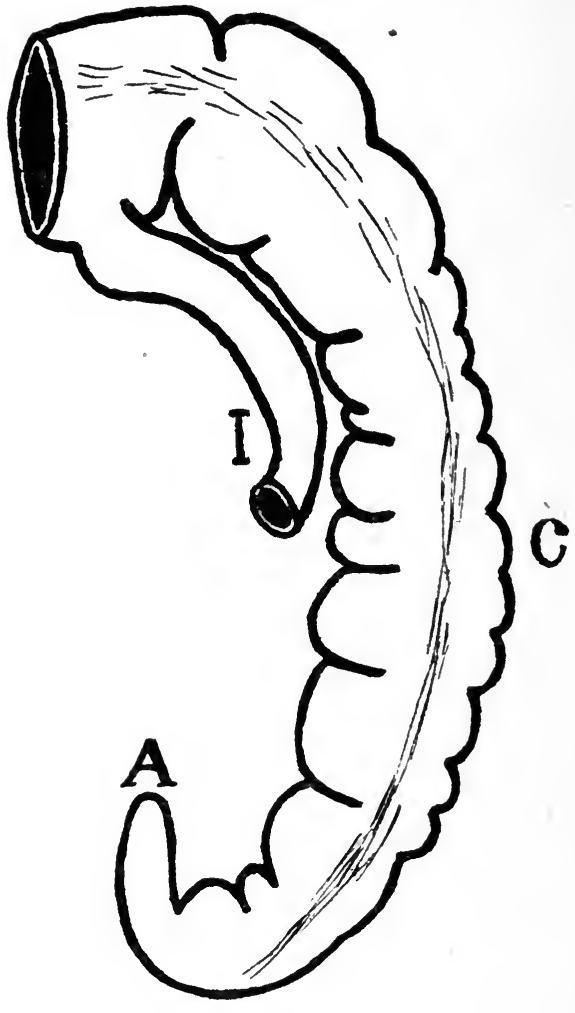

Fig. 10.

Cacal Apex with Small Lumen.

Erythizon Dorsatus, the Canadian Porcupine (after Huntington). I. Ileum.

C. Cæecum.

A. Appendix. 


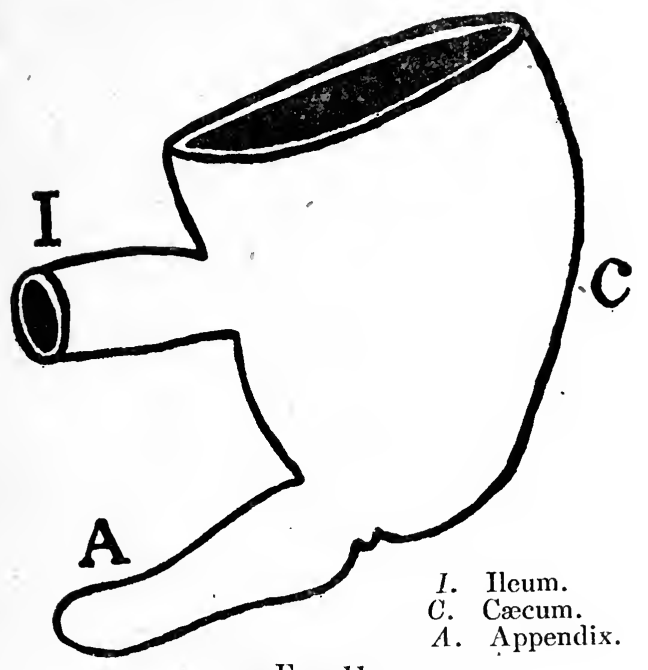

FIG. 11.

Ciacal Apex withi Sinal Lumen.

Dicotyles 'Torquatus, the Collared Peccary (after Huntington).

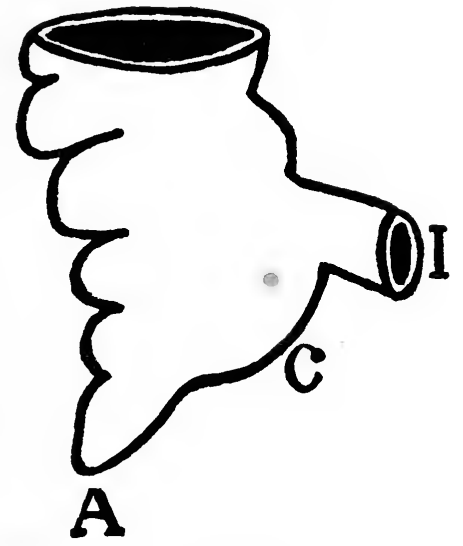

Fig. 12.

C.fechl A Phe With Sinal Lunin.

Tapirus Americanus, the American 'Tapir (after Huntington).

I. Ileum.

C. Crecum.

A. Appendix. 


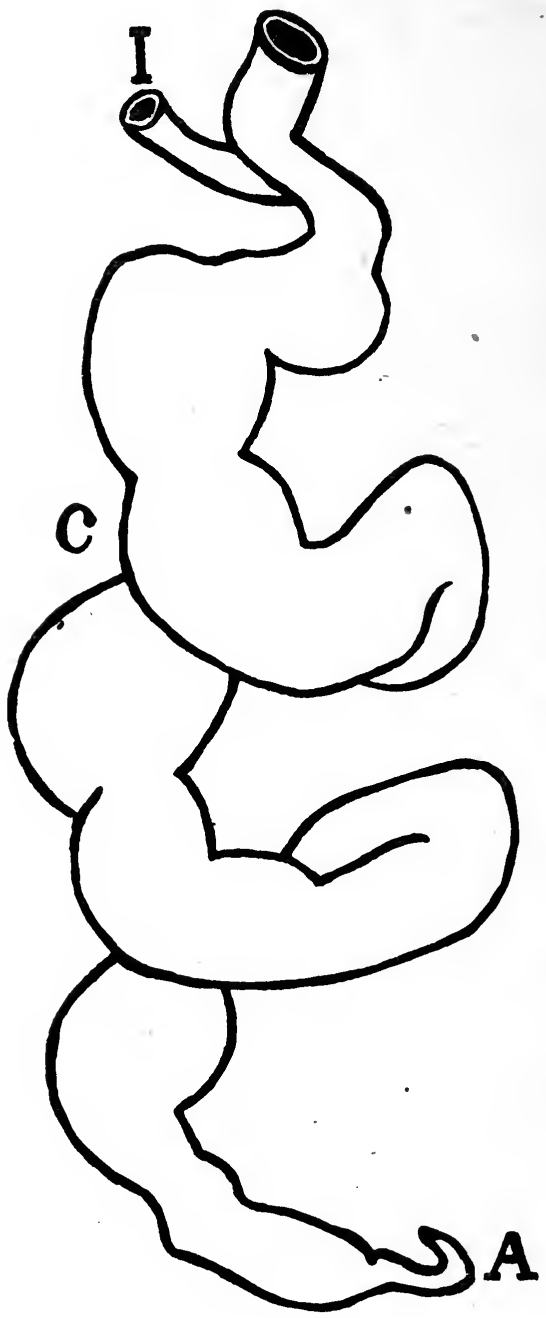

Fig. 13.

Cecial Aplex witi Small Lumen.

Trichosurus Vulpinus, the Vulpine Phalanger (after Huntington).

I. Ileum.

C. Cæcum.

A. Appendix. 


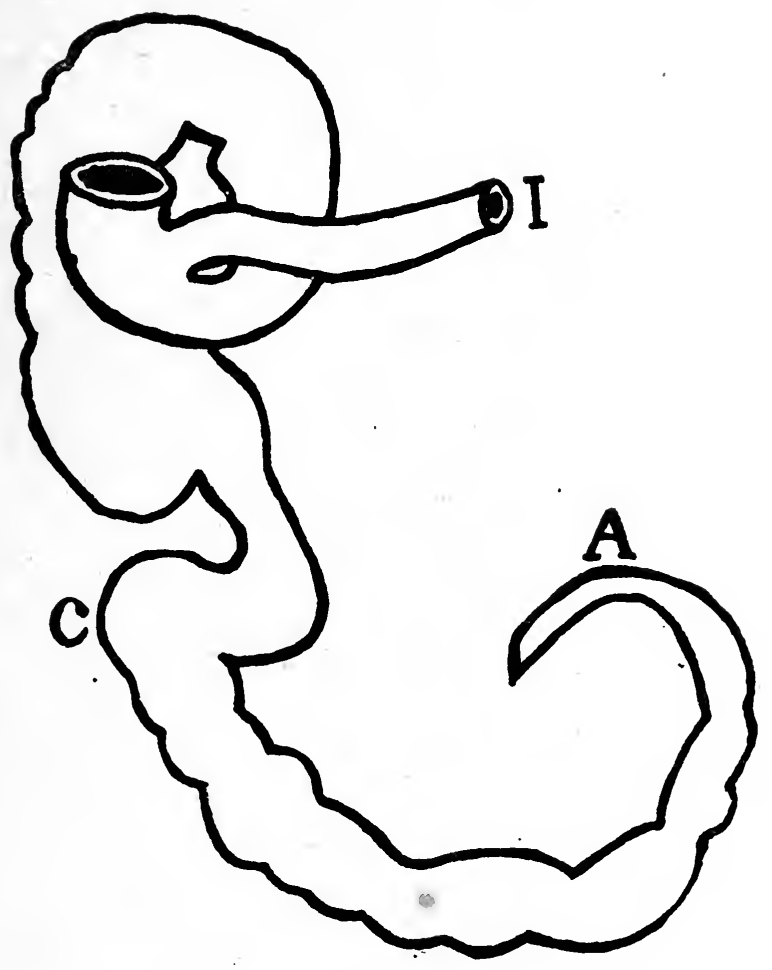

FIG. 14.

Cefal Apex witu Smale Lumin.

Phascolarctos (inereus, the Koala (after Huntington).

I. Ileum.

C. Cæcum.

A. Appendix. 


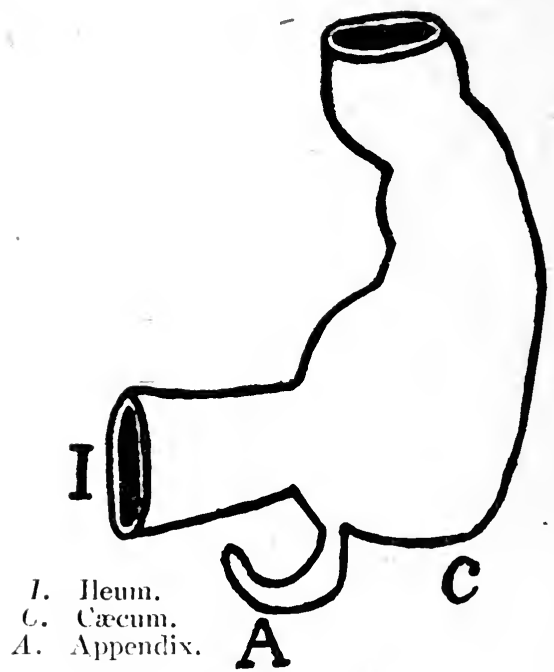

Fig. 15.

Chall apex with Siall Lumin.

Phascolomys Wombat (after Huntington).

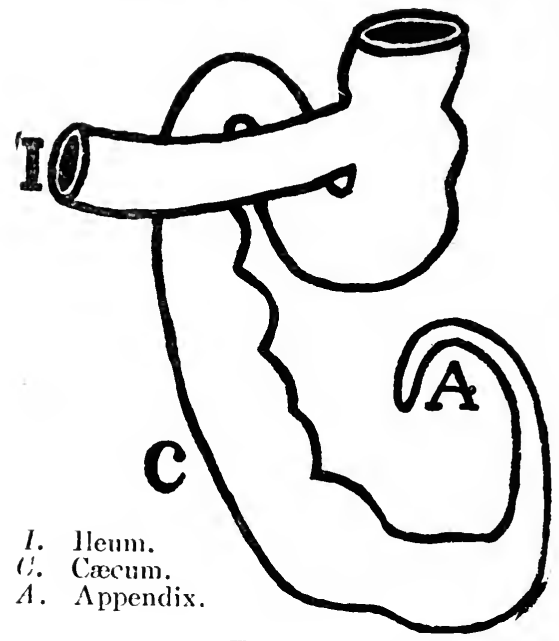

Fig. 16.

Cacal Aplax with Sind Lumin.

Lemur Macaco, the Lemur (after IImitington). 
1. Heın.

c. Ciecum.

A. Appendix.

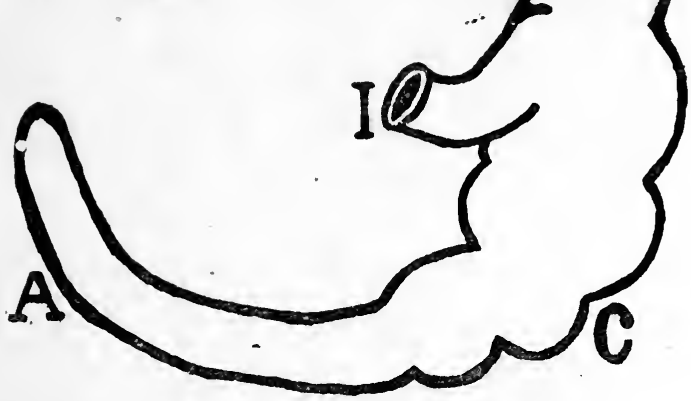

FIG. 17.

Cacal Apex witil Small Lumen.

Nycticebus Tardigradus, the Slow Lemur (after Huntington).

I. Ileum.

c. Cæcum.

A. Appendix.

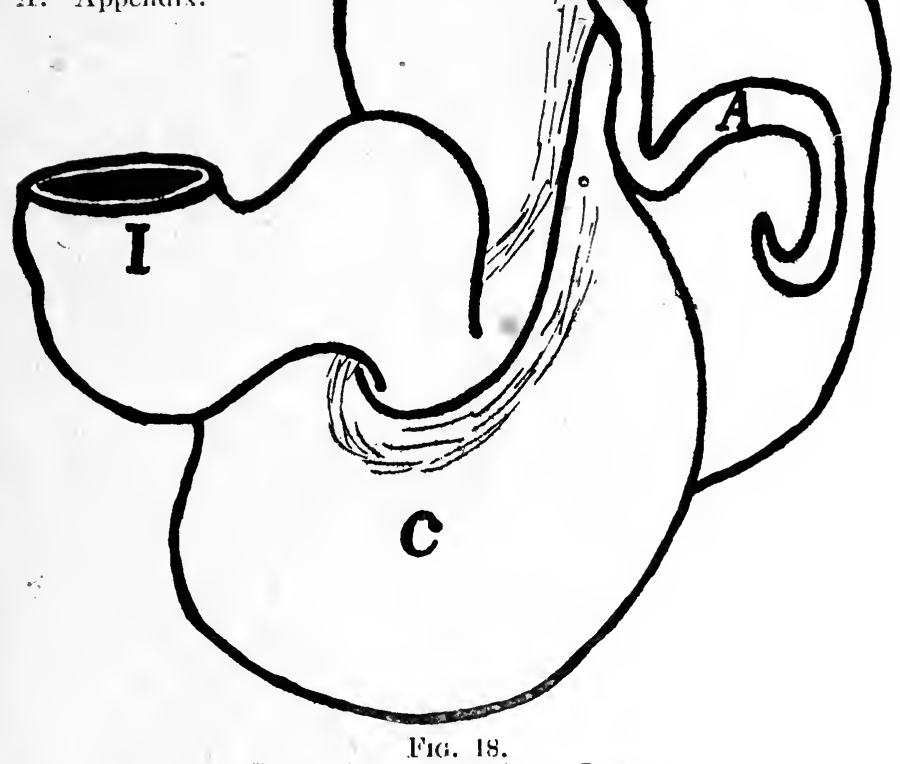

Cacal A Plix wiril Simal. I.unin.

Simia Satyrus, the Orang (after Huntington). 


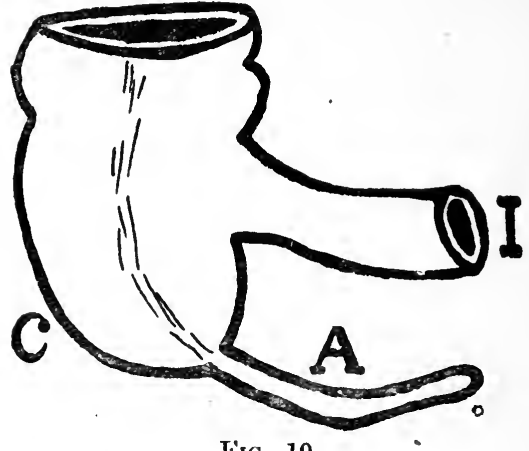

Cacal Apex with Siall Lumen.

Hylobates Hoolock, the Hoolock Gibbon (after Huntington).

I. Ileum.

C. Cxcum.

A. Appendix.

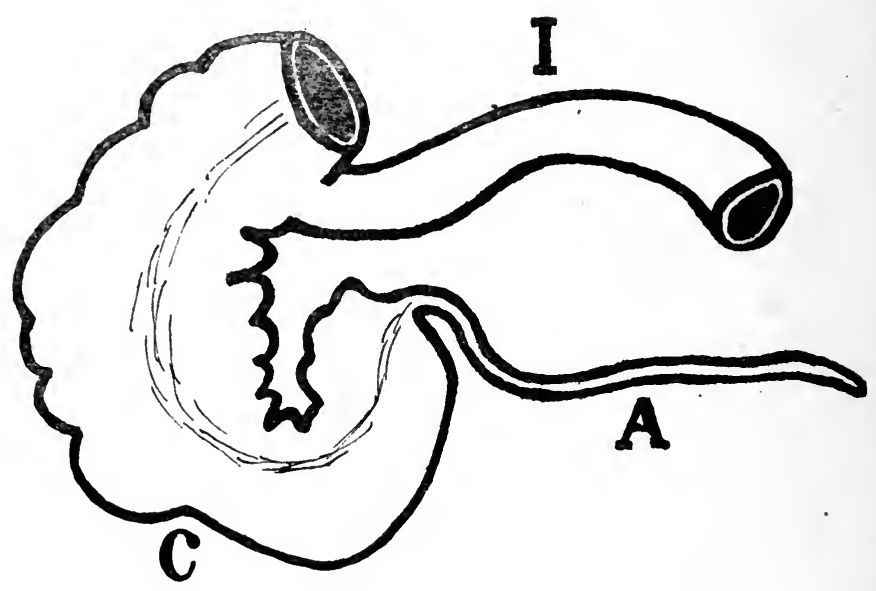

FIG. 20.

C.ecal $\Lambda$ pex with Small Lumin.

Troglodytes Niger, the Chimpanzee (after Huntington).

I. Ileum.

C. Cæcum.

A. Appendix. 


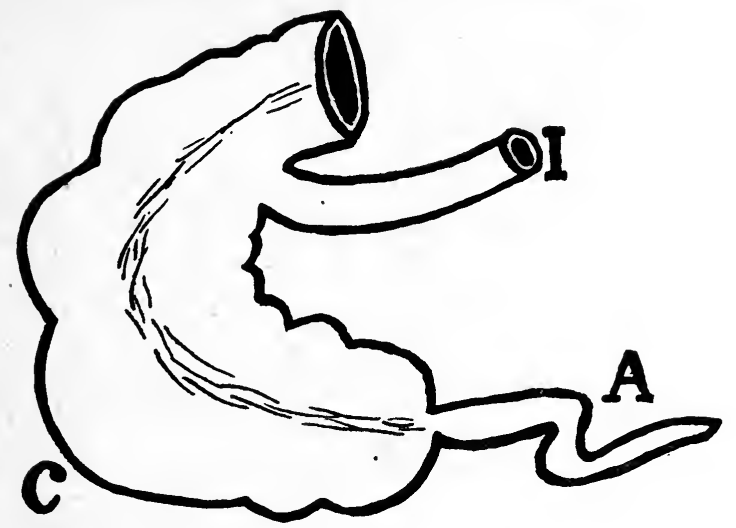

Fig. 21.

Cecar. Apex with Small Lumen.

Gorilla Savagei, the Gorilla (after Huntington).

I. Ileum.

C. Cæcum.

A. Appendix.

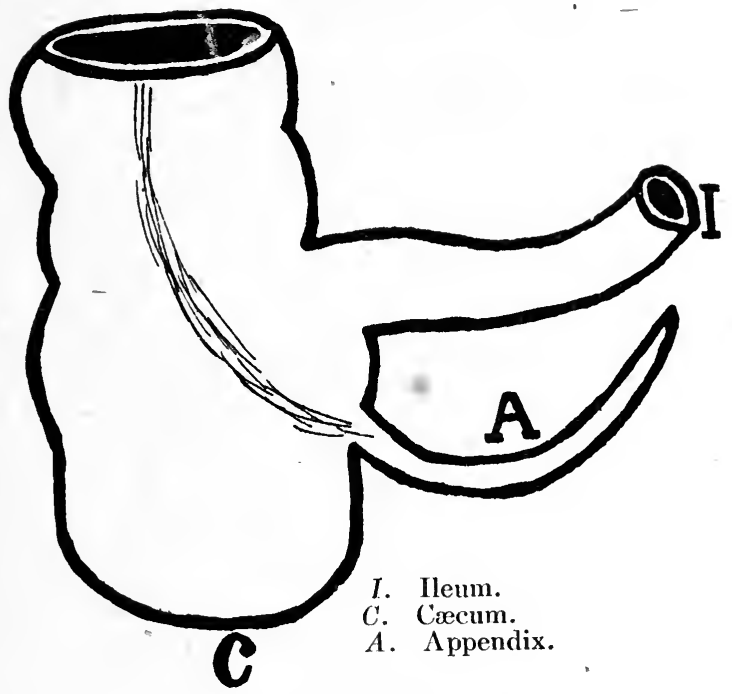

Fig. 22.

Cecal d pex with Sille Lumin. Homo Sapiens, Man. 


\section{CHAPTER IX.}

Structure of the Subepithelial Lymphatic Giands.

ALL lymphatic glands, whether interstitial or subepithelial are composed of a number of similar units. Each unit is best called a lymph nodule, but has also been termed a "lymph-follicle" or "germ-centre." The lymph nodules are the bricks of which the lymphatic workshops are built. The lymph nodules may roughly be said to average the size of a pin's head each.

Each lymph nodule consists of a mesh-work of retiform tissue amongst which are densely crowded two types of cells.

First type.-In the centre of the nodule are found large cells with abundant cytoplasm. The nuclei do not usually stain darkly. In ordinary hæmatoxylineosin sections the centre of the nodule is much paler than the periphery. These larger clear cells may also be found sparsely in other parts of the nodule. Flemming in $\mathbf{1 8 8 5}$ described numerous kario-kinetic figures in the nuclei of these large cells and hence he named the nodules germ-centres. These cells possess highlydeveloped phagocytic powers and may at times be seen to contain soot-particles, bacteria, and even other cells. - Second type.-Each cell is small in size with scanty cytoplasm and a round darkly-staining nucleus. It exactly resembles the small lymphocyte found in the blood stream. These cells are far the more numerous, 
they occupy the whole of the periphery of the nodule. They appear to be very densely crowded together and this is the more obvious on account of their darkly staining predominant nuclei. The cytoplasm does not stain well with eosin. Whatever the small lymphocytes may be in the blood, they are undoubtedly phagocytic in the subepithelial lymphatic glands as will be shown subsequently.

These two classes of cells have been termed macrophages and microphages (Ruffer), or endothelial cells and lymphocytes. But I prefer to call them large and small glandular lymphocytes. Glandular lymphocyte is a somewhat clumsy name, but although probably the large and small glandular lymphocytes in the glands become the large and small lymphocytes in the blood, it seems incautious to assume it too dogmatically in the nomenclature.

The large glandular lymphocytes are, probably, endothelial in nature. They have been said to line the reticular meshwork and to correspond with the endotheilial wall of a lymphatic vessel. It is generally assumed, following Flemming, that, as mitotic figures are frequently visible, the large glandular lymphocytes by division give rise to the small glandular lymphocytes. The large lymphocytes can reproduce themselves as large lymphocytes, however, as is seen in Hodgkin's disease (Lymphadenoma). Perhaps the large glandular lymphocyte divides to form either small or large glandular lymphocytes according to it's immediate environment. Some have described the small glandular lymphocyte as growing into a large glandular lymphocyte, but I think this very improbable. A few of the large glandular lymphocytes escape from the nodules and eventually enter the blood where they form some, at least, of the infrequent large lymphocytes there found. 
As has been said above the small glandular lymphocytes are probably derived from the large ones in the lymphatic glands. The great majority pass via the efferent lymphatic channels (and perhaps also directly) into the blood where as small lymphocytes they constitute twenty per cent. of the total white corpuscles or 1,400 per cubic $\mathrm{mm}$.*

Both small and large glandular lymphocytes function principally as scavengers, being provoked to activity by slightly different stimuli. $\dagger$

The large glandular lymphocytes may join together to form giant cells. Sometimes one large lymphocyte engulfs other cells and various débris and attains to a very great size. It may ultimately die leaving an inert pigmented mass in the gland.

Lymphoid structures do not everywhere show construction of such definite unit elements as is recorded above. Thus in the medulla of an interstitial lymphatic gland the small and large glandular lymphocytes are mingled indiscriminately. The lymph nodules everywhere become less distinct in very old animals (Baum and Halle, 1908). Clearly marked lymph nodules make up the cortex of every interstitial lymphatic gland. They are also placed eccentrically at intervals along the arterioles of the principal hæmo-lymph gland, the spleen.

Lymph nodules are present singly or in groups in all the subepithelial lymphatic glands.

After considering this unit-material or element of lymphatic glands, it remains to consider the manner in which these elements are combined to form the different lymphatic organs.

* The researches of Goodall and Gulland seem to show that many lymplocytes are also formed in the bone marrow.

$\dagger$ It is most remarkable that the glandular lymphocytes are both motile and phagocytic. The small lymplocytes in the blood are usually described as non-motile and non-phagocytic. 
In the interstitial lymphatic glands the lymphoid nodules are arranged peripherally beneath the capsule and they are the first to receive the entering lymph. But the subepithelial lymphatic glands are distinguished by the absence of afferent lymphatic vessels. (According to Lénart, Henke and others, quoted by Pybus, 1915, injections of carmine into the nasal or cral submucosa eventually find their way into the tonsils on both sides. But it is quite possible that escape of the injection material on to the surface might enter the tonsil that way (see Chapter XIII.). Anatomically, anyhow, afferent lymphatic vessels have never been demonstated.) Here the lymphatic nodules lie against the epithelium of the alimentary canal superficial even to the muscularis mucosæ. So close to the epithelium do they lie that the lymphoid and the epithelial cells are commonly mingled. There is a continuous passage of small glandular lymphocytes from the lymphoid nodule through the epithelium into the lumen of the alimentary canal and back again (see further).

The solitary lymph gland consists of a single such nodule only. The nodule is drained by an efferent basal lymphatic vessel which leads eventually to a mesenteric or other interstitial lymphatic gland.

A Peyer's patch represents an aggregation of from ten to sixty (Sobotta) lymphoid nodules. Each nodule has one aspect close to the epithelial surface which is here uncovered by villi. The human vermiform appendix, according to the late Mr. Lockwood's estimate, may be lined by as many as 150 to 200 lymphoid nodules.

In the case of the nasopharyngeal and faucial tonsils the epithelial surface is much folded, thus permitting a great collection of lymph nodules in a small space yet with each nodule abutting the surface epithelium. 
Thus are produced the tonsillar crypts and the adenoid fissures. The irregularity of surface probably also favours the stagnation of mucus and the growth of cultures of micro-organisms, and it helps to prevent the emigrated lymphocytes (see pp. 68 and 69) being swept away from the surface.

The subepithelial glands develop beneath different kinds of epithelium. The intestinal glands are lined by columnar cells, the faucial tonsils have a covering of stratified epithelium and the nasopharyngeal collections underlie a layer of ciliated columnar cells, or stratified epithelium in parts.

It may be characterised generally of the larger subepithelial glands that-(1) they have a terminal blood supply. Thus Peyer's patches and the appendix are anti-mesenterial; (2) they have a large surface area; (3) whether by folding of the surface or by situation along a diverticulum, they are so arranged as to encourage stagnation of adjacent alimentary contents. 


\section{CHAPTER $\mathrm{X}$.}

The Rabbit's Appendix.

UNDOUBTEDLY the largest and most highly specialised subepithelial lymphatic gland occurs not in man but in the rabbit. The rabbit's vermiform appendix is the particular example taken but the proximal and distal ileo-cæcal patches, though smaller in bulk, present a similar complexity of structure. (Fig. 23.)

The rabbit's vermiform (i.e. of similar even cylindrical shape to a worm) appendix measures several inches in length and $\frac{1}{4}$ in. to $\frac{1}{2}$ in. in transverse section. The wall of this tube feels quite thick. From the peritoneal aspect it is often possible to see with the naked eye the independent lymphoid nodules (really the deeper layer of these) of about the size of a pin's head. Occasionally each nodule is outlined by a just perceptible row of black dot's. On the mucous aspect can be seen the orifices of the calyx-like glands.

When a transverse section is examined under a low power it is seen that, whereas in man the lymphoid layer rarely forms as much as one-half of the mural thickness, in the rabbit the lymphoid coat constitutes up to nine-tenths. of the total thickness and the muscular coats have come to appear relatively as a very narrow band in the section: (Fig. 24.)

The lumen of the appendix is filled with bacteria most of which are gram-positive and of unusually large size. Particles of partially digested vegetable food can be distinguished. Glandular lymphocytes are often to be seen in the lumen. These can easily be shown to contain ingested bacteria. 


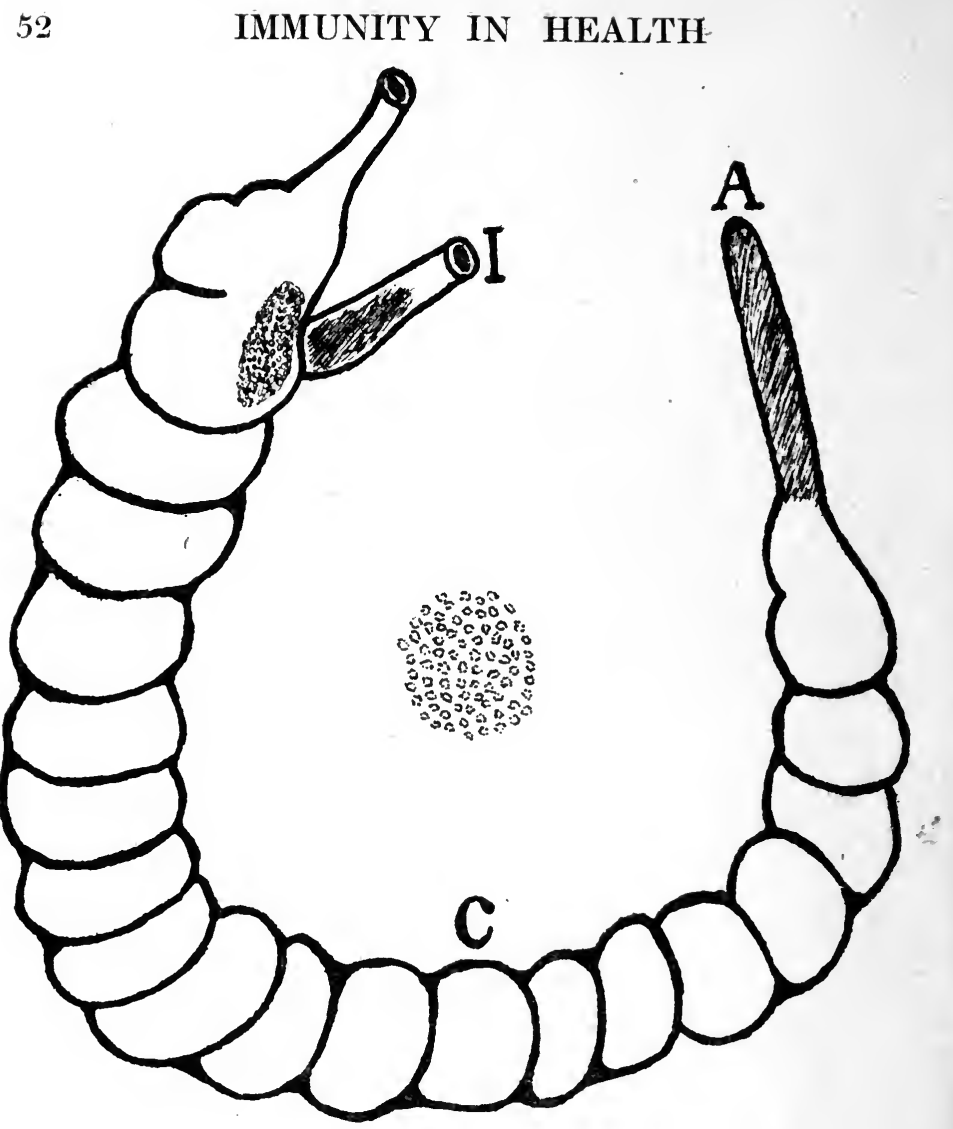

Fig. 23.

Diagram of the cxcum and appendix in a rabbit. The patches of lymphoid tissue at the ileo-cæcal junction are also shown. The small figure in the centre shows the lymphoid tissue from the peritoneal aspect as it occasionally appears to the naked eye. In the specimen flom which this diagram was taken only the creal part of the ileocreal lymphoid tissue showed this appearance.

The mucous membrane of the vermiform appendix of the rabbit is lined by columnar epithelium. Many goblet cells are to be seen. At regular intervals the columnar epithelium dips down to form a narrow stem and then spreads out dome-wise to form the deeper calyx-like portion of the gland, up into which projects 
a rounded portion of one of the superficial layer of lymphoid nodules. The projecting portion of the lymphoid nodule also is covered by the columnar epithelium of the calyx-gland, but so many small glandular lymphocytes may be seen amidst the columnar cells that in some places this layer may almost appear to be wanting. Many of the glandular lymphocytes are crowded with bacteria.

The superficial lymphoid nodules which project into the calyx-glands contain principally small glandular lymphocytes. Many of these evince their phagocytic ability by the number of ingested bacteria they display.

Beneath the superficial lies a deeper layer of lymphoid nodules. These nodules are much larger in size. Small and large glandular lymphocytes occur and in addition giant cells, the last two kinds being especially crammed with bacteria and carbon particles. Situated basally, near to the periphery of each deeper nodule, may be seen irregular masses which do not take any stains. These are brownish in colour and contain darker particles. These probably represent the indigestible débris from the omnivorous phagocytic activity, either lying in an efferent' lymphatic space or deposited more permanently in some interstices of the gland. I have often traced intermediate appearances between the giant-cell and these inert masses. Sometimes these masses are so large as to be visible to the naked eye, presenting those dotted rings on the serous aspect to which allusion has already been made.*

It is perhaps not unfair to compare the superficial layer of lymphoid nodules of the rabbit's appendix with the cortex of an interstitial lymphatic gland; and the deep layer of nodules with the medulla of an interstitial lymphatic gland.

* Similar patches of pigment have been described by Professor Shattock (1916) in the human appendix. 
Frg. 21.

Diagran of a Calyx Gland in the Rabbit's Appendix.

1. Lumen of appendix.

2. Neck of calyx crypt.

3. Calyx crypt.

4. Superficial lymphoid nodule.

5. Deep lymphoid nodule.

6. Muscular layer.

7. Serous lining.

A. Undigested vegetable food.

B. Emigrated glandular lymphocyte.

C. Bacteria.

D. Mucus exuding from a goblet cell.

E. Columnar epithelium.

$F$. Glandular lymphocyte passing through the epithelium.

$G$. Glandular lymphocyte with ingested bacteria.

H. Small glandular lymrhocyte.

I. Large glandular lymphocyte.

$J$. Mass of dead cells, bacteria and carbon particles. 


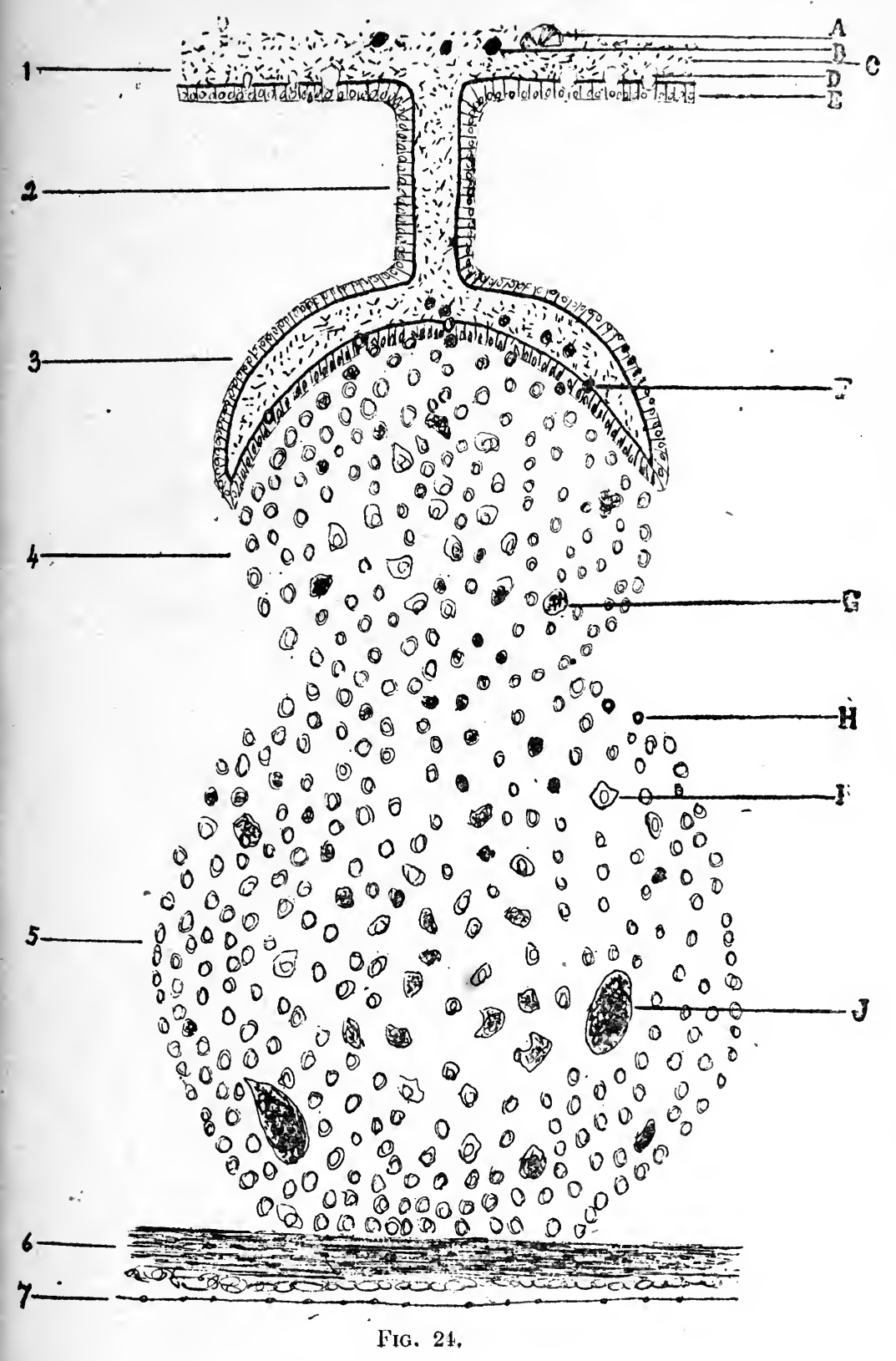




\section{CHAPTER XI.}

Life History of the Subepithejiar. Lymphatic GLaNDS.

THE records of comparative anatomy show that the subepithelial lymphatic glands occur almost if not quite exclusively in the two highest classes of animals-birds and mammals. It is in accordance with this fact that we find these structures appearing late in human embryological history. Follicles of lymphoid tissue do not appear in the tonsil till the last month of fotal life, : though the epithelial crypts are represented as early as the fourth month (Keith, 1913). Berry, in 1901, stated that the lymphoid tissue in the excal region of mammals was almost entirely a post-natal development and that it attained its maximum growth at the end of the first week.

To confirm this observation I examined the appendices of three young rabbits similar in size and appearance, and from the same litter. One was killed within an hour or two of birth, the second on the fourteenth, and the third on the twenty-eighth day after birth. Sections of the three appendices were taken and stained in precisely the same way and were drawn with the same camera lucida, eye-piece and objective, and are represented in Fig. 25. It will be seen that the lymphoid tissue can hardly be discerned in the newlyborn rabbit, but that its development is very rapid in the first few weeks after birth. When we remember 
the sterile alimentary contents of the embryo in utero, and the early development of micro-organisms when food (even, as in this series, the maternal milk) is first taken by the mouth, it would almost seem that it required the stimulus of bacteria in the alimentary canal to provoke the development' of the tissue.

With regard to the structural form of man's vermiform appendix we find the same agreement between ontogeny and phylogeny. In the animal series occur types of the globular cæcum, the cæcum with tapering apex and the cæcum with its apex modified into a cylindrical tube of narrow bore sharply demarcated from the rest of the cæcum. The human embryonic cæecum passes successively through just these stages, first a uniform cæcum, then a tapering apex, and lastly, towards the end of fœtal life, a vermiform appendage.

The asymmetrical position of the adult's appendix is due to a post-natal development of the lateral wall of the rest of the cæcum which occurs in early childhood (Keith, 1913).

Though hardly represented during fotal life, it is during the early years of childhood that the subepithelial lymphoid tissue attains its maximum development. At this period all the lymphatic glands are relatively large and apparently active. In this connection it may be recalled that a lymphocytosis is more readily provoked in early life than in the adult, and that the lymphocytes form an unusually large proportion of the white cells in the blood of young children.

It may be pointed out that the time of greatest activity of the subepithelial lymphatic glands corresponds with the period during which the individual is securing immunity against the exanthemata and other infections and it seems that we must correlate those two phenomena-the acquirement of immunity with 


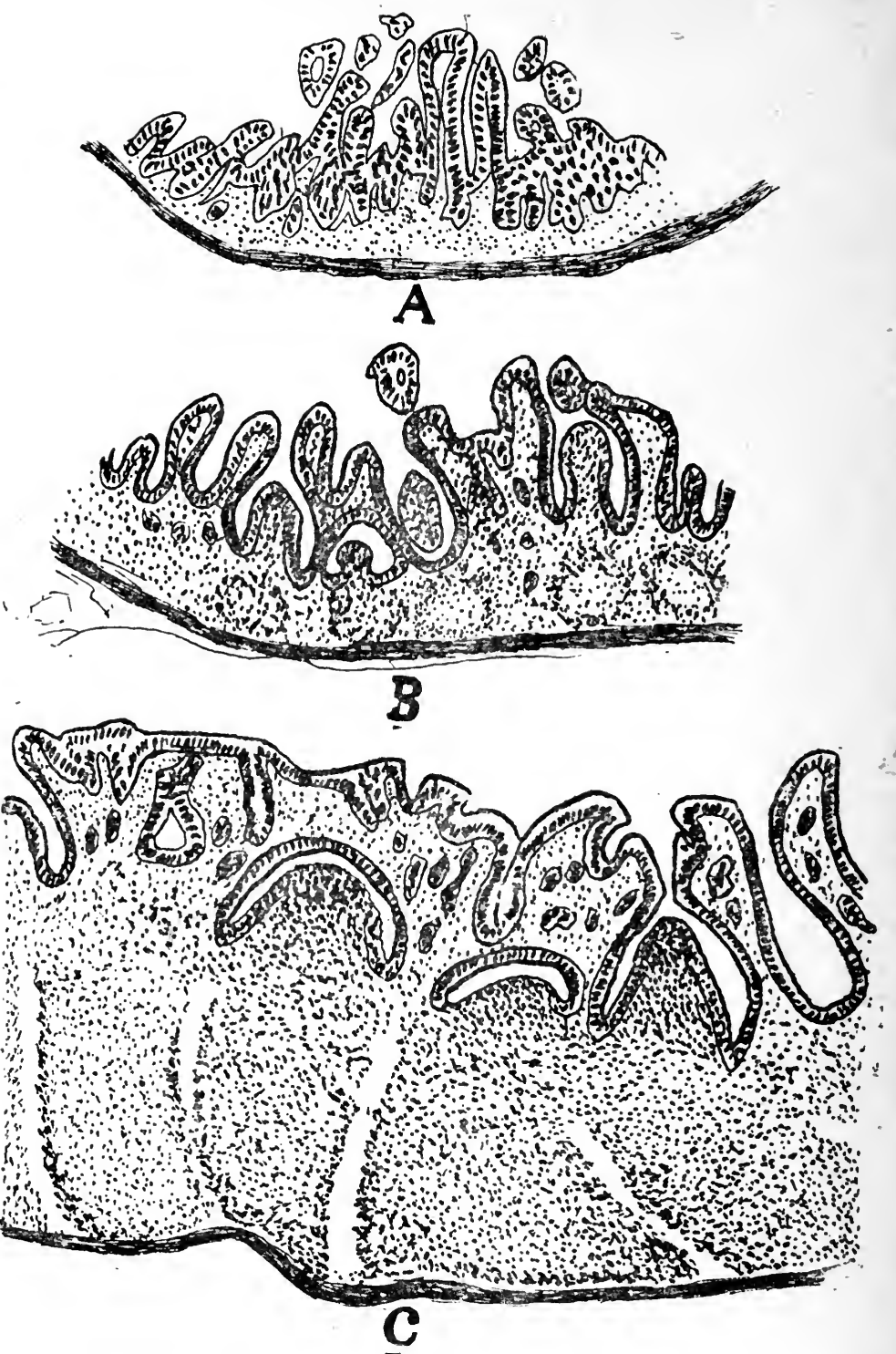

FIG. 25.

Three sections of the wall of the appendix of three rabbits from the same litter. (From camera lucida drawings.)

Section $A$ was from one killed at birth.

Section $B$ was from one killed on the 14th day after birth.

Section $C$ was from one lilled on the $28+h$ day after birth. 
- the activity and hyperplasia of the subepithelial lymphatic glands.

At or about the time of puberty a diminution in the size of these glands takes place, and in later years, when presumably a high degree of immunity has been attained, they have usually undergone a partial atrophy. In extreme old age the constituent lymph nodules have greatly diminished in size and number and the subepithelial lymphatic glands are quite inconspicuous. Doubtless many of the lymphatic nodules have undergone inflammation followed by absorption or fibosis but a true process of atrophy seems to be mainly responsible. 


\section{CHAPTER XII.}

\section{Presence of Bacteria in the Subepithelial Lymphatic Glands.}

Ar a time when $I$ was engaged in throat and ear work amongst out-patients, the way in which tonsils and adenoids appeared to attract' bacterial infections suggested to me the hypothesis that these organs by inviting a local infection possibly protected the body as a whole by conferring a general immunity, much as the vesicles in vaccination by the doctor strengthen the patient to resist small-pox. In 1911 and 1912, I adduced various pieces of evidence in support of such a contention. But if such a hypothesis were correct, it would seem probable that bacteria might be continually entering the subepithelial glands, though a local inflammatory reaction might not ensue unless the organisms possessed a high degree of pathogenicity.

These considerations led to attempts to demonstrate bacteria in the subepithelial lymphatic glands of apparently healthy animals. The appendices of rabbits were chiefly studied, but the tonsils of cats, rabbits, and other animals, and also freshly-removed human tonsils and adenoids were examined. The demonstration of bacteria in tissues is not always an easy matter, but in the case of the rabbit's appendix I was surprised at the ease with which enormous numbers of bacteria could be found in the lymph nodules within the wall 
of the appendix of a healthy rabbit (1913). Though I have examined the appendices in over a score of rabbits, some in England and some in China, and I have never failed to find these crowds of bacilli. (Figs. 1, 26, 29 and 30.)
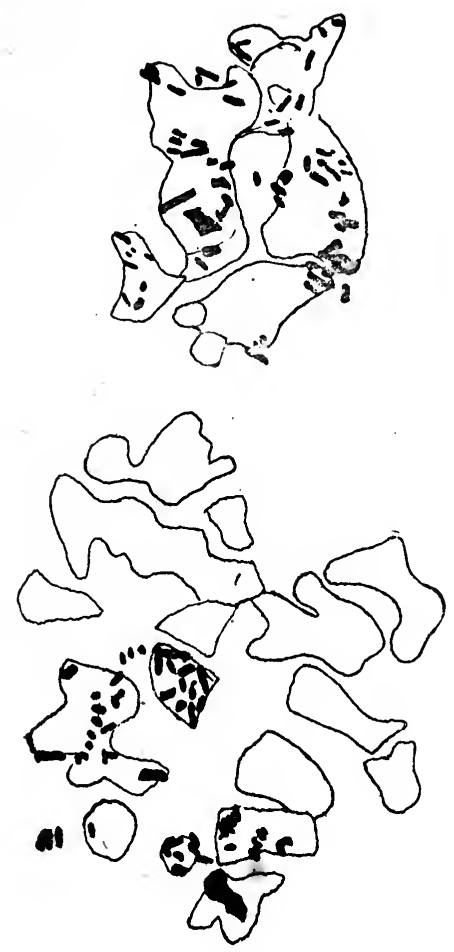

Fis. 26.

Two portions of subepithelial lymph nodes in a healthy rabbit's appendix showing ingested bacilli. (From a camera lucida drawing; eesin-Gram stain ; $1 / 12$ in. objective.)

$\therefore$ I was not then aware of previous work on the subject, but on tracing the literature subsequently, I found that as far back as 1890 Dr. Armand Ruffer had described and beautifully illustrated the presence of 
bacteria and of soot particles in the lymph nodules of the wall of the alimentary canal. He successfully demonstrated bacteria in the appendix, tonsils and Peyer's patches of the rabbit, and the Peyer's patches and tonsils of the dog, and the Peyer's patches of the guinea-pig. Dr. Ruffer in his paper referred to similar observations five years earlier by two independent

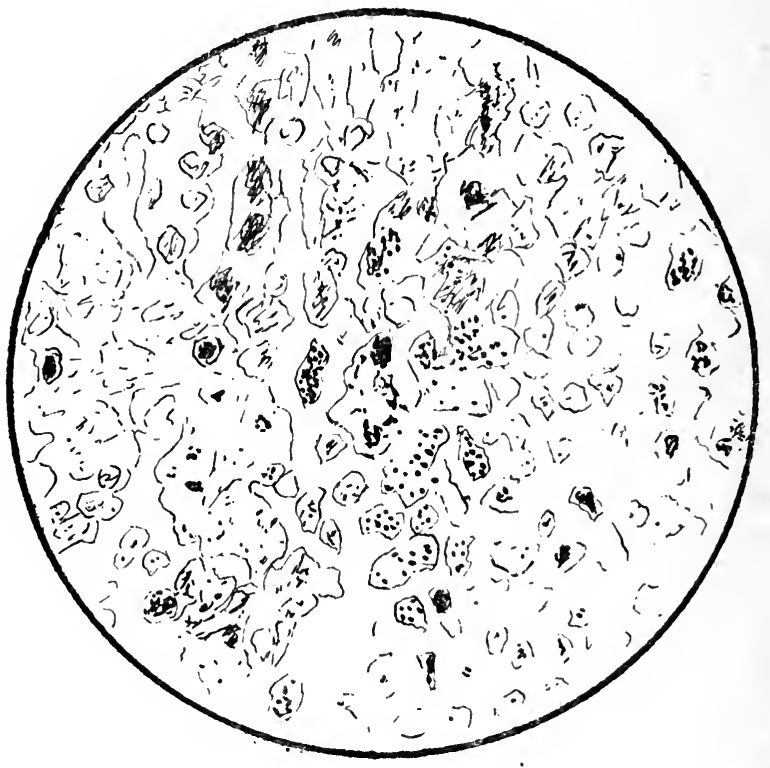

FIG. 27.

From a photograph of micrococci in the lymphoid tissue of a healthy rabbit's tonsil. (Eosin-Gram stain; 1/12 in. objective.)

observers, Ribbert and Bizozzero, but I have been unable to trace the references he gives. In spite of the high standard of Dr. Ruffer's histological demonstrations the piece of knowledge appears to have fallen into the background.

In my own experiments the rabbits were killed very quickly by fracture of the cervical spine, chloroform, 
coal gas, or prussic acid. The abdomen was immediately incised, and the appendix plunged in absolute alcohol or in 10 per cent. formalin in normal saline. Thus there could be no question of a post-mortem penetration of the tissues by the bacilli. I first found the bacilli in the lymph tissues by overstaining with cold carbol-fuchsin for

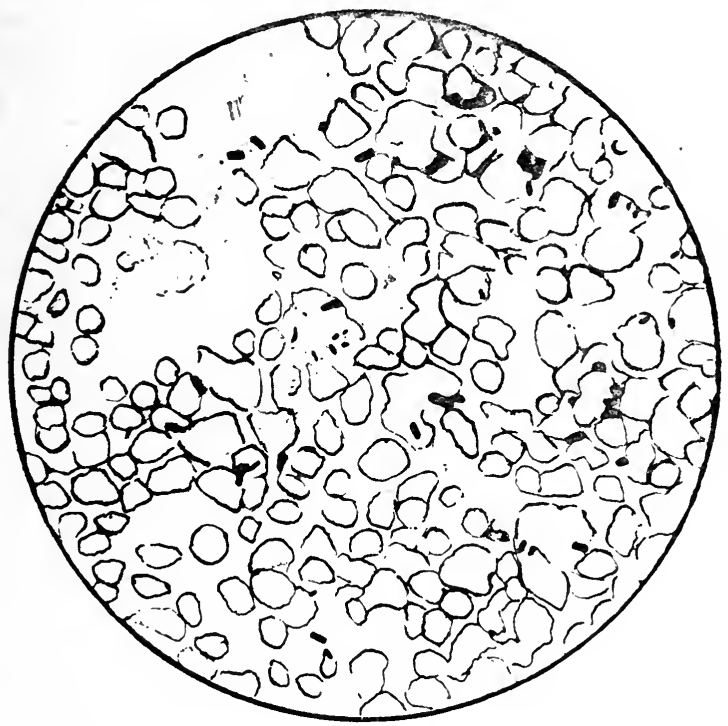

FIG. 28.

From a photograph of bacilli in the lymphoid tissue of a healthy rabbit's Peyer's patch. (Eosin-Gram stain; 1/12 in. objective.)

twenty-four hours and then decolourising with oil of cloves a varying number of hours-examining the section from time to time. But I soon found a better way which had also been used by Ruffer and his predecessors. The bacteria in the rabbit's cæcum are for the most part large in size and strongly Gram-positive. They are, possibly, anærobic, for Dr. Macfarlane was unable to cultivate them for me on ærobic media when 
the attempt was made on one occasion. I suspect these bacteria may be associated with the cellulose-splitting process which must proceed on a large scale in the rabbit's intestine. A good way in the rabbit therefore is to stain the tissues fairly deeply with eosin and then stain by Gram's method (taking care not to overdecolourise) and mount in xylol balsam. Pappen-

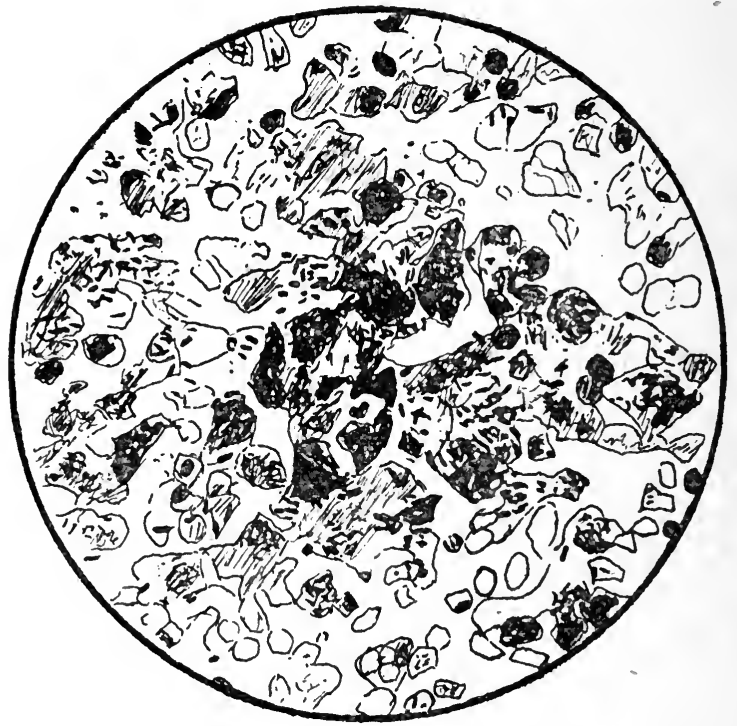

Fig. 29.

From a photograph of bacilli in the lymphoid tissue of a healthy rabbit's appendix. (Carbol-fuchsin decolourised in clove oil; 1/12 in. objective.)

heimer's pyronin and methyl green and Powell-White's eosin and totuidin blue may be used, but have not proved so satisfactory in my hands. Dr. Ruffer employed alum-carmine and Gram's method and was thus able to demonstrate clearly the nuclei as well as the bacteria in the glandular lymphocytes.

It is because the bacteria in the rabbit's intestine 
are strongly Gram positive and also have the unmistakable shape of bacilli, that their presence in the alimentary lymphoid tissues can be so conclusively proved. When we come to the demonstration of dissolving cocci in the tonsils of man and animals or Gram negative bacilli in the human appendix the matter is less certain, and I have only occasionally been able

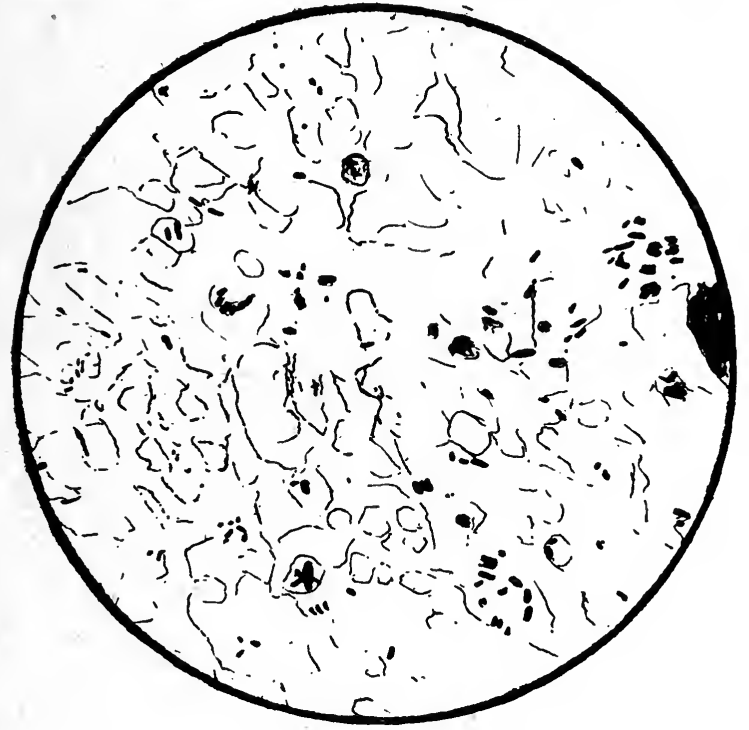

FiG. 30 .

From a photograph of bacilli in the lymphoid tissue of a healthy rabbit's appendix. (Eosin-Gram stain; 1/12 in. objective.)

to satisfy myself of their presence. But the demonstration might be easier to an expert in histology. Dr. Ruffer figured them conclusively in the dog's tonsil. Hays says " on microscopic examination numerous bacteria can often be seen in the parenchyme" [of human tonsils].

In the wall of the rabbit's appendix, most, if not all, the bacilli are intracellular being contained in the small 
glandular lymphocytes in the superficial layer of lymphatic nodules and especially in the larger glandular lymphocytes in the centres of the deep layer of lymphatic nodules. There may be from one up to a score or more of bacilli in a single, cell. They lie apparently within the cytoplasm, outside the nucleus. Some of the bacilli are poorly or irregularly stained, appearing as faint ghosts with perhaps one or two dark spots in their length. A number of the lymphocytes contain no bacteria.

I have sometimes seen intracellular bacteria in the efferent lymphatic vessels of the tonsils and other subepithelial lymphatic glands in various animals, and Butterfield (1913) describes the "perivascular lymphatics" of human tonsils as often "filled with microorganisms." 


\section{CHAPTER XIII.}

Mode of Ingestion of Bacteria by the SubEPITHELIAL Lymphatic GLaNDS.

IT has already been pointed out that the subepithelial differ from all other varieties of lymphatic glands by the total absence of afferent lymphatic channels. In the ordinary interstitial lymphatic glands the definite nodules of lymphoid tissue lie beneath the capsule and receive the entering lymph. In a subepithelial lymphatic gland these same nodules are directly beneath the epithelium, upon which they encroach. Instead of receiving lymph from the tissues these nodules welcome bacteria and possibly toxins from the adjacent lumen of the alimentary canal. The passage of toxins would be easy to understand. All the nourishment of the body has to pass through the intestinal mucous membrane. The passage of bacteria through healthy epithelium fits in less readily with our general conceptions, but that bacteria similar to those in the alimentary lumen do occur in immense numbers in the subepithelial lymph nodes has been conclusively shown in the preceding chapter. But I have repeatedly examined sections of the alimentary wall without finding bacteria save in the subepithelial lymphatic glands.

Attention has been drawn to the fact that the position and structure of many of the subepithelial glands 
are such as to encourage stagnation of the alimentary contents, and stagnation in its turn will tend to the multiplication of bacteria and their toxins.

In the lumen of the alimentary canal then are found many millions of bacteria; on the other side of the epithelium in the lymphoid tissue are to be seen fewer millions of similar bacteria. The question arises by what means these bacteria have been translated across the epithelium. What is the mode of ingestion of these bacteria by the subepithelial lymphatic glands?

Four possibilities readily occur to one. These hypothetical processes may be termed :-

1. Chemiotaxis.

2. Physiotaxis.

3. Bacterial motility.

4. Phagotaxis.

1. Chemiotaxis.-It is known that phagocytes approach bacteria. If the phagocyte is enmeshed in retiform tissue the bacteria might conceivably be attracted to the phagocyte by chemical means.

2. Physiotaxis.-Alterations of surface tension might determine the passage of bacteria between the epithelial cells.

3. Bacterial Motility.-The powers of locomotion possessed by many bacteria might lead them through the epithelial wall into the lymphoid tissue. This perhaps would be the view of those who regard the subepithelial lymphatic glands simply as weak spots poorly able to resist bacterial assault.

4. Phagotaxis.-It is common physiological knowledge that lymphocytes leave the subepithelial lymphatic glands, passing between the epithelial cells into the lumen of the alimentary canal and there engulf bacteria. Ruffer, in 1890, examined the mucus from the surface of human tonsils in four normal persons, and in each case met with "many leucocytes 


\section{MODE OF INGESTION}

full of microbes" therein. Similar observations have frequently been made both before and after that time. It has also been repeatedly noticed that in sections of the epithelium over lymphoid collections small glandular lymphocytes are to be seen between the epithelial cells. It will be seen in Fig. 1 that such glandular lymphocytes inay contain bacteria. This is frequently the case. May not glandular lymphocytes wander to the surface, surround bacteria, and return with their prey to the retiform tissue? To this process I would apply the term phagotaxis. A strong piece of evidence in favour of this theory is to be found in the fact that almost all (if not quite all) the bacteria seen in the epithelial layer lie within glandular lymphocytes. I have only seen small glandular lymphocytes in the epithelium, yet large glandular lymphocytes also contain bacteria. Possibly there is a transference of bacteria, or, as Ruffer described, the large glandular lymphocytes may engulf small glandular lymphocytes with their contained bacteria. I have seen many dead glandular lymphocytes in sections.

By this theory glandular lymphocytes found astray in the alimentary lumen would be looked upon as the few which had failed to wander back into the lymphoid tissue.

The hypothesis of phagotaxis also derives strong support from the evidence in favour of the ingestion of inert particles by the subepithelial lymphatic glands. For besides bacteria these glands may be seen to contain brownish or blackish granules of apparently inert matter. These granules are probably carbon particles for the most part. They were so described by Ruffer, who pointed out that they were a much more prominent feature in the dog's tonsil than in the rabbit's, a fact he associated with the mouth breathing habit of the dog. Sometimes these granules are sharply angular. 
rendering it unlikely that they are any body pigment. Shattock (1916) in specimens of human appendices showing pigmentation, suggested that the pigmentation sometimes seen in the lymph follicles was altered blood pigment absorbed from the alimentary canal, but the reasons given above seem to favour the view that they are largely carbon particles. It would be interesting to know whether the subepithelial lymph glands of workers in sooty atmospheres show an unusual amount of pigmentation.

To elucidate the matter a rabbit was fed for three weeks on food containing a large proportion of carbon. Lamp black was mixed with all its food in sufficient proportions to completely blacken it. The rabbit wasted, probably because it ate less of its unnaturallooking food. It was killed with choloroform and the tonsils, Peyer's patches and appendix examined after staining with eosin. The Peyer's patches showed a far greater proportion of brownish-black masses (Fig. 31) than did the Peyer's patches in several other rabbits in the laboratory whose tissues were examined at the same time. Too much value should not be attached to this observation. It was a single experiment, and the amounts of brown pigment seen in other rabbits' Peyer's patches varies considerably. It was not satisfact'orily proved that the pigment was carbon. On a subsequent occasion three young rabbits were etherised and in each case the end of the appendix was brought through an abdominal incision and the wound closed. The end of the appendix was then snipped off with scissors and an emulsion of carmine in normal saline syringed into the lumen of the appendix, the end of which was then ligatured. The three rabbits were killed with chloroform respectively 7,21 , and 42 hours after the operation, and paraffin sections prepared. Each showed carmine in the lumen of the appendix. 
In the rabbit killed after seven hours an unusual number of lymphocytes containing minute dark granules could be observed in the epithelium and even in the lymph follicles. But it could not be conclusively

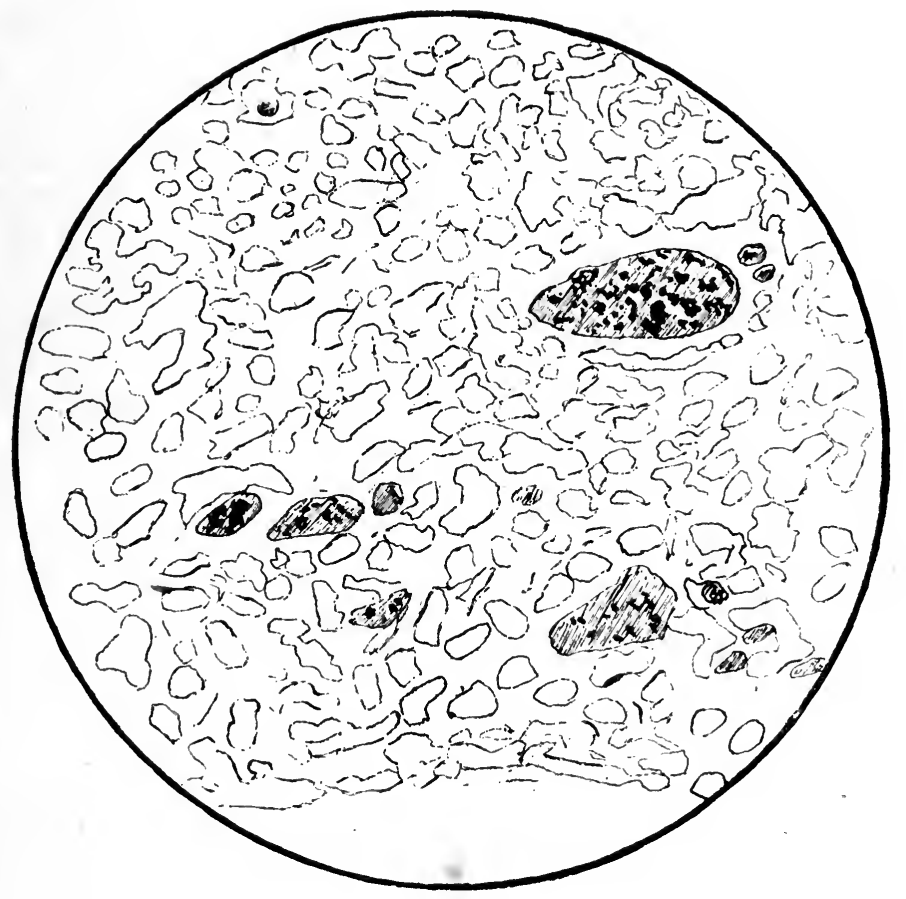

Fig. 31.

Microscopical section of a Peyer's patch from a rabbit which had had soot administered with its food for three weeks.

Stained with eosin only. (From a camera lucida drawing; 1/12 in. objective.)

The section shows glandular lymphocytes and masses of ingested soot.

stated that they were carmine particles. The appendices of the rabbits killed after 21 and 42 hours presented normal appearances. 
Spencer (1897) states, without quoting his authority :- "Carmine which has been mixed with the food of the animal passes out through the intact wall of the intestines, especially by the way of the solitary the agminated follicles."

Bond (1917 and 1918) has described an exactly similar process to phagotaxis on the granulating surface of wounds, which he terms the "return immigration of leucocytes."

It is noteworthy that the small glandular lymphocytes indistinguishable morphologically from the lymphocytes of the blood are definitely motile and phagocytic. 


\section{CHAPTER XIV.}

Pathology of the Subepitheliat Lymphatic Glands.

IN the preceding sections attention has been directed upon the Physiology of these Glands. In this and some of the following pages the behaviour of these glands in connection with disease will be studied to see how far it support's the main thesis of this book.

The grouping together of these glands derives great support from the similarity of the diseases to which they are liable. These diseases may be classified under three headings :-

1. Inflammátion.

(Chapter XV.).

2. Simple enlargement.

(Chapter XVI.).

3. Other diseases. (Chapter XVII.).

A separate section will be accorded to an account of each of these. In addition, those morbid states in which infection passes through the subepithelial lymphatic glands, gaining an entry to the general system without obvious injury to the doors it has forced, must be dealt with (Chapter XVII.).

A few general points bearing upon the connection between infectious diseases and the subepithelial lymphatic glands may be dealt with at once. Attention has already been drawn (Chapter XI.) to the period of greatest activity of these glands coinciding with the period of childhood when the exanthemata and other infectious diseases are most common. It is also to be observed that the subepithelial lymphatic glands are hyperactive or show definite inflammatory changes in 
the following complaints :- scarlatina, diphtheria, acute anterior poliomyelitis, rheumatic fever, measles (German measles rarely), typhoid fever, infantile enteritis and pertussis. Flexner and Clark, and also Landsteiner, Levaditi and Pastra have shown that the tonsils from fatal cases of acute anterior poliomyelitis contain the virus, and Trethowan describes a painful enlargement of the tonsils as a frequent early sign of the disease. These signs of activity are most developed in the initial stages of these diseases. Certainly the subepithelial lymphatic glands bear the brunt of the attack in faucial and intestinal infections. The lesions of scarlatina, typhoid fever and appendicitis illustrate this statement. Although the subepithelial lymphatic glands seem almost to invite disease, they yet seem better able to overcome it. Thus diphtheria-a localised infection-is less serious when limited to the tonsils than when it occurs elsewhere (Jacobi, quoted by Mackenzie).

The absence of the subepithelial lymphatic reaction usually signifies a very virulent type of infection or a lowered resistance, and presages a fulminating and often fatal attack. Dr. Palmer relates a typical case of a lad of $14 \frac{1}{2}$ years of age struck down by malignant scarlet fever. "The throat was normal. There was no glandular enlargement." Death occurred thirty hours after the patient felt ill enough to consult a doctor, or three days after the earliest feeling of malaise. The diagnosis seems fairly reliable - the patient had not had scarlet' fever previously; the onset was marked by vomiting and an unusually dusky scarlet fever rash appeared on the second day; a neighbour who had been with him developed scarlet fever of a mild character a few days later; a post-mortem examination helped to exclude the possibility of other disease being present. The subepithelial glands concerned enlarge as a 
result of repeated infectious diseases such as pertussis, measles, scarlatina and coryza, and also tend to hypertrophy in insanitary and unhealthy conditions, whether of the patient's general surroundings, or locally of the nose and throat (Chapter XVI.). A swollen condition of the Peyer's patches occurs in cases of obstruction of the small intestine. A limited septic infection may lead to a limited enlargement of the adjacent subepithelial lympathic gland. The following case illustrates this point.

H. W., age 18, an engine cleaner, had had left otorrhœa "as long as he can remember." He thought it followed scarlet fever. The left tonsil was very much enlarged, while the right tonsil was about normal in size.

I have on several other occasions seen this unilateral tonsillar enlargement follow an otorrhœa on the same side.

General increase of lymphatic structures, particularly of the subepithelial variety, signifies prolonged bacterial assaults, and may be accompanied by a toxinweakened heart-the so-called status lymphaticus.

It may also be observed that a lymphocytosis is characteristic of pertussis, measles, variola, mumps, infantile gastro-enteritis, some cases of tuberculosis, malaria, rickets, and syphilis, and even typhoid fever (Gulland and Goodall). Increase in the number of leucocytes, characterised by a relative gain in the lymphocytes and eosinophils, usually develops during the reactionary fever following the injection of tuberculin (Da Costa). Of course, the interstitial lymphatic glands and possibly the marrow share with the subepithelial lymphatic glands in the production of lymphocytes, but when it is borne in mind that in many of these diseases some of the subepithelial glands show activity, it is reasonable to suppose that they play no 
small part in the production of the lymphocytosis, surely a defensive reaction. In connection with the greater activity of the lymphatic tissues in children, it is worth while repeating that a lymphocytosis is more easily provoked in early life, and that the lymphocytes form a constantly higher proportion of the leucocytes in children than they do in the adult.

Further, it has already been shown (Chapter V.) that during scarlatinal epidemics a person may apparently secure immunity by a very mild tonsilitis, which is unaccompanied by rash, malaise or other signs of general injury, and that a similar immunity may be obtained in epidemic cerebro-spinal meningitis. A great proportion of those exposed to infection show the virus on their nasopharyngeal tonsils (which are liable to show some congestion), yet remain free from the disease and have indeed developed an enormously high opsonic index against the causal micro-organism.

Similarly, immune "carriers," who have never clinically suffered from the diseases, yet convey the organisms of typhoid and cerebro-spinal fever and of diphtheria, cholera and dysentery (Ledingham and Arkwright).

In France, Courmont and Rochaix have produced immunity against typhoid fever both in human. beings and animals by the introduction of dead bacilli into the large intestine. Agglutinins have resulted in the blood stream. It seems likely that the dead organisms pass through the epithelium into the subjacent lymph nodes of the solitary follicles or the appendix-just as living organisms do-and that the immunity is produced in that manner.

Finally attention may again be drawn to the patho. genic organisms normally inhabiting the alimentary canal. It' would be difficult to understand how pneumococci, Klebs-Loffler Bacilli, and the hosts of pyogenic 
and other pathogenic bacteria could exist harmlessly next to the tissues unless the body possessed some method of more or less neutralising the effects of always possible invasions.

It is noteworthy that it is not only in man that the subepithelial lymphatic glands are liable to disease. As might be expected, this side of the question has hardly been explored, but Hett has observed tonsils "like a child's unhealthy tonsils" in one Rhesus monkey and in one young gorilla; actinomycosis in a Kangaroo's tonsil ; a large cyst in a hyena's tonsil ; tuberculous disease in several monkeys' tonsils, whilst Mr. Stapley, in a personal letter to me, has written :-

"I have never seen an inflamed appendix in a wombat, but I have seen several wombats that have died from perforation of a Peyer's patch that was within an inch of the ileo-cæcal valve." 


\section{CHAPTER XV.}

Acute Inflammations of the Subepithelial Lymphatic Glands.

Atr the subepithelial lymphatic glands share a common liability to attacks of acute inflammation. The evidence marshalled helow shows that the initial lesion in almost all cases is inflammation commencing in one of the lymphatic nodules and not, at first, an ulceration of the mucus membrane. A lymphadenitis is the starting point of appendicitis as well as of tonsilitis, of pyloric ulccr as well as of the ulcers of enteric fever.

In the case of tonsilitis the mucous membrane is reddened and the whole organ swollen. Each crypt becomes choked with glandular lymphcocytes and sometimes polymorphonuclear cells and bacteria, which may overflow to appear on the surface as a projecting white spot. If ulceration occurs it comes later.

Peptic ulcers occur for the most part in the adjacent parts of the stomach and duodenum, just where the greater number of lymph nodules are found. The acid gastric juice doubtless accelerates ulceration which has once started, but the commencement of the whole process is probably an inflammation of the subepithelial lymphatic nodules, going on to suppuration with breaking down of the overlying epithelium. Landsdown and Williamson have advanced evidence in this direction. 
Peyer's patches become inflamed and swollen without ulceration in many cases of enteritis. Even in typhoid fever ulceration is by no means an essential part of the disease. Eustace Smith (1909) writes : "In children there is less tendency to ulceration of the intestine than at a later period of life. In many cases even when the fever has lasted its full period, Peyer's patches are seen as soft, non-ulcerated swellings," and Dreschfeld states : "In a few cases the lesions of enteric fever have been found with the exception of intestinal ulcers; the Peyer's patches in these cases presented swelling and congestion only. Death in the cases reported had occurred at a date (after the 21 st day), when the ulceration ought to have been well marked." Elsewhere, he says : "In a section [of Peyer's patches in early typhoid fever] stained with aniline dyes for the detection of micro-organisms, large numbers of typhoid bacilli are seen, most numerously in the centre of the follicle, where the nuclei appear less stained."

Appendicitis has been ascribed to many factors, some highly fanciful, others perhaps acting as predisposing causes. The first part of the claim that the appendix is vestigial and therefore prone to inflammation, has already been refuted. So far from the appendix being the shrinking cæcum of a vegetarian turning carnivorous, we find it best developed in association with a huge cæcum in the purely herbivorous rodents. Chronic constipation seems to predispose to the disease, whether owing to generally lessened resistance of the body, to altered bacteriological content of the cxcum, or to interference with the mobility or circulation of the appendix by peritoneal adhesions about the large bowel. The wavy contortion of the vermiform process has been said to lead to congestion and consequent lowering of the local resistance of the mucous membrane. Certain it is that the free border of the meso-appendix is so short 
that no normal appendix can be completely straightened in situ. However, it is not the vessels in its mesentery, but it is the appendix itself which is bent and bent to a far less extent than are many other portions of the alimentary tract. The vermiform process has, however, a terminal blood supply with no collateral circulation; that is, its vessels do not freely anastomose. with vessels of adjacent adoral and adanal gut, as is the case with the rest of the alimentary canal. There is theoretical ground, then, for suspecting that the absence of a free collateral circulation predisposes the vermiform process to attacks of congestion, and so perhaps to bacterial invasion. Foreign bodies have been recorded in a small but sufficient percentage of cases to give rise to the belief that they encourage appendicitis. ${ }^{*}$ Just as fig seeds have been found in the lacunæ of diseased tonsils (Pybus, 1915). Yet in neither case can one suppose that foreign bodies are the usual cause of disease in these structures. Bruising of the walls might well follow the attempts of the vermiform appendix to rid itself of the foreign body, and bruising would certainly favour bacterial invasion. Yet, it must not be forgotten that previous ulceration of the appendix is liable to be followed by a stricture, and an appendix with a stricture may act as a trap for foreign bodies. It is highly probable that the fæcal concretions found in many cases of appendicitis follow previous stricture of the lumen. Cæcal contents

* The following foreign bodies in diseased appendices have been recorded :- game-shot, pins, bristles, hairs, round worms, thread worms, cherry stones, grape stones, date stones, orange pips, and fragments of nutshells.

It must however be remembered that concretions have very often been mistaken for fruit stones. Treves, in 1896, in remarking that he, personally, had never found a genuine foreign body in the appendix, drew attention to the wonderful way in which appendicular concretions minicked certain seeds and fruit-stones. 


\section{ACUTE INFLAMMATIONS}

enter the appendix, ${ }^{*}$ and owing to the stenosis of the lumen the fluid parts escape more easily, and the hardish residue is kneaded into a concretion in which lime salts may be deposited. Eventually, the concretion may lead to ulceration and an acute attack. Adhesions of the actual vermiform process and cicatrisation of the meso-appendix leading to real kinking, tend to a recurrence of the inflammation, but are themselves the result and not the cause of the initial attack.

A traumatic causation must be admitted in a few cases. Either direct violence, as from a blow, or indirect violence, as from a strain, such as has been met with in bowling at cricket, has on rare occasions been succeeded by an attack of appendicitis. Often the injury merely lights up old trouble by breaking down adhesions.

The histories of the vast majority of appendicitis cases leave us, however, in doubt as to the actual exciting cause.

I remember once being shown an appendix (removed at operation from a very early case) which showed an intramural abscess. Kelly, in his standard work, figures a specimen of acute catarrhal appendicitis showing numerous minute ulcers, each corresponding to a lymph follicle. $\dagger$ An appendix, the seat of early catarrh, may show enlargement of the lymph-follicles without any appearnce of ulceration. I have sections of most acute early appendicitis which fail to show under the microscope any lesion of the mucous membrane, though numbers of polymorphonuclear leucocytes were visible

* Some have erroneously supposed that the vermiform process contains mucus only. If this organ be examined after death it will be found that the mucus is always stained with stercobilin, and that the lumen often contains one or more boluses of fiecal material, the colour and bulk of which may even be visible through the intact wall.

$\dagger$ " Plate I., Fig. 1.-Acute appendicitis with superficial ulceration .... with the hand-lens the ulcers are found to occupy the centre of a system of Lieberkuhn's crypts and correspond to the normal position of lymph nodes." 
throughout all the coats. All these observations support the view that appendicitis commences as a lymphadenitis, and we are led to the supposition that the exciting cause of the first attack in most cases is the presence of some virulent bacterial strain. Perhaps some variety of streptococcus is most often responsible, because in the most fulminating types of the disease the early peritoneal exudate yields a growth of virulent streptococci. Of course, as in all intestinal cases, these organisms are soon overgrown by the prevalent bacillus coli communis. Perhaps the infecting organism is more likely to occur in meat, if there is really any truth in the belief that appendicitis is less frequent amongst the more vegetarian Chinese and Japanese than amongst the more meat-eating Europeans.* Certainly, one would imagine that micro-organisms flourishing in dead animal tissues would be more attumed to living in animal tissues than would most bacteria which might be present in vegetable fibres.

It is noteworthy here to recall that appendicitis may occur early in typhoid fever. Anyone with a wide experience of abdominal cases has seen the child who develops rose spots and a tender spleen, after removal of an obviously inflamed appendix. McKillop (1912) recorded such a case in a girl of 19. The tip of the appendix was congested and swollen, and contained a facal concretion. Undoubted symptoms of typhoid fever declared themselves after appendicectomy.

* I am not sutisfied on this point. I have seen cases of appendicitis amongst Southern Chinese subsisting largely on rice, and have often noticed in the dissecting room adherent appendices in Chinese coolies on a principally vegetarian diet. Perhaps one reason for the relative infrequence of severe appendicitis amongst the Chinese may be the method of treatment. The native practitioners in China are very averse to the indiscriminate use of purgatives for all abdominal pains.

Treves, in 1902, pointed out what is indeed the usual experience, that Europeans living in the 'T'ropics are more liable to appendicitis than in Europe. The risk of having to eat decomposing or diseased meat is much greater, of course, in tropical countries. 
The rarer occurrence of tuberculosis and actinimycosis also perhaps indicates that the micro-organisms of these diseases may be the causal factor in exceptional instances.*

The ulcers in dysenteric colitis appear to start at the solitary follicles (Dalafield and Prudden). One may even speculate that the rare disease-mesosigmoiditis-may commence in the solitary follicles of the pelvic colon.

Without wishing to see subepithelial lymphadenitis in all diseases, one may yet assert that it is the probable commencement of sore throats, peptic ulcers, typhoid fever and appendicitis.

The interesting fact has often been noticed that more than one set of subepithelial lymphatic glands may be contemporaneously affected. Thus, tonsilitis will be occasionally accompanied or shortly followed by appendicitis (Pybus, 1915). One may imagine that the causal micro-organism is capable of multiplying in these cases in the differing environments of throat and cæcum. In certain specific fevers-e.g., scarlatina, all the subepithelial lymphatic glands may be seen inflamed at $\mathbf{a}$. post-mortem examination (Eustace Smith). All such cases may be rather clumsily described under the name of poly-subepithelial lymphadenitis.

This initial lymphadenitis may, of course, undergo

* The morbid anatomy of appendicitis may be summarised as follows :-

The gross changes in the early stages are increased vascularity, thickening, hardening and unusual lacerability. Iater, ulceration, gangrene and perforation may be found, and calculi, adhesions and irregularities of calibre may succeed.

The microscopic appearances include :-

(1) The presence of polymorphonuclear leucocytes in all the coats.

(2) The presence of extra-cellular bacteria in the lymph nodes. (This is of little practical value owing to the difficulty of staining gram-negative bacteria in tissues.)

(3) Necrosis of lymph nodules.

(4) Destruction of the epithelium,

(5) Later, fibrosis. 
resolution, and the patient completely recover. Sometimes, however, although the parts afterwards are normal in appearance to the naked eye, some injury to the lymph follicle remains, rendering it unduly prone to further attacks of appendicitis. I have repeatediy. seen an appendix removed in the fourth or fifth attack of inflammation, or in a quiescent period between undoubted attacks of appendicitis, which showed no adhesions, stenosis, nor obvious sign of previous inflammation. Probably, in such cases, the permanent injury consists of some microscopical lesion to the lymph follicles. That one attack of appendicitis predisposes to another is surely true. And the same can be said of inflammations of the tonsil. Theoretically, this might be due to a prolonged lowered resistance of the patient or to the continued presence of virulent organisms in the alimentary canal, but since most of the cases of recurrence of these diseases can be shown to be due to the cicatricial effects of previous attacks, it is likely that the fewer cases of recurrence where no such cicatricial effects are seen with the naked eye are also due to permanent but microscopic lesions.

In view of the constant ingestion of bacteria by the subepithelial lymphatic glands, there is no need to assume any primary lesion of the epithelium. Small glandular lymphocytes return from the lumen of the alimentary canal, laden with some exceptionally virulent bacteria.

The small glandular lymphocytes die, and the toxins of the bacteria repel the efforts of the large glandular lymphocytes to engulf and destroy the smaller cells and the bacteria together. The bacteria then commence to multiply extracellulary; the arterioles of the gland dilate and polymorphonuclear cells migrate to the scene of the conflict.

Should resolution not occur, the initial lymphadenitis 
proceeds to suppuration, and a submucous abscess forms. This soon bursts through the thin overlying

- mucous membrane, and an ulcer results. The process is multiple, and numerous fine ulcerating points can be seen at this stage. When the protecting epithelium is destroyed the attacks of the initial virus are strengthened by the irritating juices of the alimentary canal (salvia, hydrochloric acid, or tryptic ferments, as the case may be), and other kinds of bacteria, so that a chemically-irritated wound with a mixed infection ensues.

This stage of multiple fine ulcers can be seen in the vermiform process and in the aggregated lymph nodules. In the tonsils minute ulcers, corresponding to the lymph follicles, are not visible, as they occupy the sides of the crypts.

The ulcers soon extend and coalesce, and extensive areas of denuded epithelium can be seen at such a stage in inflammation of any of the subepithelial lymphatic glands.

With the appendix and the Peyer's patches the poisons may be so deadly as to produce localised patches of gangrene, involving the whole thickness of the intestinal wall.

The deepening of the ulceration may lead to abscess formation beyond the organ-always a serious condition. With the faucial tonsil a quinsy or peritonsillar abscess may be set up; with the pharyngeal tonsil a retropharyngeal abscess: with the lingual tonsil deep submaxillary suppuration (Ludwig's Angina); with the solitary lymphatic nodules of stomach and duodenum, with the aggregated lymphatic nodules of the ileum and with the vermiform process, various forms and degrees of peritoneal suppuration.

With the solitary lymphatic nodules of stomach and duodenum, and with the aggregated lymphatic nodules 
of the ileum, the deepening of the ulcers may breach the wall of an artery and lead to severe and even fatal hæmorrhage.

If recovery takes place after suppuration has occurred, some degree of cicatrisation remains. Muchrarely even perhaps all--the lymphoid tissue of the inflamed organ may be destroyed. The epithelium may be extensively removed. This may cause a localised stenosis of the tonsillar crypt or of the vermiform process, thus predisposing to the inspissation of retained material and concretion formation (in vermiform appendix anci faucial tonsil) or to cystic dilatation beyond (mucocele of appendix, cyst of faucial tonsil, and perhaps 'Thornwe!dt's cystic adenoids), or to subsequent suppuration under pressure beyond the block.

The crypts and the appendicular lumen may indeed be completely blotted out after repeated inflammation of the tonsil and the appendix respectively.

Inflammation of the intestinal lymphatic structures may be followed hy peritoneal adhesions. In the case of the vermiform process such adhesions may interfere with the blood supply of the organ. Similarly cicatrices in the meso-appendix, consequent upon lymphangitis or lymphadenitis (for the meso-appendix contains one or more lymphatic glands) may cause sharp kinking of the appendix, interfering with the blood supply or the free passage of material along its lumen.

Such 'strictures and adhesions undoubtedly predispose to further attacks of inflammation, though the presence of the latter probably lessen the risks to life of such subsequent attacks.

Birmingham writes (Shennan, 1912) that " partial ecclusion (of the vermiform appendix) is present' in 25 per cent. of all cases (of post-mortem examinations of adults), and in more than half those sixty years old, 
whereas it is unknown in the child." These figures show the surprising frequency of inflammation of this structure.

The tendency to early recurrence of inflammation after a sufficiently severe initial attack is most strongly marked in the case of the vermiform process, but is also frequently noticeable with the lymphoid tissues of the throat. Indeed, the more complex the structure of the subepithelial lymphatic glands the more surely does it exhibit' this tendency. Apart from persistence of the original virus in all its intensity, the tendency to recurrence is probably due in general to undue stagnation from cicatricial contraction.

This section cannot be closed without a serious consideration of the question of hæmatogenous infection. Inflammation of the appendix has been experimentally induced in a few cases by the injection subcutaneously of certain bacteria.

It has been suggested that the subepithelial lymphatic glands therefore become infected from the blood stream and not through the overlying epithelium. Perhaps the best clinical evidence in favour of hæmatogenous infection is the ulceration of the tonsils in secondary syphilis. In this stage of syphilis the organism is undoubtedly circulating in the blood stream.

One may add that other lymphoid tissue is often excited by general infections of the blood stream.

Neither the experimental nor the clinical evidence are conclusive, however, for it must be borne in mind that possibly in subcutaneous inoculations, and certainly in secondary syphilis, the micro-organisms pass out in large quantities in the secretions int'o the alimentary canal, and may thence be ingested by the subepithelial lymphatic glands, and in them may then give rise to morbid processes. 


\section{. CHAPTER XVI.}

\section{Simple Enlargement or Hyferplasia of the Subepithelial Lymphatic Glands.}

Chronic enlargement is an extremely common affection of the Subepithelial Lymphatic Glands, especially in the first two decades of life. All these lymphoid structures are liable to it--tonsils, adenoids, Peyer's patehes and vermiform appendix alike. The faucial tonsils can be observed directly. The vast majority of town-dwelling children in England probably have enlargement of their tonsils for some period during childhood. During one year 57,809 Lancashire school children were medically examined. Of these 2,591 (over 4 per cent.) were reported as suffering from enlarged tonsils. The distinction between a normal and an enlarged tonsil is, of course, quite an arbitrary one. When the tongue is forcibly depressed with a spatula the tonsils in any child bulge medialwards. Nevertheless, there can be little doubt that in a considerable percentage of children the faucial tonsils are sufficiently enlarged to project considerably beyond the pillars of the fauces in the absence of retching and during quiet respiration.

Enlargement of the nasopharyngeal tonsil usually accompanies that of the faucial tonsil. The frequency of these affections varies very much in different countries. They are uncommon in South China. "The Hebrew race is specially predisposed to this hyperplasia; climate is also a predisposing factor. Osler is 
of the opinion that there are more mouth breathers to the acre in England than in any other country, while Massei, in Naples, report's that he has seen only five cases during the past fifteen years in which adenoidectomy was indicated." (Crowe, Watkins and Rotholtz.) Enlargement of the lymphoid tissues of the Peyer's patches is often observed at autopsies in children. It is not' easy to speak of enlargement of the lymphoid tissues in the wall of the appendix, as there is no standard by which to reckon.

Histologically, this overgrowth manifests itself usually as a hyperplasia of the lymph nodules. It is well known that lymph nodules are capable of increasing in number as well as in size.

The majority of tonsils and adenoids removed during childhood show this structure. In the smaller proportion-and these often at a later age--the enlargement is due to the presence of fibrous tissue, probably the result of inflammation of pre-existing hyperplasia.* - This hyperplasia is probably a protective reaction to the insanitary condition of nose, mouth or throat. It certainly follows suppurative processes in middle-ear and nose. The hyperplasia is often initiated by the specific fevers.

In the unusual condition known as keratosis pharyngis, the solitary nodules in the oropharynx. are chronically enlarged, and are marked on the surface by white patches of adherent bacterial growth.

The only harmful results of the hyperplasia are mechanical. They are most marked in the pharynx, the walls of which are fixed and unyielding. The enlarged organs encroach upon and reduce the lumen, thus interfering with the functions of respiration, deglutition and speech. The nasopharyngeal tonsil may

\footnotetext{
* Messrs. Hett and Butterfield (1913) would probably disagrree with these statements.
} 
so fill the nasopharynx as to set up mouth-breathing with all its serious sequelæ. The faucial tonsils, if very much enlarged, may then impede even the mouth respiration, and cause chronic deficient oxygenation. Swelling of the lymphoid tissue about the orifice of the tuba auditiva is said to block this tube, leading to retraction of the membrane of the tympanic cavity, pentup secretions, and middle-ear suppuration, with resulting deafness.

Barnard believed that the common variety of intussusception in infants, which starts in the lower few inches of the ileum, results from an enlargement of the last Peyer's patch (which is especially prone to hypertrophy) bulging into the ileum and being seized upon by peristaltic movements.

It is just credible that localised hyperplasia of lymph nodules in the vermiform appendix may lead to functional blockage of the tube, the stagnation of contents and the formation of calculi.

General increase of lymphatic structures signifies prolonged bacterial assault's, and may be accompanied by a toxin-weakened heart in the condition known as status lymphaticus. (See Chapter XIV.). 


\section{CHAPTER XVII.}

Other Disfases of the Subepithelial Lymphatic GLands.

The subepithelial lymphatic glands may share with other lymphoid tissues in certain obscure infections, namely splenomedallary leuchæmia, lymphatic leuchæmia, and lymphadenoma (Hodgkin's disease). In the latter disease it is the large glandular lymphocytes which multiply so rapidly at' certain stages. The lymphoid tissue of the faucial tonsil is also liable to lymphosarcoma; that is, a large round-celled sarcoma which spreads to the adjacent lymphatic glands. Malignant disease of the epithelial covering of the lymph nodes is also to be met with in stratified epithelioma of the tonsil, and the not very malignant carcinoma of the vermiform appendix.

None of these diseases, however, appear to have any bearing on the main thesis of this book.

Of more import is the insidious passage of tubercle bacilli through the subepithelial lymph glands to the adjacent interstitial lymphatic glands. This condition is of very frequent occurrence, the upper cervical glands draining the faucial tonsil becoming tuberculous, whilst that organ remains healthy. Cervical glands are more liable to tuberculous disease than, for instance, are inguinal glands, and the disease commonly begins in the upper deep cervical glands which drain the tonsil. 
So, too, tabes mesenterica may be unaccompanied by obvious disease of the Peyer's patches. Caseating ileocolic glands may exist with a normal vermiform appendix.

It would seem as if the subepithelial lymphatic glands had an especially high resistance to the tuberele bacillus, but that occasionally a lymphocyte loaded with tubercle bacilli would pass to the nearest interstitial gland and there be overeome by its contained bacilli, and a tuberculous focus thus be set up. Or possibly the ingested but undigested tubercle bacilli live so slowly that their relatively inert forms have been transferred to adjacent interstitial glands before their effects begin to be produced.

It is as a rule only when the general resistance has been greatly lowered, as in the last stages of phthisis, that tubereulous ulcers on the tonsil are found, though tubereulous disease is found in a certain proportion of enlarged tonsils that have been excised. 


\section{CHAPTER XVIII.}

\section{Therapeutic Bearing.}

A genfral acceptance of the theory of the immunising function of the subepithelial lymphatic glands would probably have the following two effects :-

(1) It would lead to a more conservative surgery of the subepithelial lymphatic glands.

(2) It might stimulate further attempts at securing immunity by the administration of bacterial cultures by the mouth.

With regard to the practical bearing on surgery, it may be declared at the outset that the excision of the tonsils and appendix can never be abandoned. There has, however, at times been a tendency to remove the faucial tonsils solely because the nasopharyngeal tonsil (adenoids) is being curetted, or to remove the appendix as a routine measure in any laparotomy for other cause.

The ruthless advocates of the indiscriminate "massacre" of subepithelial lymphatic glands would urge with perfect truth that no satisfactory proof has ever been presented showing disability following removal. But the question has never been scientifically studied. What is required is to take many thousands of healthy children living under similar conditions, in half of whom the healthy tonsils had been enucleated and the adenoids completely cut off within the first two or three years of life, and then to compare the susceptibility 
of the two groups to infectious diseases during the remaining years of childhood. The statistical and scientific difficulties would be immense, but until some such investigation has been made, one must conclude that the question of disabilities following removal is quite unproven either way. Isolated cases of infective diseases following tonsilectomy have been recorded. Their occurrence may well have been accidental, but it must not be assumed too readily that removal of the tonsils and adenoids lessens the incidence of infectious disease. Indeed, the converse may be the case. A very careful investigation of the after histories of cases submitted to this operation at the Johns Hopkins Hospital has been recorded by Crowe, Watkins and Rotholtz. "During the past four years," they say, "we have seen eight cases with a history of frequent attacks of tonsilitis preceding, but never with anything but local symptoms." After partial removal of the tonsils "all went well until the next coryza, following which the joint symptoms appeared for the first time." The authors attribute this to cicatricial tissue from the first' operation narrowing the crypts as "the joint symptoms gradually disappeared and the temperature returned to normal" after complete removal of the tonsils. But in another part of their paper they write : "Organisms probably pass through the mucous membrane of the nose, nasopharynx and pharynx more frequently than is generally supposed. We have on several occasions seen, in patients whose tonsils and adenoids had been thoroughly removed, an enlargement' of the glands of the neck, a return of arthritic symptoms, repeated attacks of rheumatic fever, and especially frequently a recurrence of chorea after a mild coryza or pharyngitis."

Quite recently Zahorsky published a valuable paper on the late result's of the removal of the tonsils and 
adenoid vegetations. 150 children aged 8 to 12 were under clinical observation in private practice from six months to five years after the operation, and the following defects were observed :-

Deficient nasal respiration... $\quad \ldots \quad 38$ cases.

$\begin{array}{llllll}\text { Acute otitis media } & \ldots & \ldots & \ldots & 21 & ,\end{array}$

$\begin{array}{lllllll}\text { Bronchitis } & \ldots & \ldots & \ldots & \ldots & 49 & \text {, }\end{array}$

$\begin{array}{lllllll}\text { Bronchiolitis } & \ldots & \ldots & \ldots & \ldots & 22 & \text {, }\end{array}$

$\begin{array}{lllllll}\text { Pneumonia } & \ldots & \ldots & \ldots & \ldots & 15 & \text {, }\end{array}$

(9 of which occurred during the winter following the operation.)

$\begin{array}{llllll}\text { Rheumatic fever } & \ldots & \ldots & \ldots & 11 \text { cases. }\end{array}$

$\begin{array}{lllllll}\text { Endocarditis } & \ldots & \ldots & \ldots & \ldots & 7 & \text {, }\end{array}$

$\begin{array}{lllllll}\text { Chorea } & \ldots & \ldots & \ldots & \ldots & 6 & \text {, }\end{array}$

$\begin{array}{lllllll}\text { Diphtheria } & \ldots & \ldots & \ldots & \ldots & 3 & \end{array}$

Enlarged cervical glands ... $\ldots .15$,

Zahorsky concludes :- " The clinical impression that tonsilectomy increases the tendency to bronchial and pulmonary infection is corroborated by these figures, although they are not conclusive, as no figures are available as to the usual incidence of acute bronchopneumonia in children. That an attack of acute tonsilitis renders the child temporarily immune to a variety of dangerous infections seems probable. ... My observation shows that the child beginning his school life without the tonsils is in greater danger of acute diseases than one who still has his tonsils."

It may here be emphasised that it would be difficult to show statistically that the loss of a finger was disadvantageous; yet we can see the mechanism of digital efficiency so clearly that we can have no doubt as to the reality of the disadvantage. Granted the mechanism and utility of the subepithelial lymphatic glands, advocated in these pages, we can have little doubt as to the disadvantages entailed by their loss.

However, the body has such large powers of com- 
pensation that local losses can usually be made good. It is probable that adjacent subepithelial lymphatic glands hypertrophy and largely replace the organs removed.

Another consideration which may serve to stay the surgeon's hand in absence of definite call for operation is the fact that the subepithelial lymphatic glands lie close to an alimentary canal swarming with pathogenic organisms.

Any removal involves cutting into this region as well as dividing healthy tissues. With the vermiform appendix technical skill has so well met the difficulty that the risk in removing a normal or quiescent appendix should be little, if any, greater than the risk of exploratory laparotomy. But removal of tonsils and adenoids can make no pretence to being an aseptic operation, and septic complications are far commoner than is generally admitted. The following is a list of complications directly the result of the operation for removing these structures:-

Sapræmia with pyrexia for a week or more.

Suppurating cervical glands.

Retropharyhgeal abscess.

Suppurative otitis media.

Septicrmic abscess (e.g., abscess of rib).

Endocarditis.

Primary, reactionary, and secondary hæmorrhage.

Syncope, sometimes fatal, during anæsthesia.

Bronchitis and pneumonia.

Some cases of scarlatina, of diphtheria and of rheumatic fever have been recorded.

In view of the bacteriology of the fauces, the wonder is that septic complications are not more serious than they are. Perhaps the explanation is that the resulting wounds are freely open ones.

Dr. Mackenzie (1912) has written eloquently against 
the removal of tonsils and adenoids in the absence of definite indications.

Mindful both of their probable physiological value and also of the distinct, though not often serious, risks of the operations for their removal, one may restrict the indications for operation in a table as follows ${ }^{*}$ :-

\section{Operation.}

(1) Partial Excision of the faucial tonsils.

(2) Enucleation of faucial tonsils.

(3) Erasion of nasopharyngeal

\section{Indications.}

Chronic interference with swallowing or with speaking.

\begin{abstract}
Where there is good reason to suspect the tonsil of containing a chronic focus of infection; for example, in some cases with repeated attacks of septic sore throats with tonsillar or peritonsillar abscesses, or where there are concretions in the tonsils.
\end{abstract}

(A) Chronic obstruction to nasal breathing.

(B) Deafness, accompanied by a very large mass in the nasopharynx with retraction of the membrane which does not yield to repeated politzerisation.

The nasopharyngeal tonsil must be of very great' size to be responsible for blocking the tuba auditiva. Obstruction of the tuba auditiva is more usually due to inflammation of the mucous membrane and swelling of the lymphoid tissue about its orifice. That removal of the latter can be accomplished by the blind use of curette or finger is to my mind more than doubtful.

(4) Appendicectomy.

A probable diagnosis of appendicitis.

The indication given here is very vague. Probably no one goes through life without an inflammation of

* This table, for convenience, omits malignant disease, which is a rare but perfectly legitimate indication for the removal when practicable of any of the subepithelial lymphatic glands which may be affected. 
the appendix. But experience has shown that when this inflammation has proceeded to such a degree that the symptoms and signs point definitely to appendicitis, appendicectomy without delay gives distinctly the best result's. A mild catarrhal appendicitis, giving rise to an attack of abdominal pain, at first general, but after a few hours localised in the right iliac fossa, with slight rise of temperature, some nausea or even vomiting, a tendency to constipation, and tenderness or rigidity with diminished reflexes in the right iliac region, demands immediate excision of the appendix as, of course, do severer forms of the disease with complications.

The routine removal of the tonsils in cases of tuberculous disease in the glands of the neck, has been advocated on the grounds that the tonsils act as "portals of entry" to the tubercle bacilli. It is probable that the tonsils have so acted in such cases, but to remove them in all cases of tuberculous cervical glands is to be on a par with the wealthy merchant who returned home to find that malefactors had broken into his house through the front door and damaged his property. "Remove the door," cried the angry merchant'.

The oral or rectal administration of bacterial cultures has sometimes been attempted with some degree of success. Some immunity to typhoid fever and to tuberculosis has thus been attained. The difficulties that may be apprehended are the destruction of the dead bacilli by alimentary juices, and the considerable dilution of the fluid in which they are suspended, so that but few ever reach the surface of the subepithelial lymphatic glands. On the other hand the administration of too virulent a strain might yield such a violent reaction as to open the way for a mixed infection and an acute inflammation. Perhaps these difficulties will some day be overcome. 


\section{CHAPTER XIX.}

\section{Some General Considerations.}

IT is well to avoid teleological explanations in Science. It is, strictly speaking, incorrect to ask why does an animal possess a particular organ. One may however call attention to homologies and analogies, and one may describe the action of the organ. One may consider the advantages or disadvantages to the individual or the race, examine how the structure arises in the individual and how it comes to be perpetuated in the race. One may even speculate as to what amphimixial chance its occurrence in the species was originally due.

In other words, while taking care to avoid the specious, gap-jumping half-truths and errors of teleology, it is legitimate t'o indicate the anatomical, functional, embryological and biological significance of any structure.

It is with the biological significance of the subepithelial lymphatic glands that this section is concerned.

The disadvantage of these glands in the body is their proneness to more or less successful bacterial assaults. Besides becoming the site of a local disease they may become the portals of entry of general disease. Sometimes, while the glands do not succumb they are provoked to such hyperplasia as to cause mechanical disabilities such as nasal obstruction.

The advantage of these glands is-so it is maintained 
here-that they are constantly sampling adjacent bacteria and immunising the body against their invasion. Considering that they are constantly engulfing bacteria, it is seen how relatively infrequent is their defeat. An occasional attack of tonsilitis or appendicitis indeed may well be a cheap ransom to pay for immunity from general infections of far greater frequency and severity.

That the balance of the action of these subepithelial lymphatic glands is advantageous is indicated by their occurrence in the height of their development in the later, more developed and more successful types of animals.

The simple forms of subepithelial lymphatic glands merely underlie the epithelium; in the more complex types some kind of cul-de-sac arrangement is seen, for instance the blind lumen of the vermiform process or the lacunæ of the tonsils. The stagnation which results may perhaps favour bacterial growth in close vicinity to the lymph nodules and in some cases the cul-de-sac arrangement may lead to some control over the exposure to this growth. Thus the vermiform process may be likened to a test-tube which is filled at intervals with samples of the cæcal brew and which can be emptied by the contractions of its own musculature and washed by the mucus of its own secretion.

The cul-de-sac arrangement has this weakness that stenosis or blockage of the lumen of the cul-de-sac which may follow one attack of inflammation, will predispose to a recurrence of the trouble.

Where the subepithelial lymphatic gland is surrounded outside by a strong protecting capsule (as for instance the faucial tonsil tying in its fibro-muscular bed), if suppuration occurs its spread is limited. But hyperplasia from excessive work causes an enlargement towards the alimentary lumen and mechanical ill- 
effects may follow. Conversely, where the subepithelial lymphatic gland is feebly enclosed (as for instance the vermiform process with only the sero-musçular coat between the lymph nodules and the free peritoneal space) suppuration may become very widespread and serious. On the other hand enlargement will not encroach upon the alimentary lumen or cause harm in any mechanical way. It does, however, seem unfortunate that the appendicular artery is an "end artery." Elsewhere the arteries to the intestines with their dangerous contents anastomose freeiy with one another up to the margin of the gut. But the artery of the appendix has no collaterals with the ileal or cæcal arteries. The arrangement in the rabbit is better. Here the artery supplying the appendix also sends twigs to the adjacent lower end of the ileum. As the ileum receives in addition its own independent blood supply, an anastomosis is formed on the ileum between the ileal and appendicular arteries.

A word may be said as to the beneficial position of the noduli lymphatici aggregati which are disposed longitudinally on the antimesenterial side of the gut. Any cicatricial contraction, which might follow an attack of inflammation, will not diminish the alimentary lumen nor tend to cut off the blood supply to any part of the circumference of the gut.

As to the origin of the subepithelial lymphatic glands it' is easy to conceive the attraction of lymphocytes to the submucosa as a result of its occasional invasion by bacteria. The occurrence of lymphocyte-producing centres in this region would be of advantage tending to the persistence of this variety in the species. The ingestion of bacteria consequent upon lymphoid tissue in the submucosa would enhance the natural powers of resistance and would be a further advantage t'o its possessor. 
That the subepithelial lymphatic glands are a risk to their owners from the effects of acute attacks of inflammation can hardly be doubted. If their possession involved no counterbalancing benefits, all variations in the direction of their suppression would have a strong bias in their favour in the struggle for existence and these organs would tend to disappear in the race. In the words of Professor Keith (1912), "We know from their fossil remains that the great anthropoids are of extreme geological antiquity. Were their appendices (identical in structure with the human appendix) injurious or vestigial structures there has been ample time to accomplish their complete suppression."

Moreover, any organ that ceases to be of value degenerates. This principle of degeneration is perhaps imperfectly realised.

It has probably nothing to' do with disuse. "Disuse Inheritance " has long been abandoned as an untenable view.

Nevertheless, an organ, the lack of utility of which removes it from the sphere of natural selection, becomes the sport of variation and chance. Its constancy diminishes with every variation which arises, and the accurate inter-relationship of its parts falls in the average member of ensuing generations. So it is that the eyes of species that have lived for countless generations in the dark have ceased to see. 


\section{CHAPTER XX.}

\section{Résumé of the Hypothesis and Summary of the Evidence For and Against.}

THE hypothesis is that the subepithelial collections of lymphoid tissue play an important function in immunising the body against pathogenic bacteria in proximity to the tissues. These organs secure this general immunity by ingesting the bacteria upon or near the surface of the covering epithelium. The mechanism of ingestion may be called phagotaxis-the lymphocytes leaving the gland-tissue wander to the surfare of the epithelium or beyond into the lumen, engulf bacteria and return with them into the parenchyme of the gland where the bacteria are slowly overcome or sometimes passed on to a further relay of lymphatic glands for destruction or even via the blood to the spleen and bone marrow. Bacteria are being constantly invited into places which are nearly always impregnable. The bacteria are not only overcome, but a great number of lymphocytes capable from experience -if one may fancifully so put it-of dealing with that kind of bacterium are scattered through the blood stream ready to resist invasion elsewhere. The subepithelial lymphatic glands are not' only breeding grounds* but also training schools for lymphocytes. The opsonic index against the micro-organisms is in-

* The researches of Goodall, Gulland and Paton appear to show that very many of the lymphocytes in the blood are formed in the bone marrow. The whole question of the origin of the white cells in the blood is not yet settled. It is usually assumed that the lymphocytes do not develop into polymorphonuclear cells, but that the former arise in lymph glands, hæmolymph glands and marrow, whilst the latter are formed in the red bone marrow only. 
creased : bacteriolysins and antitoxins are produced in large quantities. The subepithelial lymphatic glands confer upon. their owners some immunity against the alien myriads of bacteria. They are the immunising stations, or, if you like, the auto-vaccination organs of the body.

The line of argument leading to this hypothesis can in brief be indicated thus. The subepithelial lymphatic glands have appeared, reached a high stage of development and persisted throughout the two highest classes of animals-namely birds and mammals. And this in spite of the apparent anomaly of their great liability to serious infectious disease. They must have a compensating function of great value. The continuous ingestion of bacteria by the subepithelial lymphatic glands considered together with our knowledge of healthily acquired immunity to infectious disease suggests the hypothesis of their auto-vaccinating function.

The chief points in favour of the hypothesis may be summarised below :-

Biological :

(1) The subepithelial lymphatic glands are only present in the two latest, highest and most successful classes of animals-namely birds and mammals.

They occur without exception throughout these two classes, including phyla of considerable antiquity in a geological scale.

Organs of no value become suppressed over long periods of time (Chapter XIX.). As the subepithelial glands are often the seat of disease, their suppression would have been accomplished long ago, had they not some compensating functions of great value.

(2) With regard to the mammalian cæcum, lymphoid - tissue is almost universally present. Sometimes this forms a protuberant mass at the apex. Quite frequently and in many widely different phyla the lumen of the 
cæcal apex is small. The lymphoid tissue then thickens the wall of this tubular mechanism. The maximum amount of lymphoid tissue is associated with the tubular type and occurs in rodents where the cæcum is of immense size and serves for the bacterial decomposition of cellulose.

Anatomical :-

(1) Position of the subepithelial glands. The lymph nodules are placed directly beneath the epithelium. They are superficial even to the fibres of the muscularis mucosæ.

(2) Structure of the subepithelial glands. Where the follicles are crowded together the overlying epithelium is folded into pits and recesses so that each lymph nodule subtends the surface. This is well seen in the nasopharyngeal and the faucial tonsils. There are no afferent lymphatic vessels.

(3) Distribution of the subepithelial glands. They do not underlie the skin which is thick, resistant, and comparatively free from pyogenic organisms on the surface, but they are found in the throat and along the alimentary tract, where the mucous membrane is thin, permitting of absorption. Moreover they occur exactly at those points where the micro-organisms flourish. The circumpharyngeal ring meets the bacteria entering with the food (and with the inspired air in the case of mouth-breathers). The Peyer's patches, the appendix, and the solitary follicles are placed around the excellent incubating media in the ileum, cæcum, and ascending colon, precisely those parts which are swarming with organisms. The stomach, on the other hand, protected from bacterial growth in its contents by the acid nature of its secretion, is almost free from lymphatic tissue, except towards the pylorus.

The whole anatomical arrangement of the subepithelial lymphatic glands is such as to bring them into 
close connection with the chief collections of bacteria lying outside of, but adjacent' to, the tissues. Physiological :-

(1) The subepithelial lymphatic glands in health are continually ingesting bacteria in enormous numbers. By all we know of the production of artificial immunity this ingestion of bacteria must enhance the general powers of the organism against these bacteria.

(2) Mere exposure to cases of infectious diseases often serves to confer immunity even in those who do not contract the complaint.

(3) The subepithelial lymphatic glands are largest and most active in young children at a period when individuals are acquiring immunity to the various common infections. In old age all lymphatic structures tend to atrophy.

Clinical :-

(1) The subepithelial glands bear the brunt of the attack in faucial and intestinal infections. Scarlet fever, typhoid fever, and appendicitis are sound examples. In infantile enteritis the Peyer's patches are swollen and infected. As a rule, the tissue which is most seriously attacked provides the greatest number of antibodies. For instance, the power of brain emulsions to neutralise tetanus toxin has been satisfactorily proved. (Ehrlich, 1906.)

(2) The subepithelial glands hypertrophy as a result of repeated infectious diseases. Whooping-cough, scarlet fever, measles, and " colds" (especially if associated with deficient exercise or unhygienic surroundings) lead to enlargement of tonsils and adenoids.

(3) It is often observed during scarlatinal epidemics that a person may apparently secure immunity by a very mild tonsilitis which is unaccompanied by rash, malaise, or other signs of general injury.

(4) In fulminating infections, where septicæmia is 
early and fatal, the lymphatic reaction is poorly developed.

Pathological:-

(1) The initial lesion of such diseases as sore throat, typhoid fever and appendicitis is a lymphadenitis.

(2) An increase in the number of the glandular lymphocytes in the subepithelial lymphatic glands accompanies most infections of them.

(3) The lymphocytes of the blood are formed in part, at least in lymphatic glands. In faucial and intestinal infections these cells are increased in number in the blood. A lymphocytosis accompanies polymorphonuclear leucocytosis in some pyogenic inflammations, and occurs alone, or predominantly, in Malta fever, measles, variola, infantile gastro-enteritis, some cases of typhoid fever, diphtheria, pertussis, rickets and syphilis. The almost constant presence of lymphocytes about an infected area seems to indicate that these cells play an antibacterial part.

What is the evidence against this hypothesis and what criticisms may fairly be levelled at it? Perhaps want of direct evidence is the weakest point in the case presented. The following series of experiments would be almost conclusive. The appendix in the rabbit can be detached from the cæcum and sutured so that it opens on the skin. A loop of jejunum (devoid of Peyer's patch) can similarly be isolated and made to open at one end on the surface. Various types of pathogenic bacteria could be introduced into these sinuses, and careful observation made as to :-

(1) Whether a stronger dose could be introduced into the appendicular than into the jejunal sinus without harmful effects. 
(2) Whether a higher degree of immunity could be produced more rapidly by injection into the appendicular than into the jejunal sinus.

Until such investigations can be made-the hypothesis can only be tentatively accepted. On the other hand the ingestion of bacteria by the subepithelial lymphatic glands is a firmly established fact, and it is hardly possible for this wholesale ingestion to proceed continuously without enhancing the natural powers of resistance.

Another line of opposition may be taken by pointing out that these subepithelial lymphatic glands can be obliterated without apparent harm resulting. Tonsils, adenoids and vermiform appendix have been removed in countless instances and few, if any, ill effects have been discerned. (See pages 94, 95 and 96, however.) These same glands are often so destroyed by suppuration or fibrosis that the lymphoid tissue eventually becomes practically non-existent. And all the subepithelial lymphoid tissue diminishes in quantity after puberty. Further the various collections of subepithelial lymphoid tissue are absent in a few of the higher and most of the lower types of animals. To all of which it may be replied that an animal can still live when one eye is removed, some animals exist without eyes at all, many successful people's eyesight is defective; yet we cannot say that the eye has no useful function. 


\section{BIBLIOGRAPHY}





\section{BIBLIOGRAPHY}

\section{AND INDEX OF NAMES}

Name

Reference

Page

ADAMI

"Principles of Pathology," 446

ADAMI \& MCCraE . "'Test Book of Pathology," 836

10,11

AlaGna, 1902 . . Arch. Ital. Di Laryngol, XXII., 157 .

BARNARD . . . "Contributions to Abdominal Surgery" .

BAUM \& HALLE, Anatom. Anzeig., XXXII. (quoted by 1908 . . . . Schäfer, "Microscopic Anatomy," 1912)

BERRY, 1895 . . Journal of Pathol. and Bacteriol., III., 160 1901 . . Journal of Anat. and Physiol., XXXV., 83

BIRMINGHAM

Bizozzero

86

Bland-Sutron, 1891 Trans. Clin. Soc., XXIV., 122

Lancet, I., 547

1908 Clin. Journal, XXXII., 177 .

BOND, 1918 . . . "The Return Immigration of Leucocytes," Brit. Med. Journ., II., 277. (See also further references given there).

BRÖWNE

Proc. Roy. Soc. Med., Epidemiol. Sect., 120

BUTTERFIELD

Carpi, Berenger .

ChassaignaC

Corner, 1913

"The Function of the Appendix and the origin of Appendicitis." Brit. Med.

Journ., I., 325

CoURMONT \&

ROCHAIX, 1911

Crowe, Watkins \& RoTHOLTZ, 1917

Da Costa

DARWIN, 1874

DeLAField \& PRUDDEN
Sem. Med., XXXI., 152 and 236

"Relations of Tonsillar and Naso-Pharyn. geal Infections to General Systemic Disorders," Bull. Johns Hopkins Hosp., XXVIII., 1

"Clinical Hæmatology" . . . . . .

"Descent of Man," 2nd Edition, 21 .

"Pathology"
$27,66,89$

3

5

76

75

4,6

88 
Name

Reference

DIGBY, 1911 . . . "Subepithelial Lymphatic Glands," Guy's Hospital Gaz., XXV., 203 : . . . .

1912 . . "Functions of Tonsils and Appendix," Lancet, I., 150

1913 . . . Lancet, I., 1731

1913 . . "Subepithelial Lymphatic Glands," Universal Medical Record, III., 109 . .

1917 . . China Medical Journal

DRESCHFELD, 1896 . "Enteric Fever" in Allbutt's "System of Medicine". . . . . . . . .

EHRLICH, 1906 . . "Studies on Immunity," Section XXXI.

FARMACHIDIS \&

VATTERONE, 1913. Rif. Mcd., XXIX., 987

FleXNeR \& CLARK, 1911

Journ. Amer. Med. Assn., LVII., 1685 .

FlemMING, 1885

FosTer, 1912

Arch. F. Mikr. Anat., XXIV.

46, 47

"Surgical Removal of Tonsils," Amer. Journ. of Surg., XXVI., 150". . .

GOODALL \& Paton, 1905

Journ. of Physiol., XXXIII., 20 .

103

Gouger, 1912

La Presse Médicale, 813

10

GraY, 1916

"Human Anatomy"

19

20

GRAUER

GRIFFITH

"Biology of the Blood Cells"

GOODALL, GULLAND

\& Paton, 1904 . Journ. of Physiol., XXX., 1.

48,103

GulliaND \&

GoOdali, 1914 . "The Blood"

75

Guy's Hospital Gaz., XXVII., 347 . . . 13

HaLL, 1913

26

HAYS, 1912

"Care of Nose and 'Throat in Children," American Journ. of Obstet., LXVI., 877

HENKE

19

HETT, 1913

"Anatomy and Comparative Anatomy of the Palatine 'Tonsil and its Role in the Economy of Man," Brit. Med. Journ., II., 743

$20,27,30$

77, 89

HETT \& BUTTER-

FIELD, 1910 . . Journ. of Anat. and Physiol., XLIV., 35 .

27, 89

Huntrngton, 1903 "Anatomy of the Peritoneum and Abdominal Cavity" 
Name

Reference

Page

74

JACOBI

KFETLIY, 1909 . . Annals of Surgery, I., 203 and 1342

1907 . . Lancet, I., 1761

1909 . . Lancet, I., 1

1909 . . Proc. Roy. Soc. Med., Surgical Section, 67

KEITH, 1912 "Functional Nature of Caecum and Appendix," Brit. Med. Journ.. II., 1599

1913 . " "Human Eimbryology and Morphology" 56,57

KELLY, 1905 . . . "Vermiform Appendix" . . . . .

Kilyn:ack, 1893 . "Pathology of the Vermifurm Appendix" 3,4

KLEIN, 1873

- "Anatomy of the Lymphatic System" .

LANDSDOWN \&

WILLIAMSON . . Brit. Journ of Surg., II., 306

LANDSTEINER, LEVADITI \&

- Pastia, 1911 . . Sem. Med., XXXI., 296

LÉNAR'T

"The Carrier Problem in Infectious

LEDINGHAM \& ARKWRIGH', 1912 Diseases"'

LUCKHARDT \& Bechr, 1911 . . Amer. Journ. of Physiol., XXVIII., 257 . Lockwoon . . . "Allbutt's System of Medicine" . . MCCUцLOCH, 1913 . Lancet, I., 1827. (See also further references given there)

Macewen, 1904 . . Brit. Med. Journ., II., 873 . . . . . .

MaCfarlane

MackenzIE, 1912 . "Massacre of the Tonsil," Maryland Med. Journ., LV., 138

Annals of Otol., Rhinol. and Laryngol., XXI., 416

MCKILLOP, 1912 . Australas. Med. Gaz., XXI., 496

Lancet, II., 37

MASSEI

MirYer, 1870

Med. Chi. Trans., LIII., 191

MILLER, 1911 . Anat. Record, V., 118

Murchison, 1866 . Trans. Path. Soc., XVII., 117 . . . .

PALMer, 1912

"A Case of Malignant Scarlet Fever,"
I.ancet, II., 758

PeYer

PyвUS, 1915

Hunterian Lectures on "Some Infections of the 'lonsils," Lancet, I., 1009, 1065 . 
Name

QUAIN, 1912

Reference

"Anatomy"

RIBBERT

Ransohorf, 1890 . Trans. Amer. Surg. Assoc., VIII., 151

RUFFer, 1890 . . "On the Phagocytes of the Alimentary Canal," Quart. Journ. of Microscopic Sci., XXX., 481 . . . . . . . . 4, 47, 61

Savini, 1914

SANTORINI, 1724

SCHÄFR, 1912

"Observ. Anatomicae Venetiis"

- "Presilential A thress, British Association.

Presidential Address, British Association, Lancet, II., 675 . . . . . . .

Soвотта . . . . "Histology" . . . . . . . · .

Shatrock, 1916 . "Mechanical Causation of Appendicitis," Brit. Med. Journ., I., 690

Proc. Roy. Soc. Med., Path. Section, 23

Shennan, 1912 . "Post Mortems and Morbid Anatomy" .

SMith, Eustace, 1909

"Diseases of Children"

SPENCER, 1897

"Pathology of the Jymphadenoid Structures," Lancet, I., 722 . . . . . .

Stapley, 1911 . . "Morphology of the Vermiform Appendix," proc. Roy. Soc. Victoria, 23 N.Ș., Pt. 11, Art. XXVIII.

53,70

79,83

STARLING, 1912 .

"Principles of Human Physiology"

'TRETHOWAN, 1912

"Acute Anterior Poliomyelitis," Lancet, II., 938

Treves, 1885 • . Hunterian Ifectures, Brit. Med. Journ., I., 527

$4,8,9$

1890

"Surgical Trreatment of 'Typhlitis"

"Surgery of the Peritoneum," Brit. Med. Journ., II., 1305

80

1902 . . "Inflammation of the Vermiform Appendix," Lancet, I., 1815 . . . . . .

WATNEY

82

ZAHORSKY, 1919

Interstate Med. Joum., XXVI., 67 
INDEX 



\section{SUBJECT INDEX}

\section{A.}

\section{Abscess formation-}

deep submaxillary, 85

intramural, 8I

peritoneal, 85 , ror

peritonsillar, 85,97

retroplaryngeal, 85

of rib, 96

submucous, 85

Actinomycosis-

in a kangaroo's tonsil, 77

of the vermiform appendix, 83

Acute anterior poliomyelitishealthily acquired immunity against, I7

subepithelial glands involved in, 74

Adenoids -

cystic disease of, 86

effects of removal of, $94,95,96$, I08

enlargenient of, 88, 89

(See also 'Ionsil, nasopharyngeal.)

Adhesions, 79, 8I, 84

Afferent lympliatic vessels, absence of, in subepithelial lymplatic glands, 49, 67, I05

\section{Agglutinins-}

absence of, in some innulue carriers, 15

in artificial immunity to typhoid fever by rectal injection, 76

\section{Alimentary immunity, I 7}

Amazons, epidemic of measles among, $I_{4}$

Amphibians, junction of small and large intestines in, 32

Anas, bilateral cæca in, 33

Anatomical evidence, 105

Anser, bilateral cæca in, 33

Anthropoid apes, 35, 102

Antibodiez, greatest number provided by tissue most seriously attacked, ro6

\section{Antitoxins-}

excess production of, 12 , IO4

production of in subepithelial lymphatic glands, 15

Appendicectomy (see appendix, excision of.)

\section{Appendicitis-}

absence of collateral circulation as cause of, 80 , ror

actinoniycosis as cause of, 83

adhesions as cause of, $8 \mathrm{r}, 84$

causes of, 79, 80, 81, 82, 83

Chinese, in, 83

chronic constipation as cause of, 79

diagnosis of, 97,98

discovery of, 3

earliest recorded case of perforation of, 3

in Europeans living in the tropics, 82

foreign bodies as cause of, 80

intranural abscess in, $8 \mathrm{r}$

Japanese, in, 82

kinking as cause of, $8 \mathrm{r}$

lymphadenitis as starting point of, 82, 107

morbid anatomy of, 83

mucous cyst as result of, 86

multiple ulcers corresponding to lynuphoid nodules in, 85

obliteration of lumen as result of, $8,9,86$

partial occlusion as result of, 86 peritoneal abscess with, 85 , Ior

polymorphonuclear leucocytes in, $8 \mathrm{r}, 83$

purgatives as cause of, 82

ransom for immunity, as, 100

recurrent attacks, 86,87 , I00

streptococci as cause of, 82

strictnre as result of, 80

symptoms of, 98

terminal blood supply as cause of, 80 , Ior

trauma as cause of, $8 \mathbf{r}$

tubercle bacilli as cause of, 83 
Appendicitis (cont.)-

trphoid fever, in, 82

ulceration absent in, 81

vegetarianism and, 82

"vestigial" character as cause of, 6,79

wavy contortion as cause of, 79

\section{Appendix vermiformis-}

absence of collateral circulation,

\section{7}

alleged uselessness of, I, 7

alleged vestigial character of, 7 bacteria in rabbit's, .5x, 6o to 66

blockage of lumen due to localised lymphoid hyperplasia, go

blood supply of, 101

carcinoma of, $9 \mathrm{I}$

chronic focus of disease, as, 10

comparative anatomy of, 35 to 45 congenital absence of, 8

contents of, $23,8 \mathrm{r}$

development of, form of, in man, 57

discovery of, 3

distribution of, in animals, 35 to 45

effects of removal of, ro8

enibrvology of, 7,56

excision of, 97

homologies of structure with that of an interstitial 1ymphatic gland, 5.3

inflammation of (sec Appendicitis.)

1vmploid tissue of, 22

malignant disease of, 97

musculature of, 100

obliteration of lumen of, 9

pernitting passage of tubercle bacilli, 92

portal of entry of disease, as, IO

position in man, 22

rabbit's. $5 \mathrm{I}$ to 55

recognition of disease of, 3

secretion of, 9

serial homologv of, with Pever's patches, 23

significance of frequent disease of, 9

small lumen of, 7

structure of, in man, 22, 105

thick wall of, 7

transplantation of, 4
Appendix vermiformis (cont.)variability in its connection with the cæcum, 7

variability in position, 7

variability in size, 7

Arctic explorers, colds among, I4

Armadillos, bilateral cæca in, 33

Astoria, epidemic of measles in, I4

Atrophy of 1ymploid tissue, 36, 59

Auricle, muscles of, 6, 7

Auto-vaccination organs, 104

\section{B.}

B.N.A. terminology, 2

Bacilii in rabbit's cæcum, 63

Bacteria-

presence of in 1rmphoid tissue of cat's tonsil, 60

presence of in lymphoid tissue of dogr's Pever's patch, 62

presence of in lvmphoid tissue of dog's tonsil, 62

presence of in lymphoid tissue of guinea-pig's Peyer's patcli, 62

presence of in 1rmphoid tissue of human adenoids, 60

presence of in lymphoid tissue of human appendix. 65

presence of in lymphoid tissue of human tonsil, 60,65

presence of in lymphoid tissue of rabbit's appendix, 60,61 , 64,65

presence of in limphoid tissue of rabbit's Peyer's patch, 62,63

presence of in lymphoid tissue of rabbit's tonsil, 60,62

presence of in subenithelial 1vimpliatic glands, 60 to 56

Bacterial moti'ity, 68

Bacteriolysins, excess production

Batsof, 12, 104

absence of faucial tonsils in, 28 junction of large and small intestines in, 32

Bears, innction of large and small intestines in, 32 
Beaver-

absence of faucial tonsils in, 28 lymphoid appendix in, 35, 37

Bioiogical evidence, ro4

\section{Birds-}

hilateral creca in, 33

junction of large and small intestines in, 32,33

lymphoid tissue in, 33, 34, 56, IO4

lymphoid tissue in bilateral creca of, 33,34

nas̉opluaryngeal tonsil in, 30

single cæecum in, 32

Blood infections in immune carriers, 15

Bone marrow (sec Marrow.)

Bos Taurus, tubular tonsils in, 30

Bradynus tridactylus, junction of large and small intestines in, 32

Brain emulsions neutralise tetanus toxins, Io6

Bronchial subepithelial lymphatic glands, I9

Bronchitis, 95

Bronchiolitis, 95

Broncho-pneumonia, 95

Bustard, bilateral cæeca in, 33

c.

Cacal tonsil, 29, 35

Cæcum-

bifid cæcum, 33

bilateral cæca, 33

distribution of, in animals, 32, 33

-form of lymphoid tissue in, associated with diet, 34

function of, $3 \mathbf{I}$

lymphoid ticsue at apex, 34

lymphoid tissue near ileo-caecal junction. $30,31,52$

post-natal derelonment of $1 \mathrm{ym}$ phoid tissue in, 56

single crecum, 32

Calculi ir: tonsil (sec also Concretion), 4

Calyx gland, 5.3, 54, 55

Canadian porcupine, lymphoid appendix in, 35,38
Canis familiaris-

crecal tonsil in, 35

crecum in, 32

projecting tonsils in, 28

11nusial amount of carbon particles in subepithelial lymphatic glands of, 69

Carbon particles, ingestion of by subepithelial 1ymphatic glands, 69,70

Carcinoma of vermiform appendix, 9 I

Cardiac disease following tonsi!lectomy, 94, 95, 96

Carmine-

injections into oral and nasal nucosa, 49

mixed with food, $70,71,72$

Carnivora-

crecal tonsil in, 35

crecum in, 31,32

Carriers in infectious disease, I4, 15,76

Castor fiber-

absence of faucial tonsils in, 28 lymphoid appendix in, 35, 37

cat -

crecal tonsil in, 35

tubular tonsils in, 30

Cellulose digestion-

in rodents, $3 \mathrm{I}$

in ruminants, $3 \mathrm{I}$

Cellulose-splittins bacilli, 64

Cercopitlecus griseo-viridis, tubular tonsils in, 28

Cerebro-spinal meningitis-

healthily acqnired inmunity against, 17

immune carriers during epidemics, 15,75

Cervical lymphatic glands-

enlargement of, in tonsillectomised children, 95

sentic discase of, 97

tuberculous disease of, 9I, 92

Chemiotaxis, 68

Chimpanzee, lymphoid appendix in, 36,44

Chinese, appendicitis among, 82

Cholera carriers, 76

Chorea in tonsillectomised chi'dren, 95

Chronic constipation, 79

Circumpharyngeal ring of lymphoid tissue, 2I 


\section{Civet-}

slightly developed appendix in, 36

tubular tonsils in, 30

Clamydophorus, bilateral cæca in, 33

Colds, clironic enlargement of tonsils and adenoids after, 75 , 106

Coli bacillaemia, 18

Coli bacilli, 17

Coli bacilluria, 18

Colic subepithelial lymphoid tissue, 23

Colourless corpuscles, 9

Compensating function, IO4

Concretions (see also Calculi) in appendix, $4,80,8 \mathrm{I}$ in tonsil, 97

Conjunctival subepithelial lymphatic glands, 19

Contact cases in infectious disease, 14

Corvus corone, bilateral cæea in,

Coryza- 33

slort duration of imnnunity in convalescents, I4

subepitlelial 1rnuphatic glands

Cowenlarged after, 75, Io6

cellulose digestion in, 3I

tubular tonsils in, 30

Criticisms of hypothesis, 107

Crow, bilateral ceca i11, 33

Crypts of tonsil (sce also I,acuna) -

choised with lymplocutes and bacteria in acute inflammation, 78

foreign bodies in, 80 obliteration of, 86

Cyclothurus didactylusbilateral caeca in, 33

Cygnus, bilateral cacca in, 33

Cysts-

in human adenoids, 86

in linn1an appendix. 86

in human tonsils. 86

in hyena's tonsil, 77

D.

Dacelo, innction of large and small intestines in, 32 basypus sexcintus, bilateral cæca in, 33

Dasypus villosus, projecting tonsils in, 28

Dasyurus -

junction of large and small intestines in, 32

tubular tonsils in, 30

\section{Deafness-}

due to swelling of lymplioid tissue at pharyngeal end of tuba auditiva, 97

as indication for erasion of the nasopliaryngeal tonsil, 97

Degeneration; principle of, 102

Deglutition, interference with, due to enlarged tonsils, 89 , 97

Iicotyles, lymploid appendix in, 36,39

Didelphys carnivora, tubular tonsils in, 30

\section{Diphtheria-}

carriers in, 76

following renoval of tonsils and adenoids, 95

healthily acquired immunity:" against, I 7

less serious if limited to the tonsil. 74

occasional lymplocytosis in, ro7 presence of organisms in throat. I7

subepithelial lrumplatic glands involved iti, 74

Diphtheroid bacilli present in throat, 17

Diseases of subepithelial lymphatic glands, 73 to $92,106,107$

Dog-

caccal tonsil in, 35

cactum in, 32

projecting tonsils in, 28

unusual an1ount of carbon particles in subepithelial lymphatic glands in, 69

Dogfish, crecum in, 32

Duck, bilateral creca in, 33

Duodenal subepithelial lymphoid tissue, 22

Dysentery-

carriers in, 76

commences in solitary follicles, 83 
E.

Fodentata, junction of large and small intestine in, 32

Efferent lymphatic vessels, bacteria in, 66

Elephant, cecunis in, 33

Endocarditis, after renioval of tonsils and adenoids, 95

Fndothelial cells of lymphoid tissue, 47

Enteric fever (sec also 'Typloid fever), lymphocytosis in, I07

Enucleation of faucial tonsils, indications for, 97

Epithelioma of tomsil, 9 I

Frasion of nasopharyngeal tonsil, indications for, 97

Erythrizon dorsatus, 1ymphoid appendix in, 35,38

Europeans living in the tropics, appendicitis among, 82

Evolution and the subepithelial lymphatic glands, I, ro4

\section{Exantliemata, 73}

Excision of adenoids-

indications for, 97

a septic operation, 96

Excision of appondix, indications for, $07,9^{8}$

Excisious of faucial tonsils, indications for, 97

Eyes, conıarison with subepithelial 1rmplatic glands as to disability from absence or defect of, $\operatorname{so} 8$

\section{F.}

Faces, half weight of formed by bacteria, I7

Faroe Island, epidenic of measles i11, 13

Fancial tonsil (sec 'Tonsil, fancial.)

Felis domestica--

caecal tonsil in, 35

tubular tonsils in, 30

Felis Leo, crecal tonsil in, 35

Felis Pardus, tubular tonsils in, 30

Fibrosis of lymoloid tissue, 36,59

Fiji, epidemic of measles in, I3, i4

Fingers, injuries and disease of 110 proof of uselessness, 9
Fishes-

crenm in, 32

junction of small and large intestines in, 32

pyloric creca of, 33

rectal glands of, 33

wandering ancebocytes in gills of, 27

Foreisn bodies-

in tonsillar crypts, 80

in vermiform appendix, 80

Fulminating infections, 74

G.

Gangrene-

of Peyer's patch, 85

of vermiform appendix, 85

Germ centre, 46

German measles, subepithelial lymplatic glands involved in, 74

Giant cells in lymphoid tissue, ${ }^{8} 8$. 53

Gibbon-

lymploid appendix in, 36, 44 projecting tonsils in, 28

Glandular lymphocytes-

large, $47,48,53,66,69,84$

small, $47,48,51,53,65,69,72$, 78,84

Goose, bilateral caeca in, 33

Gorilla-

lymphoid appendix in, $36,4.5$

projecting tonsils in, 28

tuberculous tonsils in, 77

unhealthy tonsils in, 77

Grivet monkey, tubular tonsils in, 28

H.

Hamatosenous infection of subepithelial lymphatic glands, 87

Hamolympli glands, 12

Hamorrhage-

from nlceration of solitary follicles of stonach duodenum and ilenm. 86

primary, reactionary and secondarv after removal of tomsils and adenoids, 96 
Hairy armadillo, projecting tonsils, 28

Hare, lymploid appendix in, 35

Hassal's concentric corpuscles, 26

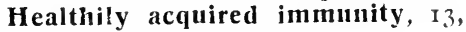
104

Healthy carricrs, 14

Heart-

anresthetic srncope during removal of tonsils and adenoids, 96

disease of, following partial tonsillectonly, 94, 95

endocarditis, following removal of tonsils and adenoids, 94, 95

toxin-weakened in status 1ymphaticus, 75

Herbivora, caecnm in, 31

Heron, cxcum in, 32

Hippodotamns, projecting tonsils in, 28

Hodgkin's disease, 47, 91

Homo Sapiens-

1vmploid appendix in, 36, 45

projecting tonsils in, 28

Horse, crecum in, 33

Hottentots, epidenic of measles among, I4

Hyena, cyst in tonsil of, 77

Hylohates Lar. -

crecum in, 33

projerting tonsil in, 28

Hyvernlasia -

of subepithelial glands, 88,89

causes of, 89

results of, 89,90

Hvnertrophy-

of subopithelial 1rmplatis glands after partial removal, 96

as result of repeated infections diseases. 106

Hypothosis of the immunisins function of the subenitho'ia! Ivmphatic glands. 103

criticisms of, 107,108

eridente for, In4, 105. In6. In7

furtler exnerimental evidence required, 107,108

Hyrax, creca in, 33

I.

Ichnemmon. slightly developed appendix in, 36
Ileal subepithelial lymphatic glands, 22

i11 birds, 30

in nammals, 30

in the pig, 30

in the rablit, 30

Ileo-cacal junction (see Junction of large and small intestines.)

Ileo-caecal Iymphoid patches in the rabbit-

distal, 30, 52

proximal, 30,52

Immunising organs, 15,100

Immunising stations, 104

Immunity-

acrpluired-

artificiallv, I3

by introduction into large intestine, 76,98

by oral administration, 93 . 98

naturallv, I3

healthily or physiologically, I.3

patholocically, I3

inlierent. 13

Indian python, crecum in, 32

Infantile enteritis, 74, 75, ro7

Infectious diseases, 73,75

Influenza-

epidemics of, I3, I4

healthilv acquired immunity against, 17

presence of organisms of in throat, 17

Ingestion by subepithelial lymphatic glands-

of carmine narticles, $70,7 \mathrm{r}, 72$

of dead bacilli, 76

of live bacilli, 68, 106, 108

of soot particles, 54,69

Inguinal lymnhatic glands, tuberculous disease of, 91

Interstitial lymphatic glands, 2, 16 arrangenent in medulla of, 48 nodules in cortex of, 49

Intussusception due to enlargement of last Peyer's patcl, 90

J.

Japanese, appendicitis among, 82

Jejunal subepithelial lymplıoid

tlssue, 22 
Joint attacks following partial tonsillectomy, 94, 95

Junction of small and large intestine, three types of, 32, 33

K.

Kangaroo, actinomycosis of tonsil of, 77

Keratosis Pharyngis, 89

Kinking of Vermiform Appendix, 79,86

KIebs-Loffler bacilli (see also Diphtheria), 76

Koala, appendix in, 36, 4I

L.

Lacuna of Tonsil (see a!so Crypts of 'lonsil), 20, Ioo

fig seeds in, 80

stagnation in, $5 \circ, 87$, roo

ulcers of, 85

Lagomys Pusillus, lymphoid appendices in, $3.5,37$

Lamp Black mixed with rabbit's food, $70,7 \mathrm{I}$

Large Intestine, subepithelial 1ymphoid tissue in, 23

Laryngeai subepitheliai lymphatic glands. 19

Laughing Jackass, junction of large and small intestines in, 32

Lemurs, lymploid appendix in, 36 , 42,43

Lemur Macaco, lymphoid appendix in, 36,42

Leopard, tubular tonsils in, 30

Lepus cuniculus (see also Rabbit) -

crecum in, 33

lymphoid appendix in, 35

tubular tonsils $\mathrm{i} 11,30$

Lencocytes, excess production of, 12

Leucocytosis, in progenic infections, 107

Lingual tonsil, 20

Lion, crecal tonsil in, 3.5

Little anteater, bilateral caca in, 33

Ludwig's angina, 85

Lympli nodule, 46

distribution of, 48,49

less distinct in old age, $4^{8}$
Lymphadenitis, the starting point of-

appendicitis. $78,82,107$

dysenteric ulcers, $8_{3}$

niesosigmoiditis, $8_{3}$

pyloric ulcer, 78

tonsilitis, 78,107

typhoid ulcers, $78,79,107$

Lyniphadenoma, 47,91

Lynıliatic glands-

active in early life, 57

as antibacterial factories, 12

classification of, 2

interstitial, 2, 16

only present in birds and mamnials, 28, 104

subepithelial, 2

unit of structure of, 46

Lympliatic lencliamia, 9 I

I. ymphatic vessels-

afferent, 49, 67, 105

efferent, 49,66

perivascular, 66

Lymplocytes-

accumulation as results of clironic bacterial attacks, ro, IOI, 107

antibacterial action of, 107

breeding ground for, 103

emigrated, 50, 68, 69

excess production of, Io,

formed in lymphatic glands, $4^{8}$, ro7

in epithelium overlying lymphoid tissue, $49,53,54,55$, $69,7 \mathrm{I}$

large, 47

large glandular, $47,48,53,66$, 60,84

not the chief reaction to infectious disease, 15

on surface of tonsils with contained bacteria, $10,54,55.068$

passage into lumen of alimentary canal, 10, 54, 5.5. 68

probably to not become polymorplonuclears. I 5, I03

proportion in the blood, 48, 57 small, 48

small glandular. $47,48,51,53$, $65,69,72,78,84$

training scliools for, Io3

Lymphocytosis-

characteristic of various diseases, 75,107 
Lymphocytosis (cont.)-

readily provoked in early life, 57.76

constantly present in the first years, 57

following tuberculin infections. 75

Lymphosarcoma of tonsil, 91

Lyre bird, bilateral caeca in, 33

M.

Macrophage, 47

Malignant scarlet fever, 74

Mammals-

caccull in, 32, 33

fancial tonsils in, 28

lymploid tissue in, 28, 56, 104

lymplnoid tissne in caecun of, 34 to 45

nasopliaryngeal tonsil in, 30

occurrence of fancial tonsils in, 28,30

protuberant type of fancial tonsil, 28,29

tubular type of fancial tonsil,

\section{Man-} $2 S, 29$

caecum in, 32

distribution of subepithelial lvmphatic glands in, 19 to 26 lymploid appendix in, 36,45 projecting tonsils in, 28

Manatus Americanus, lificl cecum in, 33

Manatee, lifid eaecum in, 3.3

Marrow-

as antibacterial factory, 12, 16. IO3

as source of lymphocytes, 4 , 103

as source of polymorplionuclear cells, 103

Marsupials, junction of large and

Measlessmall intestines in, 32

epidemies of, 13,14

lealthily accuired immunity against, 17

lymplocytosis in, 75, 107

subepithelial glands chronically enlarced after, 75, 106

subepithelial glands involved in. 74

Meckel's diverticulum, $6,7,8$
Membrana tympani, retraction of, 97

Menura victoria, bilateral cæca in, 33

Mesenteric lymphatic glands, 49

tuberculous disease of, 92

Meso-appendix, 79, 86

Meso-sigmoiditis, $\delta_{3}$

Microphage, 47

Middle ear, suppurative processes of 90,95

Mitotic figures, in lymph nodules, 47

Mode of ingestion of bacteria, 67

Monkeys, tuberculous tonsils in, 77

Monotrenes, crecum in, 32

Morbid anatomy of appendicitis, $8_{3}$

Moullon, projecting tonsils in, 28

Mouth breathing, 90

Incocele of vermiform appendix, 86

Muscularis nucosae, 49, 105

Musculature of vermiform appen. dix, function of, 100

N.

Nasal obstruction, 9.5

Nasopharyugeal tonsil (sce tonsil, nasopliaryngeal)

Noduli lymphatici aggregati (see also Pever's patches) advantage of longitudinal disposition, roI

discovery of, 3

position of, 22

recounition of disease of, 3

structure of, 22

Noduli lymphatici so!itarii-

of duolenum, 22, 78

of large intestine, 23, 105

of small intestine, 22, I05

of stomacli, 22,78

structure of, 49

North American Indians, epidemic of micasles among, I4

Nose, suppurative processes of, sa 
o.

Obstruction of the small intestine, enlargement of Peyer's patches in, 75

Oesophageal subepithelial lymphoid tissue, 2 I

Opossum, tuibular tonsils in, 30

Opsonic index, 76,103

Oral administration of bacterial cultures, 98

Orang Outang-

cæcum in, 3.3

lymphoid appendix in, 36, 43

Ornitliorhynchus, crecum in, 32

Oro-pharyngeal subepithelial lymphoid tissue, 21

Keratosis pharyngis of, 89

Ostrich, bilateral cæca in, 33

Otis, bilateral cæca in, 33

Ovis musman, projecting tonsils in, 28

P.

Parrot, junction of large and sinall intestines in, 32

Passage of bacilli through subepitheilal to interstitial lymphatic glands, $9 \mathrm{r}$

in case of Peyer's patches, 92

in case of tonsils, 91

in case of vermiform appendix, 92

Pathogenic bacteria, harmless presence of, in alimentary canal, 17

Patho!ogical evidence, ro7

Pathology of the subepithelial lympliatic glands, 73 to 92

Pavo, bilateral caca in, 33

Peafow1, bilateral creca in, 33 .

Peccary, lymphoid appendix in, 36,39

Peptic ulcers, 78

Perforation in appendicitis, 85

Peritoneal abscess, 85, IOI

Peritoneum, bactericidal powers of, 17

Peritonsillar abscess, 85, 97

Perivascular lymphatics, microorganisms i11, 66

Pertussis (see also Whooping cougli)-
Pertussis (cont.)-

1ymphocytosis in, 75

subepithelial lymplatic glands clironically enlarged after,

subepithelial lymphatic glands involved in, 74

Peyer's patches (see also Noduli Iymphatici Aggregati) -

discovery of, 3

enlargement of, 90

in infantile enteritis, 107

perforation of, in wombats, 77

peritoneal abscess with, 85

permitting passage of tubercle bacilli, 92

position of, 22, I05

recognition of disease of, 3

structure of, 22, 49

in typhoid fever, 106

uncovered by villi, 49

Phagocytic power of glandular lymphocytes, 5I, 53

Phagotaxis, 68, I0 3

Phascolarctus cinereus, lynuphoid appendix in, $36,4 \mathrm{I}$

Phascolymis wombat, lymphoid appendix in, 36,42

Phasianus, bilateral creca in, 33

Pheasant, bilateral cæca in, 33

Physiological evidence, ro6

Physiology of subepithelial lymphatic glands, 73

Physiotaxis, 68

Pigmented masses in subepithelial lyniphatic glands, $4 \mathrm{~S}, 5 \mathrm{r}, 53$

Pinna, extrinsic and intrinsic muscles of, $6,7,8$

Platypus, crecum in, 32

Plica triangularis, 20

Pneumococci, presence in throat, I 7,76

Pneumonia in tonsillectomised children, 95

Polymorphonuclear lencocytes, 95 in acute appendicitis, $8_{1}, \delta_{3}$

Poly-subepithelial lymphadenitis, 83

Porcupine, absence of faucial tonsils in, 28

Portals of entry of disease, tonsils and appendix as, ro, 74,99

Post-mortem penetration of tissues by bacilli, 63

Primates, cacum in, 33 
Principle of degeneration, 102

Processus wermiformis (see Appendix Vermiformis)

Pyogenic bacteria, harmless presence of in alimentary canal, 76

Pyloric caca of fishes, absence of lymphoid tissue in, 33

Pyloric subepithelial tymphoid tissue, 22

Pyloric ulcer, lympliadenitis the starting point of, $7 \mathrm{~S}$

Pyrexia, following removal of tonsils and adenoids, 96

Puma, slightly developed appendix in, 36

Purgatives, use of, and appendicitis, 82

Q.

Quinsy, 85

R.

Rabbit (see also Itepus Cuniculus)

cæcum1111, 33

calyx glands of , 53, 54, 55

collateral circulation to appendix of, Ior

1ymphoid appendix in, 35, 5I, $52,53,54,55$

post-natal development of lymphoid tissue in, 56

tubular tonsils in, 30

Ransom for immunity, 100

Rat, absence of fancial tonsils in, 28

Recurrent attacks of inflammation of the subepithelial lymphatic glands, $84,86,8_{7}, 100$

Rectal administration of bacterial cultures, $76,9^{8}$

Rectal gland of the dogfish, absence of lymphoid tissue in, 33

Removal of tonsils and adenoids, complications and sequelæ of,

Reptiles94, 95, 96

cæcum in, 32

junction of large and small intestines in, 32
Reptiles (cont.)-

nasopharyngeal tonsil in, 30

Retiform tissue, 46

Retraction of membrana tympani, 97

Retropharyngeal abscess, 85

Return immigration of leucocytes, 72

Rhesus monkey, unhealthy tonsils in, 77

Rheumatic fever-

following partial tonsillectomy, 94.

following removal of tonsils and adenoids, 95

healthily acquired immunity against, 17

subepithelial lympliatic glands involved in, 74

Rib, abscess of, after removal of tonsils and adenoids, 96

Rickets, 1ymphocytosis in, 75, 107

Rodents-

caecuin in, 33

lymploid appendix in, 35, 5 I

Ruminants, cellulose digestion in, 3I

S.

Sapramia following removal of tonsils and adenoids, 96

Sarconia of tonsil, 9I

Sarcophilus satanicus,, 32

Scarlatina-

following removal of tonsils and adenoids, 96

healthily acquired immunity against, $14,17,76,106$

malignant, a case of, 74

polysubepithelial lymphadenitis in, 83

subepithelial lympliatic glands:

bear brunt of attack in, 74, 106

chronically enlarged after, 75, Io6

inflamed in, 76,83

Scyllium canicula, cæecum in, 32

Septal nasopharyngeal tonsil in the sheep family, 30

Septicæmia in fulminating Infections the lymphatic reaction poorly developed, Inf 
Septicamic abscess after removal of tonsils and adenoids, 96

Sexual function, alleged relation of

\section{Sheep-} tonsil to, 5

caecum in, 33

septal nasopharyngeal tonsil in, 30

Simia satyrus-

cæcum in, 33

lymploid appendix in, 36, 43

Small intestine, subsepithelial lymphoid tissue in, 22

Solitary follicles (see Noduli

Lymphatici Solitarii). particles-

in glandular lymphocytes, 53, $54,55,69$

in lymphoid tissue of alimentary canal, 69, 70, 7I

Specific fevers, hyperplasia of tonsils after, 89

Speech, interference with, 90, 97

Spleen-

as antibacterial factory, 12, 16, I03

lymph nodules in, 48

Splenomedullary leuchæmia, 9i

st. Kilda, epidemic of influenza in, 13

Status lymphaticus, 75,90

Stenosis of vermiforn appendix, $\$ 6$

Stercobilin, 8I

Stomach-

lymphoid tissue in, 22, 105

in ruminants, $3 \mathrm{I}$

Streptococci-

as cause of acute appendicitis, 82 presence in healthy throats, 17

Stricture of vermiform appendix, 86

Struthio, bilateral cæca in, 33

Subepithelial lymphatic glandsabsence of in some animals, 104 absence of from mouth, 26 absence of from nasal fossæ, 26 absence of from skin, 23, 105 absence of afferent lymphatic vessels, 49, 67, I05

absence of reaction of, in fulminating infections, 74

active in early life during acquirement of immunity, 57, 73, 106

analogous diseases of the different ones, 4,73

appendicular, 22
Subepithelial lymphatic glands (cont.)

atrophy in old age, 59, 106

bear brunt of faucial and intestinal infections, 73, 106

best developed in highest types of animals, 100, 104

bronchial, I9

characteristics, three general of, 50

circumpharyngeal ring, 21

colic, 23

comparable with a chain of forts rather than with a wall, 26 comparative anatomy of faucial, ileal and cæcal groups, 27 to 45,104

compensation after removal of, 96

conjunctival, I9

counterbalancing benefits of, 8 , IO4

disabilities following removal, $94,95,96,108$

disadvantages of, 99

discovery of, 3

discovery of ingestion of bacteria by, 4

disease of in other animals than man, 77

distribution in relation to areas of bacterial activity, 23,24 , $25,26,27$

duodenal, 22

enlargement of, following repeated infections, 74

epithelium covering, 50, 105

faucial, 19

generally, 2

giant cells in, 48

hyperplasia of :

causes of, 88, 89

results of, $89,90,99$

ileal, 22

inmunuising stations, as, 15,104 increased number of lymphocytes in, during infections of, 107

inflammiation of, 73,78 to 87

ingestion of dead bacteria by, 76 ingestion of live bacteria by, 68 jejunal, 22

large intestine, of , 23

laryngeal, 19

life history of, 56

lingual, 20

lymph nodules in, 49 
Subepithelial lymphatic glands (cont.)-

lymphocytes with engulfed bacteria on surface of, 68

nasopharyngeal, 20

occurs only in hirds and mammals, 104

œsophageal, 2 I

oropharyngeal, 20

organs for acquiring immunity, as, 15,100

origin of, IOI

pathology of, 73, 107

physiology of, 73, 106

pigmented masses in, 48, 53

polysubepithelial lymphadenitis, 83

pyloric, 22

recognition of disease of, 3

recurrent attacks of inflammintion of, $4,86,87$

restrain bacterial activity in the alimentary canal, ro

results of inflammation of, 85,86 small intestine of, 22

stagnation of alimentary contents in association with, 50, 68 , 100

structure of, 49, 105

submucous abscesses of, 85

superficial to muscularis mucosæe, 49, 105

surgery of, 2, 93

" trachoma," I9

Summary of evidence for main hypothesis, I04 to I07

Suppurative middle ear disease after removal of tonsils and adenoids, 95,96

Suppurating cervical glands after removal of tonsi:s and adenoids, 96

Supratonsillar fossa, 20

Surgery of the subepithelial lymphatic glands, 2, 93

Swan, bilateral caeca in, 33

Syphilis-

lynıpocytosis in, 75, 107

secondary ulceration of tonsils in, 87

Syncope, anastletic, during removal of tonsils and adenoids, 96

T.

Tabes mesenterica, 93
Tapir, lymphoid appendix in, 36 , 39

Tapirus Americanus, lymphoid appendix in, 36,39

Tasmanian Devil-

junction of large and small intestines in, 32

tubular tonsils in, 30

Tasmanians, epidemics of measles among, I4

Teleological explanations, 99

Terminal blood supply, 50

Test tube, vermiform appendix as a, 100

Tetanus toxin, neutralised by brain emulsions, Io6

Thornwaldt's disease of adenoids, 86

Three-toed sloth, junction of large and snall intestines in, 32

\section{Thymus-}

development of, 26

first appears as a subepithelial lymphatic gland, 26

Thymus glands, 27

\section{Tonsil-}

crecal, 29, 35

faucial-

action during deglutition, 20

advantages of irregular surface of, 49,50 , I00

calculi or concretions in, 4,97 capsule of, 100

chronic focuses of disease, ro

comprative anatomy of, 7,27 , $28,29,30$

crypts or lacunæe, 20, 56

cyst of, 77,86

derelopment of, 56

diphtheria limited to, 74

disease of, in other animals than man, 77

embryology of, 7

enlargement of, 88,89

resilts of, $89,90,100$

enucleation of-

indications for, 9;

for tuberculo'ts disease of cervical glawis, 98

epithelioma of, git.

excision of -

indications for, 97

sequelæ of , 94, 95, 96

fibrosis of, 89

foreign bodies in lacunæ of, 80 function of, $4,5,6$ to II, IO3 


\section{INDEX}

Tonsil (cont.) -

history, $3,4,5$

hyperplasia of, 89

inflammation of-

in infectious diseases, 73

as ransom for immunity, 100

recurrent attacks of, 84,86 , 87 , 100

unilateral, 75

Lymphadenitis the starting point of inflammations of, 78,107

occurrence in mammalia, 28

permitting passage of tubercle bacilli, $9 \mathrm{I}$

"portals of entry " of disease, Io

protuberant and tubular types and their distribution, 28 , 29, 30

position of, 19,20

quinsy, 85,97

recurrent attacks of inflammation, $84,86,87$, 100

relations of, 20

sarcoma of, 9 I

secretion of, 9

stagnation in lacunæ of, 50, 100

structure, 20, 49

tuberculous disease in monkeys', 77

ulceration of in secondary

lingualsyphilis, 87

deep submaxillary ${ }^{i t}$ abscess with, 85

position of, 20

structure of, 20

nasopharyngeal (see also Adenoids.)-

advantages of irregular surface, 50

discovery of, 3

effects of removal of, 94,95 , 96, 108

enlargement of and its results, 89,50

erasion oriexcision ofindications for, 97

position of, 20

recognition of disease of, 3

structure of, 20,49

Tonsillar recess, 20

Tonsillar sinus, 20

Trachoma glands, I9
Trauma as cause of appendicitis, $8 \mathrm{I}$

Trichosurus Vulpinus, lymphoid appendix in, 36,40

Tropics, appendicitis in, 82

Tuba auditiva-

lymphoid tissue at lower end, 2 I

when swollen, as cause of deafness, 97

Tubercle bacilli-

indisious passage through subepithelial to interstitial glands, 9r

presence in alimentary tract, I8

Tuberculin injections, 1ymphocytosis following, 75

Tuberculosis-

artificial immunity against, bv introduction of dead bacilli into the rectum, 98

bovine type, 18

of cervical lymphatic glands, 9r, 98

of ileocolic lymphatic glands, 72

of inguinal lymphatic glands, 9I

of tonsils-

in man, 92

in monkevs, 77

of vermiform appendix, 83

Typhoid-

appendicitis in, 82

artificial immunity against, by introduction of dead bacilli into the rectum, 76,98

carriers in, 76

healthily acquired immunity against, $I 7$

lymphadenitis the starting point of ulcers, 78 , I07

lymplocytosis in, 75, I07

Peyer's patches bear brunt of infection in, 106

subepithelial glands involved in, 74

typhoid bacilli in lymphoid no. dules in, 79

without ulceration, 79

U.

Ulceration-

in appendicitis, 85

in dvsenteric colitis, 83

peptic, 78,86

of Peyer's patches, 70, 86 


\section{Ulceration (cont.)}

of tonsils, 78

in secondary syphilis, 87

in tuberculosis, 92

in typhoid fever, 79

Unit of structure of lymphatic glands, 46

\section{v.}

\section{Variola-}

healthily acquired immunity against, 17

lymphocytosis in, 75, Io7

Vegetarianism and appendicitis, 32

Vermiform appendix or process (sec Appendix vermiformis)

Vestigial structures, I, 6, 7

"Virgin soil," I3

Viverra Civetta, tubular tonsils in, 30
Vulpine Phalanger, lymphoid ap- pendix in, 36,40

W.

Weasel, junction of large and small intestine in, 82

Wedge-tailed eagle, bilateral cæca in, 33

Whale, junction of large and small intestine in, 32

White-handed Gibbon, cæcum in, 33

Whooping cough (see also Pertussis) -

healthily acquired immunity against, 17

leading to enlarged tonsils and adenoids, ros

\section{Wombat-}

lymphoid appendix in, 36,42 perforation of last Peyer's patch in, 77

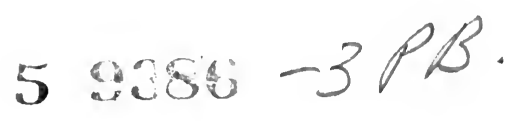







\section{PLEASE DO NOT REMOVE CARDS OR SLIPS FROM THIS POCKET}

\section{UNIVERSITY OF TORONTO LIBRARY}

QR

181

D54

Biologica!

ii Meclical

\section{Digby, Kenelm Hutchinson}

Immunity in Health 


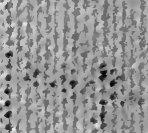

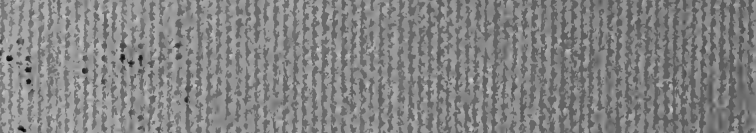

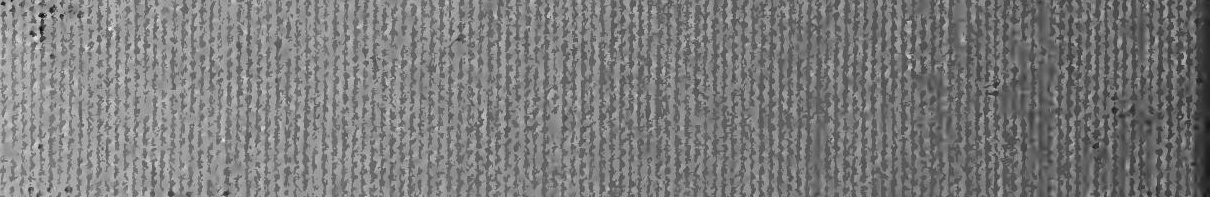
(2)

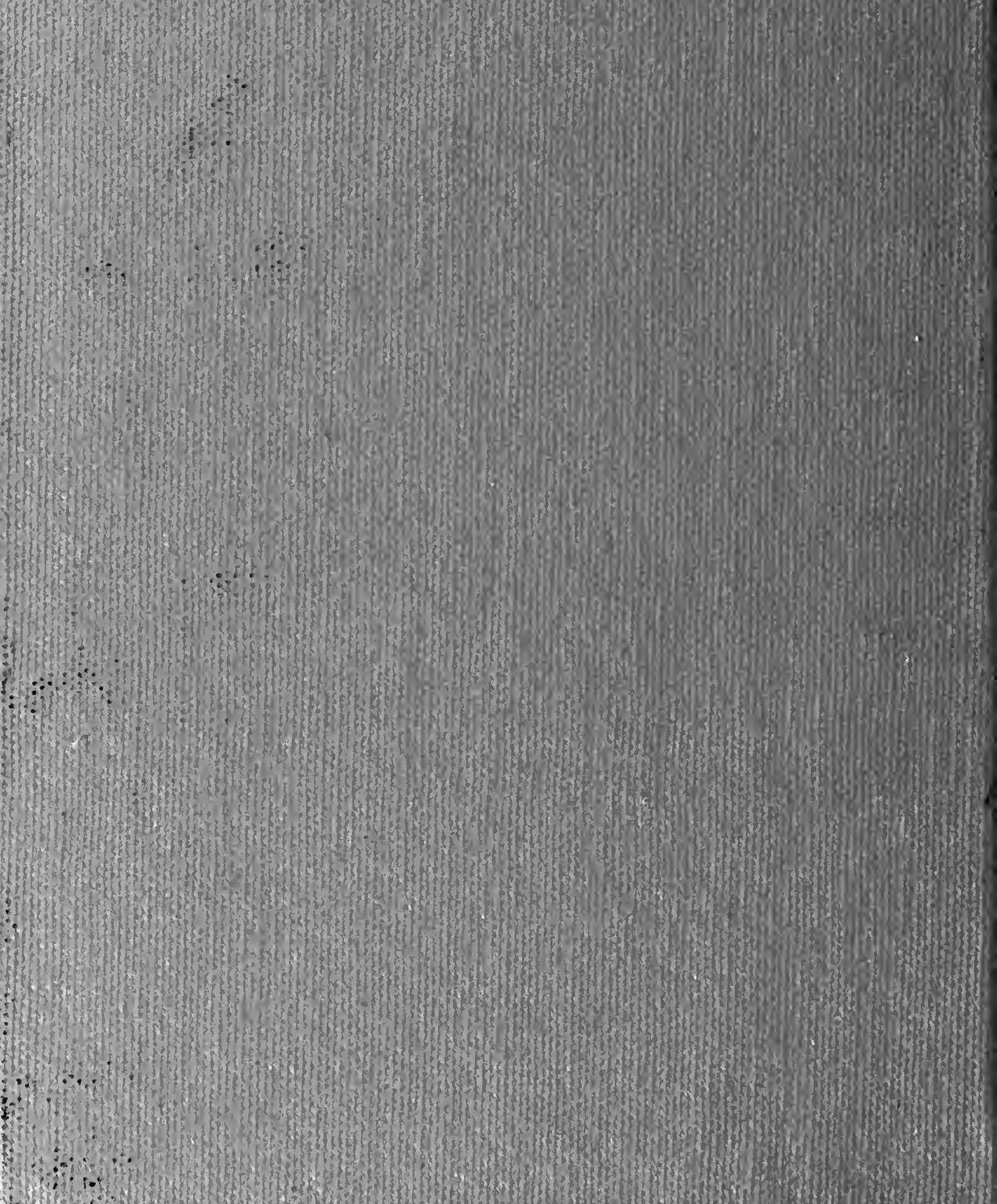

